Generic Mineral Technology

\title{
CENTER FOR PYROMETALLURGY
}

Director: Dr. D.G.C. Robertson

Report 18 - Final Progress Report G1145229 AND G1155229

Periods: April 1, 1996 - September 30, 1996

October 1, 1996 - March 31, 1997

April 1, 1997 - September 30, 1997

DH.FE- $957 \times 9.7808$

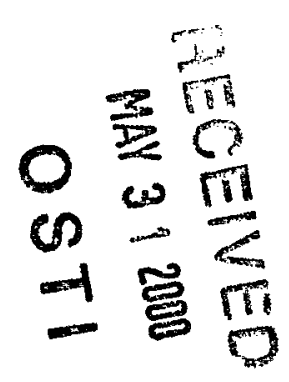

THE CENTER FOR PYROMETALLUGRY

Department of Metallurgical Engineering

215 Fulton Hall, University of Missouri - Rolla

Rolla, MO 65409-1460

Telephone 573-341-4709

Facsimile 573-341-6934

PROCESSED FROM BeST AVAILABLE COPYY 


\section{TABLE OF CONTENTS}

\section{Contract/Grant G1145229}

No. $2927^{\star}$ Counter - Current Metallurgical Reactor.............. 5

No. 2929 Phase Equilibria in Smelting Aluminum................. 6

No. 0472 Solid - Liquid Equilibrium in Steels.................... 13

No. 0871 Mercury Extraction and Recovery..................... 14

No. 0872 Removal of Impurities from EAF Dust............... 15

No. 3271 Thermodynamic Properties of Carbonyl Systems.... 16

No. $3671 \quad$ Ladle Refining of Copper............................... 17

\section{Contract/Grant G1155229}

No. 2900 Administration and Technology Transfer............. 18

No. 2928 Submerged Combustion In-Bath Smelting............. 23

No. 2930 Zinc Metal Vapor Sensor Development................ 33

No. 2931 Remediation and Recovery of Metal Values

from Lead Smelting and Copper Refining Slags...... 40

No. 0471 Impurity Element Volatilization and Absorption........ 43

No. 0671 Kinetics of Magnesium Removal from Aluminum..... 44

No. 0873 Development of a New Pyrometallurgical Process

for the Removal of Heavy Metal Contaminants

from Mineral Industry Wastes........................ 58

No. 1871 Surface Tension of Slags.......................... 80

No. 2571 Mathematics of Modeling Flow in CC Reactors....... 86

No. 3971 Interfacial Phenomenon in Aluminum Alloy-Salt

Systems.................................................. 87

No. 3972 Modeling and Simulation of Strip Casting Processes. 94

* Numbers 29XX represent UMR projects; others are affiliate projects 


\section{DISCLAIMER}

This report was prepared as an account of work sponsored by an agency of the United States Government. Neither the United States Government nor any agency thereof, nor any of their employees, make any warranty, express or implied, or assumes any legal liability or responsibility for the accuracy, completeness, or usefulness of any information, apparatus, product, or process disclosed, or represents that its use would not infringe privately owned rights. Reference herein to any specific commercial product, process, or service by trade name, trademark, manufacturer, or otherwise does not necessarily constitute or imply its endorsement, recommendation, or favoring by the United States Government or any agency thereof. The views and opinions of authors expressed herein do not necessarily state or reflect those of the United States Government or any agency thereof. 


\section{DISCLAIMER}

Portions of this document may be illegible in electronic image products. Images are produced from the best available original document. 


\section{A MESSAGE FROM THE DIRECTOR}

Since the last progress report submitted (for the period of Oct. 1, 1995 to Mar. 31, 1996), in view of the demise of the Bureau of Mines and the close-out of the Minerals Institute Program, the emphasis has been on meeting the requirements of a Final Project Report for each of the remaining projects. With the diminution of funding and staff, this has necessarily been given precedence over reporting progress. Consequently, this Final Progress Report covers the three six-month periods since the last report:

April 1, 1996 to September 30, 1996

October 1, 1996 to March 31, 1997

April 1, 1997 to September 30, 1997

Eight of the projects of Contract/Grant G1155229 ended in September 1996. Two projects, numbers 2931 (UMR) and 3972 (OSU), ended in September of 1997. A few of these projects had intermediate project reports written, and these are included here. Each of the projects has a completed Final Project Report. For those projects for which a copy of the final report had not previously been forwarded to the Contract office, a copy of the Final Project Report (or a copy of pertinent identifying pages) is included in the appropriate project report.

This Final Progress Report includes a copy of the Final Project Report for one project, No. 2929 from Contact/Grant G1145229. All of the projects of this Contract/Grant had been scheduled for completion in September1995 (the last funding had been in FY 1994 for this grant). In addition, because the Final Project Reports for the six other research projects for Contract/Grant G1145229 had been sent as they became available (to several different assigned Contract Officers), a supplemental report is given here for these other projects. This delineates the title, author, manuscript type (thesis, publication, etc.), and other pertinent report information, along with an indication as to when each Final Project Report had been forwarded, and to whom.

In summation, each of the projects under Contract/Grant G1145229, and each of the projects under Contract/Grant G1155229 now has had a Final Project Report submitted to the assigned contract officer.

In conclusion, I would like to thank everyone who contributed to the success of the Generic Mineral Technology Center for Pyrometallurgy - the Federal Government personnel (Bureau of Mines and others); the Advisory Committee personnel from industry and the Bureau of Mines; the Principal Investigators and supporting academic personnel; and especially to the many students, who worked with dedication and persistence. They are our future. A relatively modest expenditure has produced a rewarding return of many trained 
personnel, technical presentations, publications, theses, symposia, meetings, and other interactions.

Metallurgy is a relatively small portion of the overall scientific and technical community; pyrometallurgy is a small field within metallurgy, and has received relatively little attention in the academic world. The support which research in pyrometallurgy obtained from the Bureau of Mines maintained more research activity in academia than would otherwise have been the case.

Working as the Center's Director has been a gratifying experience. I would particularly like to acknowledge the work of Dr. Art Morris (UMR), Dr. David Gaskell (Purdue), and Dr. Jim Foster (then of Michigan Tech.), who wrote the original successful grant application in 1982, which brought the Generic Mineral Technology Center for Pyrometallurgy to UMR.

Mr. Dan Paulson, Director of the Rolla Research Center in the 1980's was a strong supporter of the Center. I would also like to acknowledge the work of the numerous members of the Research Council from industry and the Bureau of Mines. They evaluated project proposals on their merits and always encouraged the submission of proposals from all universities who were eligible.

The Center for Pyrometallurgy continues at Rolla, without the "Generic Mineral Technology" prefix. We have been successful in maintaining a strong pyrometallurgy group, with excellent laboratory and computing facilities, and are now obtaining funds for research from the NSF and industry. The members of the group are Dr. David Robertson, Dr. Mark Schlesinger, and Dr. Kent Peaslee.

David G.C. Robertson 


\section{Contract/Grant G1145229}

2927 Mathematical and Physical Modeling of Flow Phenomena and Mixing in Three-Phase Counter-Current Metallurgical Reactors (Robertson-UMR)

\section{Project Scope and Goals:}

To study aspects of pyrometallurgical refining in three-phase counter current reactors by the following methods:

A) Physical modeling of longitudinal mixing and fluid flow followed with correlation of the data by dimensional analysis.

B) Mass transfer modeling of potential counter-current refining reactions, particularly to study the effects of reversion.

C) Mathematical modeling of the complex three-phase counter-current reactor system to aid prediction of the performance of a large-scale reactor (work to be conducted by MIT-funding initiated in 1993-1994).

Funding: FY92 \$62,817; FY93 \$62,775; FY94 \$65,862

Graduate Students: Messrs. L.R. Nelson and K.N. Swamy (doctoral candidates)

Report Period: $\quad$ Supplement to April 1994 - September 1995 (End)

\section{Final Report:}

The Final Project Report was a thesis: "Application of Theoretical and Physical Models to Smelting and Refining Processes", by Krishnaswamy Narayana Swamy, 127p., approved by the University of Missouri-Rolla in 1996 as partial requirement for Doctor of Philosophy degree in Metallurgical Engineering. A copy had been sent to Louis Summers, Branch of Procurement, Pittsburgh, PA with a letter of transmittal dated December 23, 1996. 


\section{Contract/Grant G1145229}

2929 Phase Equilibria in the Ca-Mg-O System (Schlesinger-UMR)

Project Scope and Goals:

To determine the composition of $\mathrm{Ca}-\mathrm{Mg}$ alloys in equilibrium with pure solid $\mathrm{CaO}$ and $\mathrm{MgO}$ as a function of temperature, and to assess the published Gibbs energies of formation of $\mathrm{CaO}$ and $\mathrm{MgO}$ in the light of these results.

Funding: $\quad F Y 93 \$ 56,385$; FY94 \$62,105

Graduate Student: Mr. Xiaoping Xu

Report Period: $\quad$ Supplement to April 1994 - September 1995 (End)

Final Report:

A thesis serves as the Final Project Report. The thesis, "Phase Equilibria in the Oxide Saturated Ca-Mg-O System", by Xiaoping Xu (52p.), was approved as partial requirement for a Master of Science degree in Metallurgical Engineering. A copy of the pertinent identifying introductory pages of the thesis follow as a part of this Final Progress Report. 
PLASE, EQUIIIBRIA IN THE OXIDE SATURATED Ca-Mg-O SYSTEM

$B Y$

XIAORING XU, 1967-

A THESIS

Presented to the Faculty of the Graduate School of the UNIVERSITY OF MISSOURI - ROLLA

in Partial Fulfillment of the Requirements for the Degree

MASTER OE SCIENCE

in

METAILURGICAI ENGINEERING

1997
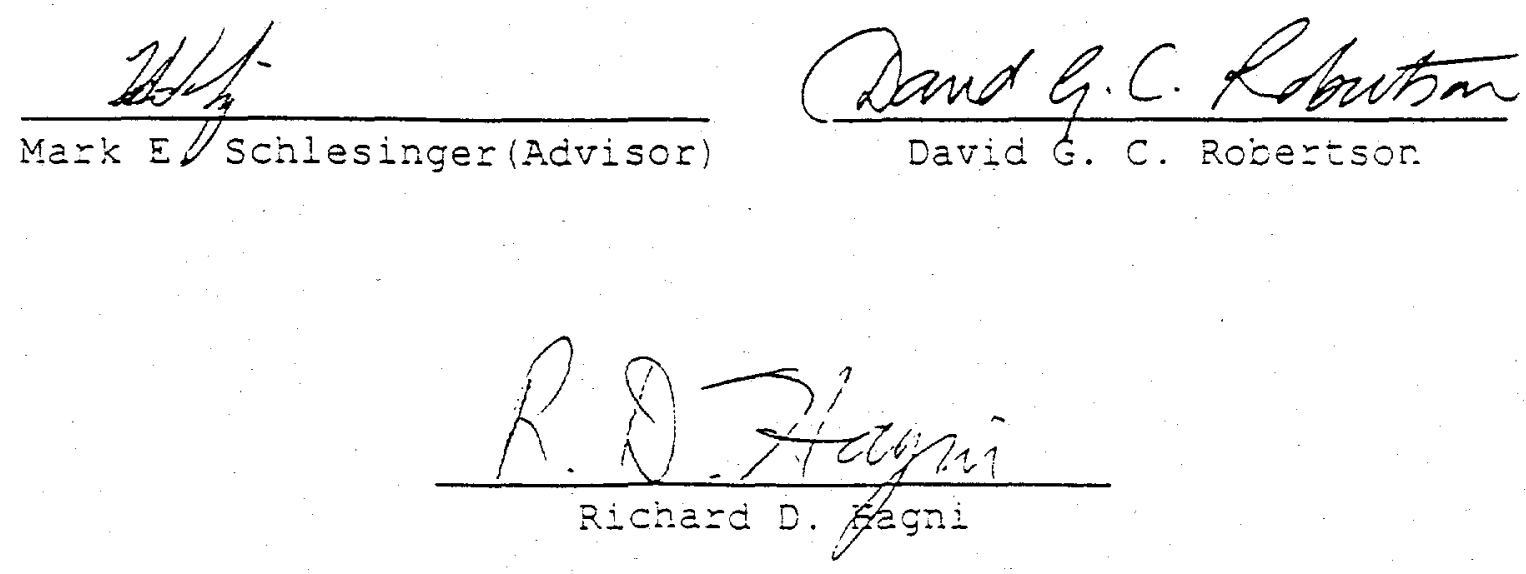


\begin{abstract}
In recent years, the Gibbs energies of formation in the standard compilation of thermodynamic data for magnesium oxide and calcium oxide were seriously challenged by some researchers, and major revision of these values was suggested through their work. On the other hand, some work seems to support the conventional values in standard compilations.

The purpose of this project is to assess the validity of the newly published values. The phase equilibrium technique has been designed to investigate the thermodynamic properties of $\mathrm{MgO}$ and $\mathrm{CaO}$ by analyzing the results of the equilibria,

$$
\begin{aligned}
& \mathrm{CaO}+\mathrm{Mg}=\mathrm{MgO}+\mathrm{Ca} \\
& \mathrm{MgO} \text { (crucible) }+\mathrm{Ca}=\mathrm{Mg}+\mathrm{CaO}
\end{aligned}
$$

The Gibbs energy differences between $\mathrm{MgO}$ and $\mathrm{CaO}$ have been measured in the temperature range $1398 \mathrm{~K}-1473 \mathrm{~K}$. The results obtained from reaction (1) indicate that the Gibbs energy of formation for $\mathrm{MgO}$ is higher than that for $\mathrm{CaO}$ by about $20 \mathrm{~kJ} / \mathrm{mol}$, thus less stable than $\mathrm{CaO}$ in the temperature range. The results of reaction (1) partially support the conventional conclusion, although the difference is lower than that obtained from conventional values. The results of reaction (2) are very scattered, and thus unreliable.
\end{abstract}




\section{ACKNOWLEDGEMENTS}

I would like to express my sincere gratitude to my advisor, Dr. Mark E. Schlesinger, for his constant support, guidance and encouragement throughout the entire period of this project. Sincere gratitude is also extended to Dr. David G. C. Robertson and Dr. Richard D Hagni for their serving on the committee and reviewing my thesis, especially Dr. David G. C Robertson for his very valuable discussions and assistance.

My appreciation goes to Mr. Bob Lunsford for technical support, and Mr. Scott Miller for his help in conducting SEM analysis. Special thanks go to Drs. Hongiie Li and Dhiren Panda for their very helpful suggestions, discussion and assistance. I also want to thank all my fellow graduate students in the Center for Pyrometallurgy for their friendship and assistance.

I would also like to acknowledge financial support from the United States Bureau of Mines through the Generic Mineral Technology Center for Pyrometallurgy

Finally, I wish to express my deep appreciation to my wife, Feng Yu, for her love, understanding and support. 
TABLE OF CONTENTS

Page

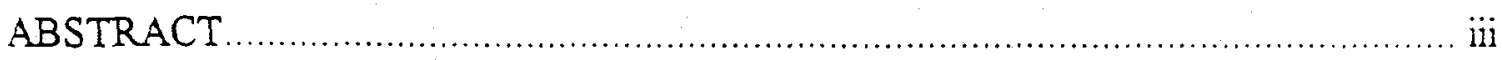

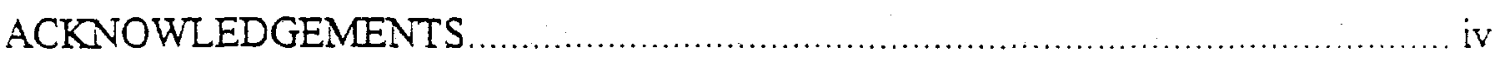

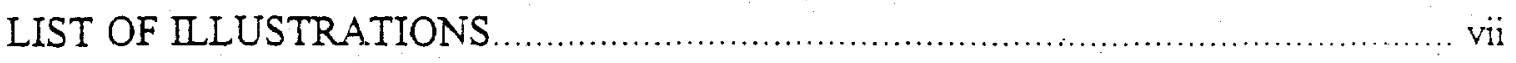

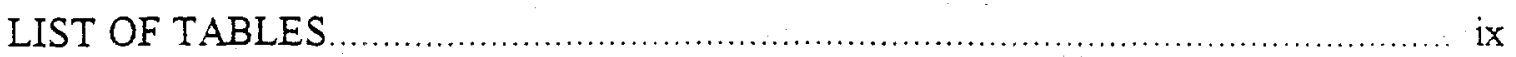

SECTION

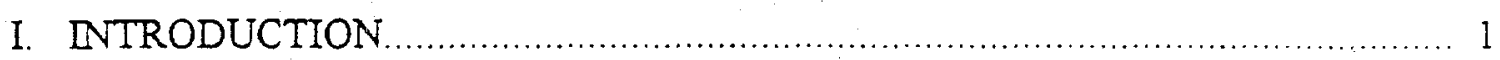

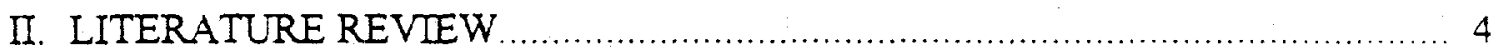

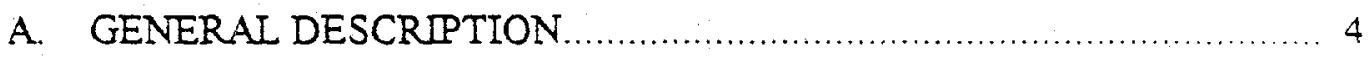

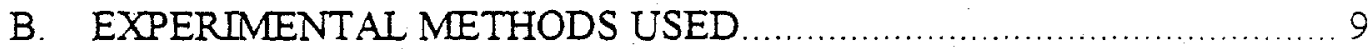

C. DISCUSSION OF PREVIOUS WORK ……................................ 17

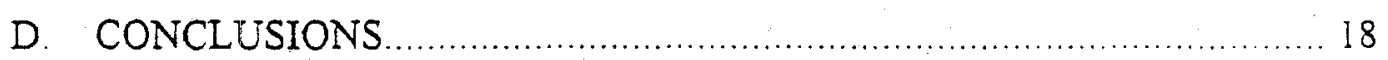

II. EXPERIMENTAL METHOD

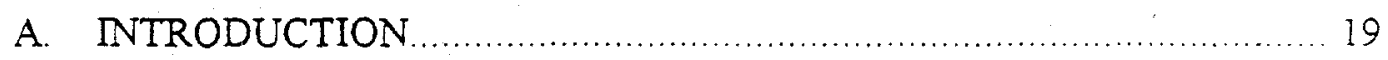

B. EXPERIMENTAL PROCEDURE

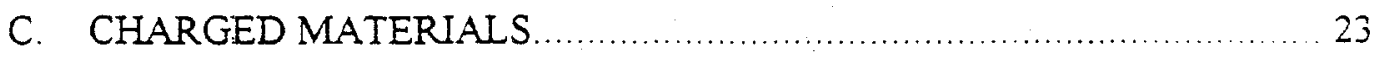

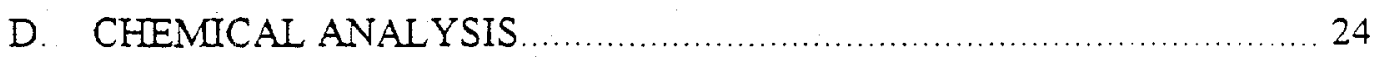

IV. EXPERIMENTAL RESULTS AND DISCUSSIONS .................................... 25

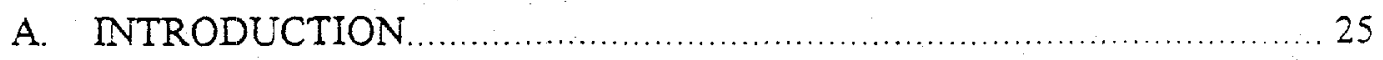

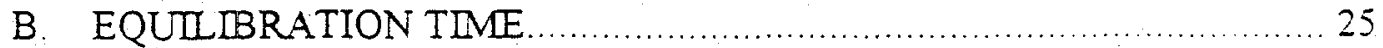

C. DISCUSSIONS OF CALCULATION METHODS ................................ 27

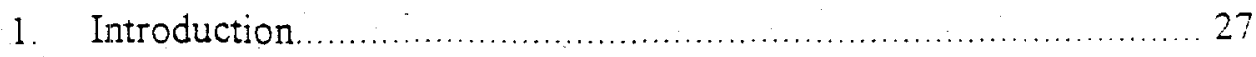

2. Thermodynamic Model for Ca-Mg Binary System......................... 29 
3. Calculation of the Gibbs Energy Differences................................... 32

D. EXPERIMENTAL RESULTS AND DISCUSSIONS …………............. 34

1. The Results of Reaction: $\mathrm{Mg}+\mathrm{CaO}=\mathrm{Ca}+\mathrm{MgO} \ldots \ldots \ldots \ldots \ldots \ldots \ldots \ldots . . . . . . . . . . . .34$

2. The Results of Reaction: $\mathrm{Ca}+\mathrm{MgO}($ crucible $)=\mathrm{Mg}+\mathrm{CaO} \ldots \ldots \ldots \ldots . .38$

3. Gibbs Energy Differences Between $\mathrm{MgO}$ and $\mathrm{CaO} \ldots \ldots \ldots \ldots \ldots \ldots \ldots \ldots \ldots . . . . . . . . . . . .42$

E. COMPARISONS OF RESULTS FROM DIFFERENT WORK …............ 44

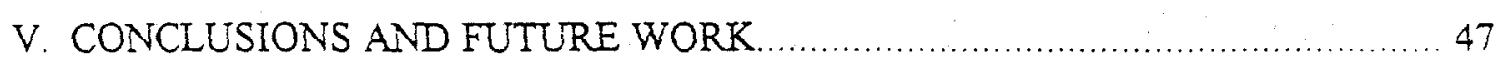

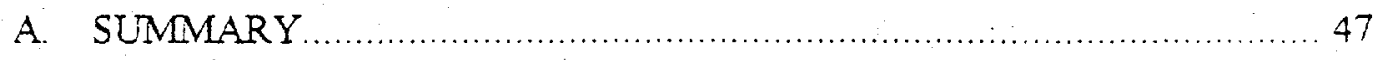

B. SUGGESTIONS FOR FUTURE WORK........................................ 48

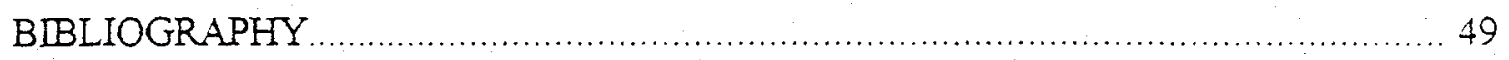

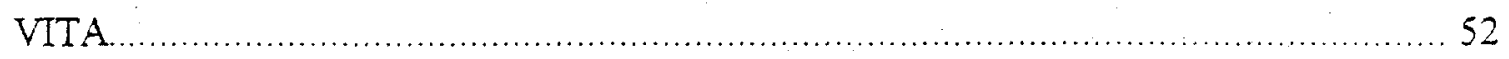




\section{VITA}

Xiaoping Xu was born on August 6, 1967 in Anhui, People's Republic of China (PRC). He received his primary and secondary education in Anhui, PRC. He received his Bachelor's degree in Metalhurgical Engineering from Central South University of Technology in Changsha, Hunan, PRC in 1990.

He has been enrolled in the Department of Metallurgical Engineering at University of Missouri-Rolla since August, 1995. He has been a Graduate Research Assistant for the Generic Mineral Technology Center for Pyrometallurgy since then. 


\section{ContractUrant G1145229}

0472 Solid-Liquid Equilibria in Continuously Cast Steels (Poirier- Univ. Ariz.)

Project Scope and Goals:

To measure the equilibrium partition ratios that are applicable to the solidification of three different grades of steel (92125, X-70, and 52100).

Funding: FY93 $\$ 62,976$; FY94 $\$ 69,699$

Graduate Students: Mr. Paul Ocansey and Mr. Alexander Parker

Report Period: $\quad$ Supplement to April 1994 -September 1995 (End)

Final Report:

The Final Project Report was: "Equilibrium Partition Ratios of C, Mn, and Si in a High Carbon Steel," by Paul M.N. Ocansey and D.R. Poirier, Materials Science and Engineering, A211, 1996, p. 10-14. A copy of this report has been forwarded to Louis Summers, Branch of Procurement, Pittsburgh, PA with a transmittal letter dated December 23, 1996. 


\section{Contract/Grant G1145229}

0871 An Experimental Study of the Fundamental Thermodynamic Aspects of Mercury Extraction and Recovery form Sulfur-Containing Minerals (HagerCSM)

\section{Project Statement and Goals:}

The treatment of mercury-containing minerals by thermal processing is complicated in the presence of sulfur because of the formation of mercury sulfates; e.g. $\mathrm{HgSO}_{4}$ and $\mathrm{HgSO}_{4} \cdot 2 \mathrm{HgO}$, respectively. The formation of these species during thermal processing substantially decreases the vapor pressure of mercury and thus the transport efficiency of the gaseous phase. Moreover, in the recovery of mercury from a reactor off-gas, the formation of such sulfates and oxy-sulfates can interfere with the collection of metallic mercury.

The objectives of this study are to (i) measure the Gibbs free energy of formation of the mercury sulfate and oxy-sulfate species using the transpiration technique, (ii) combine these results with selected data from the literature to construct a reliable series of vapor pressure / stability diagrams for the $\mathrm{Hg}-\mathrm{O}-\mathrm{S}$ system at various temperatures, and (iii) use the results to identify the optimal conditions for mercury extraction and recovery.

Funding: $\quad$ FY92 \$69,800; FY93 \$69,900; FY94 \$27,000

Graduate Student: Mr. Guy L. Fredrickson

Report Period: Supplement to April 1995-September 1995 (End)

Final Report:

The Final Project Report was a two-volume thesis, "A Fundamental Thermodynamic Study of the Phase Relationships in the Mercury-Oxygen-Sulfur System at High Temperatures: $\mathrm{HgO}, \mathrm{HgSO}_{4}, \mathrm{HgSO}_{4} \bullet \mathrm{HgO}$, and $\mathrm{HgSO}_{4} \bullet 2 \mathrm{HgO}$," by Guy Lawrence Fredrickson (Vol. 1 p.0-395, Vol. 2 p.396-582), approved February 1996 by the Colorado School of Mines as partial requirement for a Doctor of Philosophy degree in Metallurgical and Materials Engineering. A copy of the thesis was forwarded to Louis Summers, Branch of Procurement, Pittsburgh, PA with a letter of transmittal dated May 2, 1996. 


\section{Contract/Grant G1145229}

O872 Experimental Investigation of Selective Chloridizing Roasting for the Removal of Impurities from EAF Dust and Other Zinc Feed-Stocks Prior to Thermal Reduction (Hager-CSM)

\section{Project Scope and Goals:}

In order to recover zinc from EAF dust, thermal treatment is generally utilized. Under the high temperatures and strongly reducing conditions required to reduce the zinc in the thermal processor (Flame reactor, Waelz kiln, Plasma reactor, etc.), a number of impurities will be co-vaporized. These impurities, principally $\mathrm{Pb}, \mathrm{Cd}, \mathrm{Na}, \mathrm{Cl}$, and $\mathrm{F}$, cause problems when attempting to extract the zinc. The objective of this project is to use selective chloridizing roasting to attempt to eliminate $\mathrm{Pb}$ and $\mathrm{Cd}$ from the EAF dust, while still maintaining $\mathrm{Zn}$. Thus, the goal is to maximize the extraction of $\mathrm{Pb}$ and $\mathrm{Cd}$, with minimum covaporization of $\mathrm{Zn}$.

Funding: $\quad F Y 93 \$ 40,000 ; F Y 94 \$ 41,400$

Graduate Students: Ms. Christina Viklund and Mr. Jesse White

Report Period: Supplement to April 1994-September 1995 (End)

Final Report:

The Final Project Report was a thesis: "Experimental Investigation of Selective Chloridizing Roasting for the Removal of Impurities form EAF dust and Other Zinc Stocks Prior to Thermal Reduction," by Jesse Franklin White (124p.), approved by the Colorado School of Mines in December, 1995 as partial requirement for a Master of Science degree in Metallurgical and Materials Engineering. A copy of the thesis had been sent to the Bureau of Mines, Division of Procurement, Washington D.C. with a letter of transmittal dated February 29, 1996. 


\section{Contract/Grant G1145229}

3271 Determination of Thermodynamic Properties of $\mathrm{Cu}-, \mathrm{W}-$, and CoCarbonyl Systems (Chandra-UNR)

Project Scope and Goals:

Cobalt, chromium, rhodium, and tungsten coatings deposited via decomposition of carbonyls are of great interest to produce corrosion resistance and high temperature resistance. In this study, thermodynamic behavior of $\mathrm{Co}_{\mathrm{O}}$ $\mathrm{Cr}, \mathrm{Rh}, \mathrm{W}$, and other carbonyls have been investigated.

Funding: $\quad F Y 92 \$ 80,861 ;$ FY93 $\$ 58,199 ; F Y 94 \$ 53,000$

Graduate Student: Mr. Michael L. Garner

Report Period: $\quad$ Supplement to April 1994-September 1995 (End)

Final Report:

"Vapor Pressures and Thermodynamic Properties of Tungsten, Chromium, Cobalt and Rhodium Carbonyls". Garner, Michael. Thesis in partial requirement for MS in Metallurgical Engineering, Univ. of Nevada-Reno, June 1994, 79 pp.

"Low Temperature Vapor Pressure Measurements of W-, $\mathrm{Cr}-$, and Co-Carbonyls". Garner, Michael, Dhanesh Chandra, and K.H. Liu., Journal of Phase Equilibria, V. 16, No. 1, 1995, pp. 2429.

"Line Profile Analysis of Rhodium Metal Obtained from the Decomposition of Hexarhodium Hexadecacarbonyl". Chandra, Dhanesh, Himanshu Mandalia, and Michael L. Garner. Advances in X-Ray Analysis, V. 38, 1995, pp. 413-435.

These papers could have sufficed as the Final Project Report. Professor Dhanesh Chandra chose to write a formal report to supplement these. A copy of this report, "Thermodynamic Properties of $\mathrm{Cr}-, \mathrm{W}-$, and $\mathrm{Co}-$ and Other Carbonyl Systems," by Professor Dhanesh Chandra, June 30 , 1996, 27 pp., was sent to Louis Summers, Branch of Procurement, Pittsburgh, PA with a letter of transmittal dated October 7, 1996. 


\section{Contract/Grant G1145229}

3671 Ladle Refining of Copper Produced by Single-Stage Smelting (ThemelisColumbia University)

\section{Project Scope and Goals:}

The single stage copper making process offers environmental and energy advantages over the conventional two-stage copper smelting processes.

However, it results in an unacceptably high level of impurities (As, $\mathrm{Sb}$, and $\mathrm{Bi}$ ) in anode copper. The objective of this project is to provide a quantitative description of the rate phenomena on the removal of impurities from molten "blister" copper by injection refining and develop engineering correlations which can be used in the design of industrial-scale tests, at an existing smelter, and eventually an industrial prototype.

Funding: $\quad F Y 92 \$ 74,826$; FY93 \$73,811; FY94 \$69,992

Graduate Student: Mr. Baozhong Zhao

Report Period: Supplement to April 1994- September 1995 (End)

Final Report:

On August 1, 1996, a copy of the thesis, "Ladle-Refining of Copper Produced by Single-Stage Smelting," by Baozhong Zhao (115p.) was approved by Columbia University as partial requirement for a Ph.D. degree, was sent to Louis Summers, at Pittsburgh, PA. Two additional published papers, listed below, completed the Final Project Report. These two were forwarded to Louis Summers with a letter of transmittal dated August 21, 1996.

"Kinetic Study of As, Sb, and Bi Removal From Copper by $\mathrm{SF}_{6}$ Injection," Zhao, Baozhong and Nickolas J. Themelis. Proceedings Gas Interactions on Nonferrous Metals Processing (Ed. By D. Saha), TMS-AIME, 1996, p. 127-143.

"Kinetics of As and Sb Removal From Molten Copper By $\mathrm{Na}_{2} \mathrm{CO}_{3}$ Fluxing," Zhao, Baozhong and Nickolas J. Themelis. Proceedings EPD Congress 1996 (Ed. Garry W. Warren), TMSAIME, 1996, p. 515-526. 


\section{CONTRACT/GRANT G1155229}

2900 Administration and Technology Transfer. Generic Mineral Technology Center For Pyrometallurgy (UMR - Robertson)

\section{Project Scope and Goals:}

Administration of the Center for Pyrometallurgy, operation of the Information and Reference Center, and technology transfer to industry and government laboratories of data and software for thermodynamic calculations.

Funding: $\quad F Y 95,96,97 \$ 76,672$

Report Period: April 1, 1996 - September 30, 1997

\section{Final Report:}

\section{Information and Reference Center:}

The aim of the Information and Reference Center (IRC) is to act as a focus for pyrometallurgical information and to maintain a record of the activities of the Center. Each GMTC had evolved its own method of operation for its IRC to meet the needs of its constituency.

During the period, Mr. Lee Neumeier continued to work part-time as the coordinator for IRC activities, but at a substantially reduced schedule. Helen Miller, part-time secretary, assisted Mr. Neumeier as time permitted in activities such as servicing requests for software and related data and updating working documents such as reference inventory. Efforts were continued in tracking reports, particularly final reports, for completed projects. All Pl's remained cognizant of contractual requirements to account for project funds with published and/or special reports, and/or theses. Also copies of completed works were forwarded to both the Rolla and Washington, D.C., offices. Final reports (published, special, theses) were so identified. Pl's are to be commended in their efforts in getting out timely notification of theses and published reports.

So far as possible with available funds, an ongoing activity was continuation of procurement of highly selective pyrometallurgy-related conference/symposia proceedings. Other reference items were received and cataloged as appropriate.

Reference materials not generally held by the IRC were recommended by GMTCP staff for procurement by the central University Library under the Dougherty Fund endowment or other available library funding. Such vigilance 
has increased importance as central libraries, under budget constraints, no longer automatically order volumes in important metallurgical series. Serious gaps in the series soon occur if this is not monitored.

Early in the period, a limited number of requests were processed for Center for Pyrometallurgy software after the latest round of modifications, and for the book "Thermodynamic Data for Elements, Compounds, and Alloys," compiled by Dr. A. E. Morris and Dr. M. E. Schlesinger (both for a nominal charge). The software service has now generally ceased with the retirement of Dr. Morris.

\section{Administration:}

Administrative work during the period was routine. The most important task was the organization of the final Research Council Meeting, held in Rolla on September $8-10$ 1996. The Program for this meeting is given below:

\section{CENTER FOR PYROMETALLURGY \\ RESEARCH COUNCIL MEETING PROGRAM}

September $8-10,1996$

Because Federal Regulations prohibit payment for meals by the Center for Pyrometallurgy there will be a Registration Fee of $\$ 40$.

\section{SEPTEMBER 8}

8:00 p.m. Hospitality Room, Howard Johnson

Dr. Robertson will register as many people as possible. Credit cards are acceptable.

\section{SEPTEMBER 9}

TIME

SUBJECT

SPEAKER

Missouri Room, University Center East

8:00 a.m. Registration

Coffee and juice will be available

$8: 20-8: 30$

Welcoming remarks Dr. David Robertson

Dr. Jan Kor

8:30-9:00

The Ohio State University Projects Interfacial Phenomena in Aluminum/

Ramesh Narayanan Molten Salt Reactions 
TIME

SUBJECT

SPEAKER

9:00-9:30

Modeling of Thin Strip Casting Processes

Shailesh Gupta

9:30-10:00

Univ. of Arizona Project

Impurity Element Volatilization

from Matte

Dr. David Lynch

10:00-10:30 a.m. Break

10:30-11:00 UMR Project

Zinc Vapor Sensor Mr. John Venarsky

11:00-11:30 MIT Project

Mixing in Counter-Current Reactors Dr. G. Trapaga

11:30-12:00 Univ. California Project

Kinetics of Magnesium Removal from Mr. Qian Fu

Aluminum

12:00-1:00 p.m. Luncheon, Silver and Gold Room, UCE

1:00-1:30 UMR Project

Technology Transfer Dr. Art Morris

Preserving and Enhancing the USBM Database

1:30-2:00 Purdue Univ. Project

Surface Tension of Metallurgical Slags

Mr. David Skupien

2:00-3:00 UMR Presentations and Tour, in Fulton Hall

Pyrometallurgical Treatment by Submerged Mr. Dhiren Panda Combustion

Remediation and Recovery of Metal

Values from Slags

Relative Stability of $\mathrm{CaO}$ and $\mathrm{MgO} \quad$ Mr. Xiaoping Xu

Solubility of Lead and Bismuth in Steel

Mr. S. Malhotra

Slag Splashing

Mr. Le-Wen Chang

Mr. Ajay Garg

Recycling Oil Filters

Mr. Darrell Roberts 
TIME

SUBJECT

Metsim Demonstration

FREED and THERBAL Demonstration

\section{SPEAKER}

Dr. H. Li

Dr. A. E. Morris

3:00-3:30 p.m. Break, in Fulton Hall

3:30-4:30 Presentations and Tour continue

6.00 p.m. Dinner at Zeno's. Tea Room. Wine with dinner, no bar. After dinner - drinks, ping pong, poker, and talk, at Robertson's.

\section{TUESDAY, SEPTEMBER 10}

8:00 a.m. Meeting of Research Council and PI's, in Missouri Room, University Center East

9:00-10:00 Optional tour of UMR facilities, including possibly the old USBM Foundry, the Materials Research Center, Metallurgical Engineering

10:00 a.m. Meeting completed. Visitors depart for St. Louis.

Considering that the Center was about to be wound up, and that there was therefore no new funding to discuss, the meeting was well attended, with Drs. Kor, Kaplan, Shumaker, and Peterson representing the Research Council. All Principal Investigators and/or their graduate students attended.

\section{Visitors:}

A number of visitors came to the Center during the reporting period.

Date

January 16-18, 1996

January 29-31, 1996

February 20, 1996

March 27-29, 1996

March 28, 1996
Visitor

Dr. A. Cameron

Dr. Don Satchell

Dr. N. Saxena

Dr. H. Eric

Dr. John Stubbles

Anna Bostrom

Daniel Widlund

Dr. J. P. Birat

Dr. Chantal Houpert
Affiliation BOC Gases

University of the Witwatersrand Charter Steel Royal Institute of Tech. Stockholm, Sweden IIRSID, France 
July 9 - August 16, 1996

July 25, 1996

Sept. 11, 1996

Sept. 29 - Oct. 1, 1996

December 5-8, 1996

April 28, 1997

May 311997

June 6, 1997
Dr. Rodney Jones

Dr. Brian G. Thomas

Dr. Bob Kaplan

Sylvain Van den Rul

Dr. Tor Lindstad

Dr. N. K. Batra

Mr. Frank Vonesh

Mr. Steve James
MINTEK, South Africa

University of Illinois

Consultant

Union Miniere, Belgium

SINTEF, Norway

Indian Inst. Tech., Kanpur

MG Industries

Big River Zinc

The Director of the Center organized a visit to copper smelters in Texas, New Mexico, and Arizona, from May 17 to 27, 1996. We visited the smelters at EI Paso, TX (Asarco), Hidalgo, NM (Phelps Dodge), Hurley NM (Phelps Dodge), San Manuel AZ (BHP), and Miami AZ (Cyprus). We also visited the Phelps Dodge laboratories at Morenci, AZ. The Center personnel who took part in this visit were Dr. Robertson, Dr. Schlesinger, Dr. Li, Mr. K. N. Swamy and Mr. Adrian Deneys. The purpose of the visit was to make contacts and to let the industry know of the research capabilities of the Center.

Employment of Undergraduates:

Mr. Nick Schupp worked with Adrian Deneys on the "Remediation and Recovery of Metal Values from Slags" project.

Two undergraduate students, Mr. Mathias Chintinne and Elise Bellemans from the University of Leuven in Belgium worked at the Center during July and August 1997 , on process modeling and vacuum induction melting. 


\section{Contract/Grant G1155229}

2928 Pyrometallurgical Treatment by Submerged Combustion In-Bath Smelting (SCIBS): Applications and Control (Robertson-UMR)

\section{Project Scope and Goals:}

Study of fundamental process chemistry and kinetics of the submerged combustion in bath-smelting process.

Funding: FY95 $\$ 57,782 ;$ FY96 $\$ 62,902$

Graduate Student: Mr. Dhiren Panda

Report Period: $\quad$ April 1996-September 1996 (End)

\section{Progress/Final Report:}

A thesis comprises the Final Project Report. The thesis, "Submerged Combustion In-Bath Smelting in Metallurgical Reactors," by Dhiren Kumar Panda, 172 pages, as part of the requirement for a Doctor of Philosophy in Metallurgical Engineering, was approved at the University of Missouri-Rolla in 1997. Copies of the pertinent identifying pages of the thesis follow within this Final Progress Report. 


\title{
SUBMERGED COMBUSTION IN-BATH SMELTING
}

IN METALLURGICAL REACTORS

by

DHIREN KUMAR PANDA, 1966-

\begin{abstract}
A DISSERTATION
Presented to the Faculty of the Graduate School of the

UNIVERSITY OF MISSOURI - ROLLA

in Partial Fulfillment of the Requirements for the Degree
\end{abstract}

DOCTOR OF PHILOSOPHY

in

METALLURGICAL ENGINEERING

1997

Mand G.C. Rbutian

David G. C. Robertson, Advisor

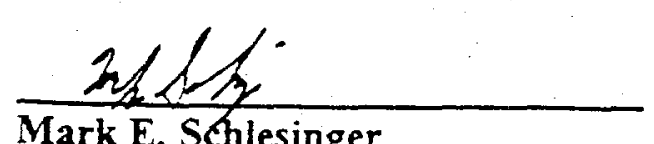

Mark E. Schlesinger

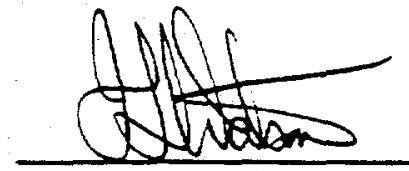

John L. Watson

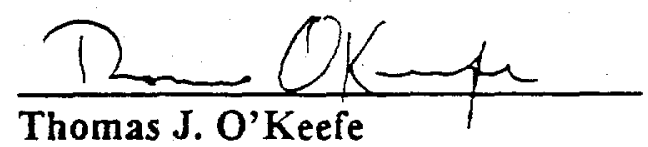

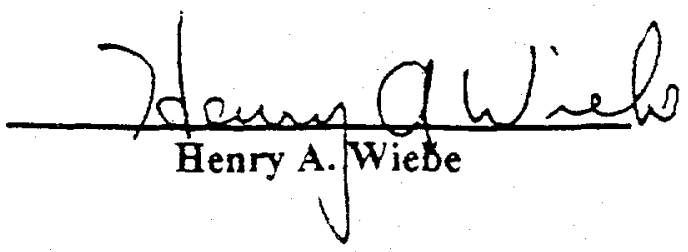




\begin{abstract}
The SCIBS (S Submerged Combustion In-Bath Smeiting) process has been in use worldwide for the past two decades to process materials - mainly tin, zinc, and lead concentrates. The process involves injecting fuel, either gaseous or liquid, through a lance into a molten bath of slag or concentrate. The injection of large volumes of gases results in extremely turbulent conditions, providing intense mixing of the melt. The mixing helps in obtaining faster rates of reaction due to enhanced mass transfer rates. The presence of large volumes of gases also provides for excellent fuming conditions, which helps in the removal of volatile species such as lead, zinc, and cadmium.

Research work has been carried out at the Center for Pyrometallurgy at the University of Missouri-Rolla to study the fundamentals of the SCIBS process to treat waste oxide materials containing zinc and lead. The research has been sponsored by the US Bureau of Mines and is currently focused on treating zinc retort residue wastes from the MO-OK-KS tri-state area. The material contains approximately $6 \% \mathrm{Zn}$, and $2 \% \mathrm{~Pb}$, as the main elements of concern. The project is aimed at cleaning up the slag by adding a reductant, nameiy coke or charcoal, to the molten slag bath, in order to fume off lead and zinc, among other volatile oxides. The resulting slag is expected to pass the TCLP (Toxicity Characteristic Leaching Procedure) test so that it can be rendered non-hazardous, and disposed of safely. The experimental results show that the process can produce final slags consistently having less than $2 \% \mathrm{Zn}$ and $0.1 \% \mathrm{~Pb}$.
\end{abstract}




\section{TABLE OF CONTENTS}

Page

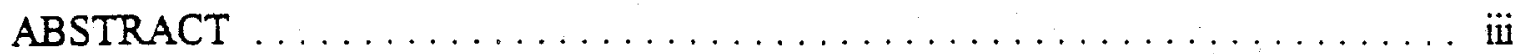

ACKNOWLEDGEMENTS $\ldots \ldots \ldots \ldots \ldots \ldots \ldots \ldots \ldots \ldots \ldots \ldots \ldots \ldots \ldots \ldots$ iv

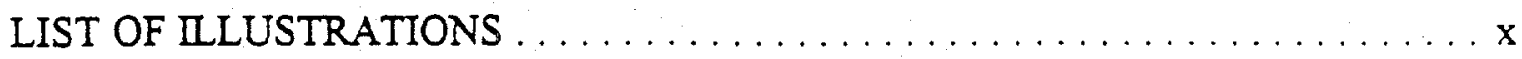

LIST OF TABLES $\ldots \ldots \ldots \ldots \ldots \ldots \ldots \ldots \ldots \ldots \ldots \ldots \ldots \ldots \ldots \ldots$ SECTION

I. INTRODUCTION $\ldots \ldots \ldots \ldots \ldots \ldots \ldots \ldots \ldots \ldots \ldots \ldots$

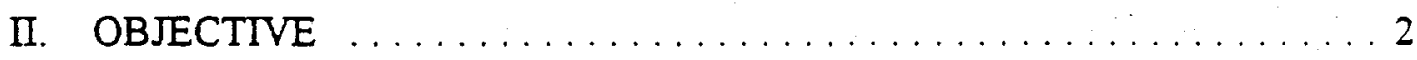

II. LITERATURE SURVEY $\ldots \ldots \ldots \ldots \ldots \ldots \ldots \ldots \ldots \ldots$

A. SCIBS PROCESSES $\ldots \ldots \ldots \ldots \ldots \ldots \ldots \ldots \ldots \ldots$

1. Development of SCIBS $\ldots \ldots \ldots \ldots \ldots \ldots \ldots \ldots \ldots$

2. Process Description ...................... 9

a. Reactor $\ldots \ldots \ldots \ldots \ldots \ldots \ldots \ldots \ldots \ldots$

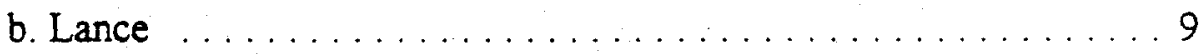

c. Feed Preparation . . . . . . . . . . . . . . . . . 13

d. Gas/Fume Handling . . . . . . . . . . . . . . 14

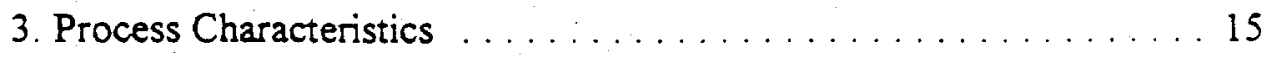

4. Reaction Zones in the SIROSMELT Furnace ............ 19

B. SELECTIVE REDUCTION OF OXIDES $\ldots \ldots \ldots \ldots \ldots \ldots 21$ 


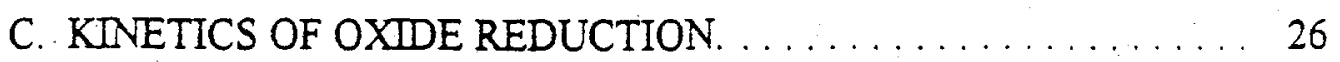

1. Possibie Mechanisms of Oxide Reduction $\ldots \ldots \ldots \ldots \ldots 26$

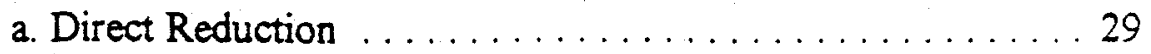

b. Indirect Reduction ..................... 31

c. Indirect vs. Direct Reduction $\ldots \ldots \ldots \ldots \ldots \ldots \ldots \ldots \ldots$

d. Indirect Reduction by FeO . . . . . . . . . . . . . . . . 34

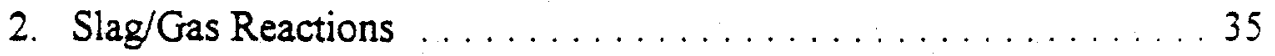

D. SUMMARY OF SLAG FUMING STUDIES $\ldots \ldots \ldots \ldots \ldots 38$

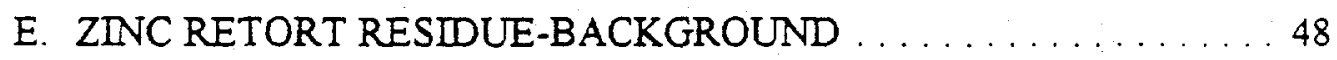

IV. MATERIALS AND CHARACTERIZATION ............. 50

A. ZINC RETORT RESIDUE $\ldots \ldots \ldots \ldots \ldots \ldots \ldots \ldots \ldots$

B. COKE/CHARCOAL ............................ 64

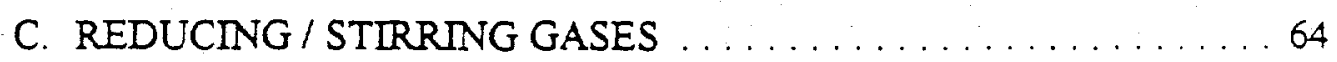

D. FLUXES/CHEMTCALS .......................65

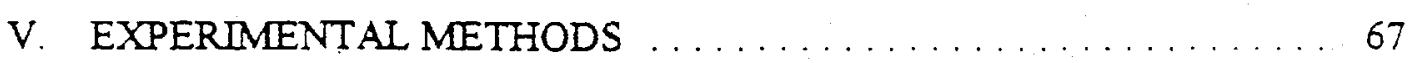

A. EXPERIMENTAL APPARATUS $\ldots \ldots \ldots \ldots \ldots \ldots \ldots \ldots$

1. Crucible Assembly . . . . . . . . . . . . . . . . . . . . 67

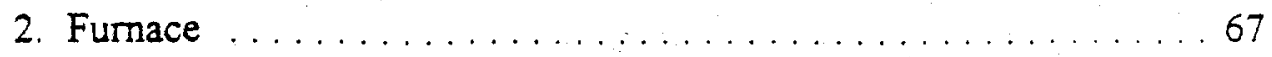

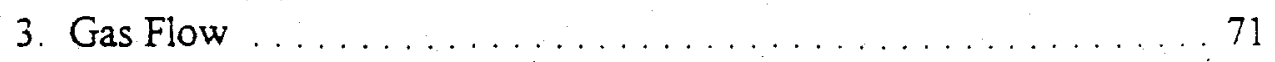

4. Lance System . . . . . . . . . . . . . . . . . . . . . . 73 
5. Design Modifications to Prevent Zinc Recycling .......... 73

6. Data Acquisition ............................. 75

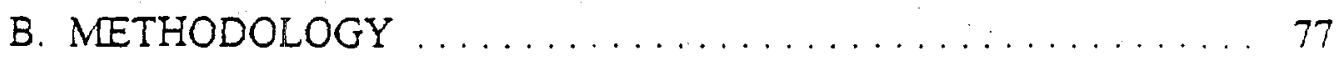

C. SAMPLING AND CHEMICAL ANALYSIS $\ldots \ldots \ldots \ldots \ldots .82$

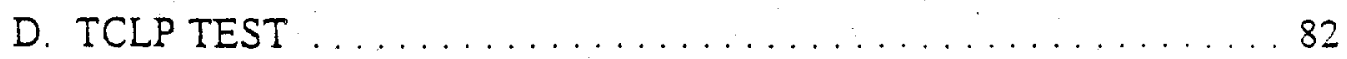

VI. EXPERMENTAL RESULTS $\ldots \ldots \ldots \ldots \ldots \ldots \ldots \ldots \ldots \ldots$

A. SMELTLNG RUNS $\ldots \ldots \ldots \ldots \ldots \ldots \ldots \ldots \ldots \ldots \ldots \ldots \ldots$

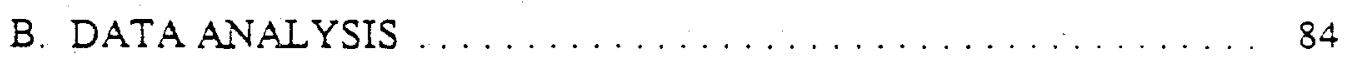

C. FUMING OF ZINC USING COKE/CHARCOAL ........... 90

1. Pre-reduction stage $\ldots \ldots \ldots \ldots \ldots \ldots \ldots \ldots \ldots \ldots . \ldots \ldots$

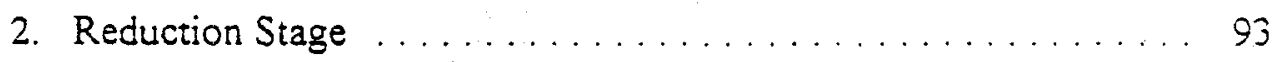

a. Effect of Basicity ......................... 93

b. Effect of Flowrate ........................ 93

c. Effect of Temperature ....................... 96

d. Effect of Type of Reductant . . . . . . . . . . . . . 96

e. Effect of Sulfur ......................... 96

D. FUMING OF LEAD USING COKE/CHARCOAL .......... 96

1. Pre-reduction stage $\ldots \ldots \ldots \ldots \ldots \ldots \ldots \ldots \ldots \ldots$

2. Reduction Stage ............................ 104

a. Effect of Basicity ......................... 104 


\section{Page}

b. Effect of Flow Rate ....................... 104

c. Effect of Temperature ... . . . . . . . . . . . . . . . . 107

d. Effect of Type of Reductant . . . . . . . . . . . . . . . . 107

e. Effect of Sulfur . . . . . . . . . . . . . . . . . . . . 107

E. FUMMNG WITH REDUCDNG GASSES .............. 111

1. Reduction with $\mathrm{CO} / \mathrm{CO}_{2}$ Mixtures $\ldots \ldots \ldots \ldots \ldots \ldots \ldots 114$

2. Reduction with $\mathrm{H}_{2} \ldots \ldots \ldots \ldots \ldots \ldots \ldots \ldots \ldots \ldots$

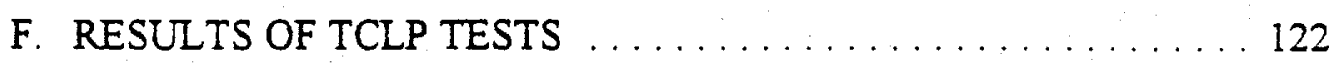

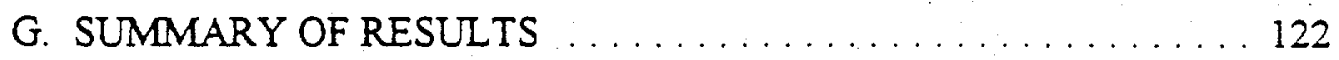

VII. DISCUSSION OF RESULTS $\ldots \ldots \ldots \ldots \ldots \ldots \ldots \ldots \ldots \ldots \ldots$

A. ROLE OF IRON OXIDES IN THE SLAG $\ldots \ldots \ldots \ldots \ldots \ldots 125$

B. THE STATE OF OXIDATION OF THE INITIAL SLAG . . . 125

C. SUMMARY OF REDUCTION MECHANISMS $\ldots \ldots \ldots \ldots 126$

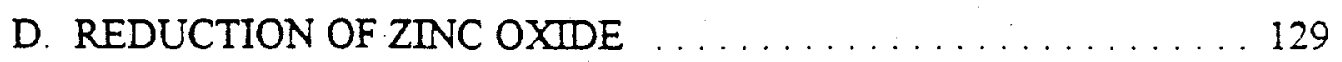

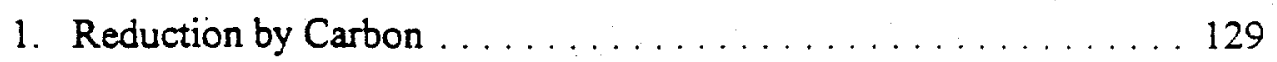

2. Reduction by Gases $\ldots \ldots \ldots \ldots \ldots \ldots \ldots \ldots \ldots \ldots \ldots$

3. Role of Gas/Slag Reactions in Zine Fuming by Coke/Charcoal . . . 136

E. REDUCTION OF LEAD OXIDE ................ 136

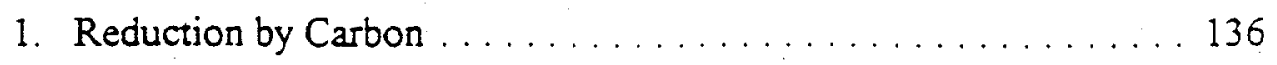

2. Gaseous Reduction ....................... 138 
VIII. CONCLUSIONS .............................. 140

IX. RECOMMENDATIONS FOR FUTURE WORK ........... 143

A. STUDY OF REACTION MECHANISM $\ldots \ldots \ldots \ldots \ldots \ldots 143$

B. ADDITIONAL TEST WORK ..................... 145

C. NOVEL EXPERIMENTAL TECHNIQUES ............. 146

D. PHYSICAL MODELING ................... 147

E. MATHEMATICAL MODELING ................ 148

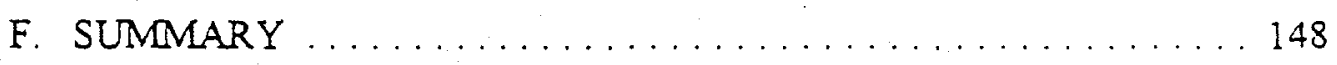

APPENDICES

A. SAMPLE PYROSIM CALCULATION ON SELECTIVE REDUCTION

B. SLAG SAMPLE PREPARATION, MICROWAVE DISSOLUTION,

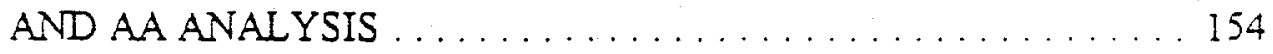

C. DLMENSIONS OF CRUCIBLE AND CALCULATION OF VOLUME AND NOMINAL SURFACE AREA ................... 163

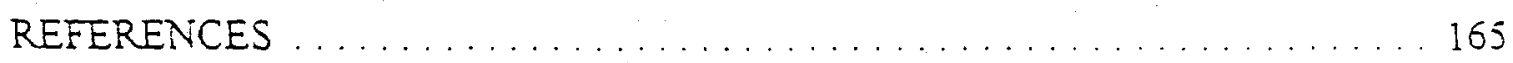

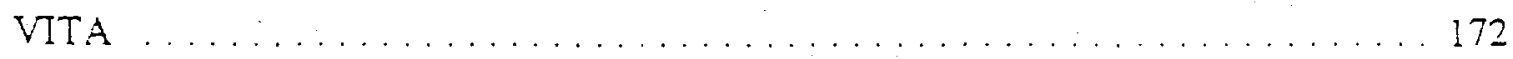




\section{VITA}

Dhiren Panda was bom on January 25, 1966, in Rourkela, India. He obtained his high school and intermediate diplomas as a student of Ispat (EM) School, Rourkela, in 1983 and 1985, respectively. He pursued his undergraduate engineering education at Regional Engineering College, Rourkela, from where he graduated with a B.Sc. (Hons.) in Metallurgical Engineering. He was employed as a Metallurgical Engineer in the Central Metallurgical Laboratory - I, Tata Engineering and Locomotive Co., Jamshedpur, India, during the period June '89-November '90. From December, 1990, he has been employed as a Graduate Research Assistant in the Generic Mineral Technology Center for Pyrometallurgy, while working towards his $\mathrm{MS}$ and $\mathrm{PhD}$ degrees in the Department of Metallurgical Engineering at the University of Missouri-Rolla. 


\section{Contract/Grant G1155229}

2930 Zinc Metal Vapor Sensor Development (Mattox-UMR)

Project Scope and Goals:

The development of a zinc vapor sensor for use in primary zinc metal processing applications using zinc oxide as a sensor material.

Funding: FY95, FY96 \$64,826

Graduate Student: Mr. John Venarsky

Report Period: $\quad$ April 1996-September 1996 (End)

Progress/Final Report:

A thesis comprises the Final Project Report. The thesis, "The Effect of Zinc Vapor on the DC Resistance or Polycrystalline Zinc Oxide," by John Jeffery Venarsky, was approved (1997) as partial fulfillment of requirement for a Master of Science Degree in Ceramic Engineering, at the University of Missouri-Rolla. A copy of the pertinent identifying introductory pages follow as part of this Final Progress Report. 
THE EFFECT OF ZINC VAPOR ON THE DC RESISTANCE OF POLYCRYSTALLINE ZINC OXIDE

by

JOHN JEFFREY VENARSKY, 1970 -

A THESIS

Presented to the Faculty of the Graduate School of the

UNIVERSITY OF MISSOURI-ROLLA

In Partial Fulfillment of the Requirements for the Degree

MASTER OF SCIENCE

in

CERAMIC ENGINEERING

1997
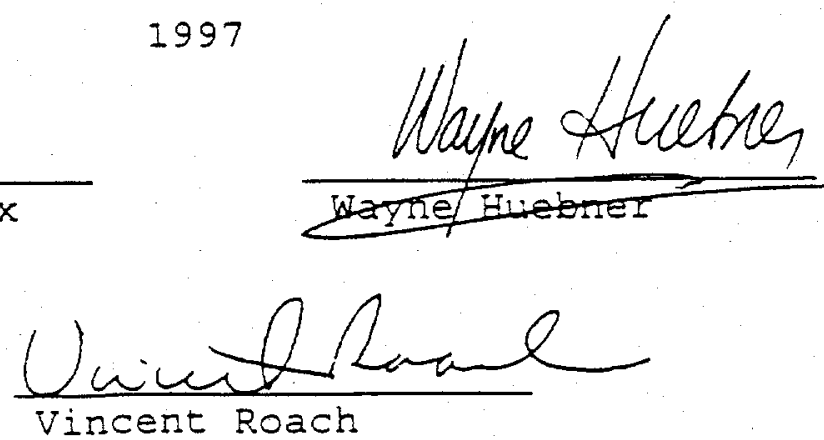


\section{ABSTRACT}

The effect of zinc vapor on the dc resistance of polycrystalline zinc oxide was investigated at temperatures of 700 and $800^{\circ} \mathrm{C}$. The partial pressures of zinc vapor used to investigate this behavior ranged from 1E-04 to IE-02 atmospheres. The results show that the resistance of polycrystalline zinc oxide is significantly decreased in the presence of zinc vapor at these temperatures. The decrease in resistance is attributed to donor electrons associated with adsorbed zinc on the surface of zinc oxide, and not to bulk diffusion of zinc into the oxide. The decrease in resistance is also found to be dependent on the zinc partial pressure, with higher zinc pressures producing a larger decrease in resistance. The relationship between zinc partial pressure and resistance is not observed to depend strongly on temperature. 


\section{ACKNOWLEDGMENT}

I would like to thank my parents John and Glenda Venarsky, and my brother Michael for all of the love, patience, and support they have given me throughout the course of my education.

I would also like to thank my advisor, Professor Douglas M. Mattox, for making all of this possible and for his considerable patience, guidance, and understanding over the years.

I would also like to thank the Center For Pyrometallurgy, the United States Bureau of Mines, and the United States Department of the Interior for their financial support for this research.

I would further like to thank the faculty and staff in the Ceramic Engineering department for making both my undergraduate and graduate education an enriching experience. Special thanks go out to the crew in the shop, Jack Jones, Gale Papen, Mike Roberson, and Richard Turner, whose help and advice made my experimentation possible.

I would further like to thank my girlfriend kimberly Hoppfinger for her love, patience, and support during my years in graduate school. I would finally like to thank cecil Gerber, Brian Gorman, Shawn Kathmann, Mark Knott, Kerry Meinhardt, Dave Reed, Kirk Sharpe, and Joe Szabo for the endless interesting conversations over the years. 


\section{TABLE OF CONTENTS}

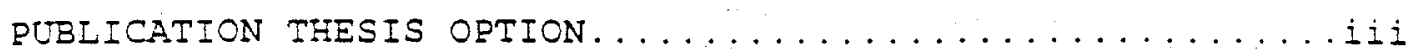

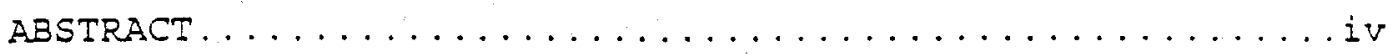
ACKNOWLEDGMENT $\ldots \ldots \ldots \ldots \ldots \ldots \ldots \ldots \ldots \ldots \ldots \ldots$ LIST OF ILLUSTRATIONS ..........................

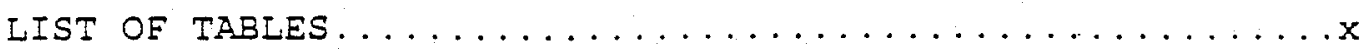

PAGE

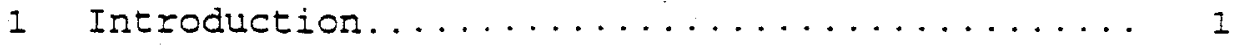

1.1 zinc smelting............... 3

1.2 Electronic structure of zinc oxide..... 7

1.3 Bulk response model............. 9

1.4 Surface response model............ 13

1.5 Effect of oxygen, hydrogen, and carbon monoxide on zinc oxide's resistance..... 16

1.6 Previous studies of zinc vapor effects on the resistance of zinc oxide ...... 17

2 Experimental Procedure............... 20

2.1 Sample preparation.............. 20

2.2 Experimental chamber............. 21

2.3 Electrical measurements.......... 21

2.4 Zinc vapor generation and calibration... 22

2.5 Zinc vapor exposure experiments....... 25

3. Results and Discussion............... 27 
PAGE

3.1 Zinc vapor calibration results........ 27

3.2 Zirc vapor exposure results......... 28

3.2.1 Resistance vs. time results..... 28

3.2 .2 Response to zinc vapor........ 31

3.2.3 Temperature dependence of the response............... 33

4 Conclusion.................... 35

References........................ 37

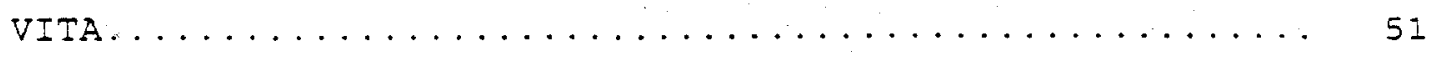




\section{VITA}

John Jeferey Venarsky was born on October 20, 1970 in Columbia, Illinois. At the age of 10 months he moved to Mascoutah, Illinois where he spent the majority of his childhood. He attended elementary school, junior high school, and high school in Mascoutah. He received his high school diploma in August 1988 from Mascoutah Community High School and began attending junior college and Belleville Area college shortly thereafter.

He attended Belleville Area College for two years until he transferred to the University of Missouri-Rolla in August of 1990 where he pursued his Bachelor of Science Degree in Ceramic Engineering. During his undergraduate education, he worked at Kohler Co. in Kohler, Wisconsin and Coors Ceramics Co. in Grand Junction, Colorado through the University of Missouri-Rolla's Co-op Work Program. He was an active member of the American Ceramics Society and Keramos Ceramics Fraternity and the recipient of the Kent Weisenstien Scholarship during his undergraduate education. He received his Bachelor of Science in Ceramic Engineering in May of 1993. He began pursuing his graduate degree in July of 1993 and has persisted in doing so until the present time. 


\section{Contract/Grant G1155229}

2931 Remediation and Recovery of Metal Values from Lead Smelting and Copper Refining Slags. (Robertson - UMR)

\section{Project Scope and Goals:}

To investigate the volatilization of metals from slags under relatively oxidizing conditions (conditions where a reduction agent is not introduced).

The slags to be investigated will be lead blast furnace type slags, and possibly molten EAF dusts, secondary copper slag and electrolytic zinc leach residues. The motivation for processing these types of materials is two-fold. Firstly, the materials contain valuable metals, which can, in principle, be recovered. Secondly, the materials are classified hazardous wastes and are therefore expensive to dispose of (in the USA).

The proposed method to treat these materials is to process the slags at some temperature above their melting point, and then to selectively fume-off undesirable elements like lead, sulfur, or volatile halogen species, by carefully controlling the oxidation potential,.

Funding: $\quad F Y 95,96,97 \$ 138,536$

Graduate Student: Adrian Deneys

Report Period: $\quad$ April 1996-September 1997 (End)

\section{Progress/Final Report:}

The Final Project Report consists of the attached report (by A. Deneys). Two published papers, presented at technical society meetings are being sent under separate cover:

1). "A Two Liquid Slag Mixing Experimental Technique for Studying the Oxidative Pre-Fuming Treatment of Lead Blast Furnace Slag."

Deneys, Adrian, David Robertson, and Nick Schupp.

1997 EPD Congress, Ed. By B. Mishra, TMS-AIME, 1997, pp. 621-634.

2). "Recovery of Cobalt from a Viburnum Trend Lead Blast Furnace Slag."

Deneys, Adrian C., David G.C. Robertson, and Rodney T. Jones.

Proceedings of Nickel-Cobalt 1997, Vol. Il, Pyrometallurgy Fund. and Process

Development, Ed. By C.A. Levac and R.A. Berryman, CIM, 1997, pp. 23-39. 


\title{
Metal Recovery from Slags
}

\author{
Final Report \\ Performed for: \\ United States Bureau of Mines \\ Slags Project: USDI G1155229 under grant R-5-35569 \\ by \\ Adrian Deneys \\ Center for Pyrometallurgy \\ University of Missouri-Rolla \\ Supervised by \\ Dr. David G.C. Robertson \\ Center for Pyrometallurgy \\ University of Missouri-Rolla
}

Period: 31 August 1995 - 31 August 1997

\section{Synopsis}

Approximately 100000 stpy of lead bast-furnace slag arises during primary lead smelting in Missouri. The slag is currently stockpiled, and contains approximately $8-12 \% \mathrm{ZnO}$. In addition, the slag fails the EPA toxicity characteristic leaching procedure (TCLP) for hazardous metals, notably because of the relatively high lead content, and will require further processing to render the material non-hazardous for long-term disposal.

Several processes have been proposed to treat the slag by selectively fuming the lead and zinc from the slag. The lead and zinc vapor species are then recovered as a saleable byproduct. Differences in the processes arise from the widely different reactors available, the manner in which the lead and zinc are recovered, and the ability to recover additional metal values from the slag, e.g. cobalt.

As originally proposed, the project titled Remediation and Recovery of Metal Values from Lead Smelting and Copper Refining Slags and Slag-Waste Mixtures (funded by the USBM) focused on a novel oxidative pre-fuming stage found in one particular process, viz. the Enviroplas process. It was originally speculated that significant fuming of lead and zinc (and other possible species) could take place in the holding furnace (also termed pre-fumer) which preceded the fuming furnace. Subsequent (unpublished) pilot scale tests, conducted on lead blast furnace slag, conclusively demonstrated that some lead fuming would take place, however zinc fuming would be minimized if the temperature of the reactor was maintained below $1300^{\circ} \mathrm{C}$. A mechanism was proposed by which zinc fuming could result (in the absence of a reductant) via the reaction of ferrous iron with zinc oxide to produce ferric iron and zinc vapor. An experimental technique was developed to study the reaction in greater detail, and to better understand the kinetics of zinc fuming in the absence of a reductant. The results of this study were published (1). 
In addition to containing lead and zinc, the lead blast-furnace slag (arising from the Viburnum Trend) also contains a significant quantity of cobait which could potentially be recovered as another by-product. Using previously unpublished experimental data, a detailed study was conducted to evaluate the potential benefit of recovering cobalt (in addition to zinc) from lead blast furnace slag, and hence determine the optimal thermal processing route. The study showed that cobalt could significantly contribute to the process if a recovery of greater than $80 \%$ of the incoming cobalt could be attained (2).

Based on the results obtained, and the continued effort to find a solution to safely dispose of lead blast-furnace slag, further work is being carried out. The most recent experimental program attempts to measure the temperature distribution close to the arc attachment zone of a direct-current arc-furnace, such as that envisaged for oxidative pre-fuming and for slag fuming. Towards this objective a $78 \mathrm{~kW}$ laboratory-scale furnace has been constructed at the University of Missouri - Rolla; the apparatus has been commissioned and preliminary results have been obtained.

\section{Conclusions}

1. A detailed study of the possible evolution of zinc from lead blast furnace slag, in the absence of a reductant, was conducted, the results of which were published (1);

2. A study of cobalt recovery from a Viburnum Trend lead blast furnace slag by pyrometallurgical processing has been performed, the results of which were published (2);

3. Future work on the temperature distribution close to the arc attachment zone of a d.c. furnace for slag cleaning is being conducted.

\section{References}

1. Deneys, A., Robertson, D., and Schupp, N, A Two-Liquid Slag Mixing Experimental Technique for Studying the Oxidative Pre-Fuming Treatment of Lead Blast Furnace Slag, 1997 EPD Congress, Edited by B. Mishra, TMS, 1997, pp. 621-634

2. Deneys, A.C, Robertson, D.G.C., Jones, R.T., and Worcester, A.W., Recovery of Cobalt from a Viburnum Trend Lead Blast Furnace Slag, Proceedings of NickelCobalt 1997, Vol. II, Pyrometallurgy Fundamentals and Process Development, Edited by C.A. Levac and R.A. Berryman, CIM, 1997, pp. 23-39 


\section{Contract/Grant G1155229}

O471 Impurity Element Volatilization and Adsorption.

(Lynch/Davenport - Univ. AZ)

Project Scope and Goals:

The original research goal was to evaluate the fundamental kinetics of volatilization of minor elements from molten matte. Achieving fundamental volatilization rates proved elusive, but saturation conditions were easily achieved with a small amount of stirring, even given the $200 \mathrm{~g}$ matte specimens employed in this investigation. While fundamental kinetic data could not be obtained, it was possible to collect and evaluate substantial thermodynamic data.

Funding: FY95,96 $\$ 66,990$

Graduate Student: Mr. Xu Zhong

Report Period: April 1996-September 1996 (End)

Progress/Final Report:

A thesis served as Final Progress Report. This thesis, "Thermodynamics of Trace Elements As, Bi, Pb, and Sb in Copper-Iron and Nickel-Copper Matte", by Xu Zhong, $225 \mathrm{p}$., was approved by the University of Arizona as partial requirement for a Doctor of Philosophy degree on November 27,1996. A copy of the pertinent introductory identification pages of the thesis had been sent to Louis Summers, Branch of Procurement, with a transmittal letter dated 18 December 1996. 


\section{Contract/Grant G1155229}

0671 Kinetics of Magnesium Removal from Aluminum.

(Evans - University of CA - Berkeley)

\section{Project Scope and Goals:}

A fundamental study of the kinetics of magnesium removal from recycled aluminum alloys.

Funding: FY95, $96 \quad \$ 69,059$

Graduate Student: Qian Fu

Report Period: $\quad$ April 1996 - September 1996 (End)

Progress/Final Report:

A progress report follows for the period April 1996 to September 1996. The Final Project Report consists of a manuscript in two parts submitted to the Metallurgical Society (TMS). A complete copy of the manuscript is being sent to the contract offices under separate cover. The appropriate bibliographical data on the two parts of the manuscript are:

(a) "Chlorine Fluxing for Removal of Magnesium from Molten Aluminum. Part I Laboratory scale measurements of reaction rates and bubble behavior. Fu Qian, Dong Xu and James W. Evans submitted to TMS-AIME, November 1997. 19 pages plus 12 figures.

(b) "Chlorine Fluxing for Removal of Magnesium from Mother Aluminum: Part II. Mathematical Model. Fu, Qian and James W. Evans, Submitted to TMSAIME, August 1997. 14 pages plus 2 tables, 13 figures. 
0671 Project Report for the period April 11996 to September 301996

Kinetics of magnesium removal from molten aluminum by chlorine fluxing

(Evans -Univ. of California,Berkeley)

Funding: FY $95 \$ 69,059$ FY $96 \$ 69,059$

Student: Qian Fu

Report:

\section{Introduction}

In our previous experimental studies, liquid phase mass transport has been identified as the rate controlling step in the chlorine fluxing of aluminum-magnesium alloy. In this report, a simple mathematical model was constructed to calculate the reaction progress. A computer program was also made to incorporate the bubble volume change during reaction and the equilibrium concentrations which have not been counted in the math model. The calculated results compared well with the experimental results.

Also in this report, a capacitance bubble probe which can be used in molten aluminum will be reported. Preliminary results showed that this capacitance probe not only survived in molten aluminum but also yielded reasonable signals.

\section{Previous Studies}

We have studied the reaction kinetics involved in chlorine fluxing of $\mathrm{Al}-\mathrm{Mg}$ alloys through emission gas analysis and melt sample analysis. In the emission gas study, emissions of aluminum chloride and chlorine were observed at temperatures below $710^{\circ} \mathrm{C}$. This confirmed a previous report of a barrier to reaction at these temperatures. Above $710^{\circ} \mathrm{C}$, little chloride and no chlorine emissions were observed when $\mathrm{Mg}$ concentration in the melt was high. However, when the $\mathrm{Mg}$ content of melt dropped below a certain point, chloride emission start to rise dramatically.

In the melt sample study, reactions at temperature higher than $710^{\circ} \mathrm{C}$ were studied. A critical $\mathrm{Mg}$ concentration was revealed. When the $\mathrm{Mg}$ concentration in the melt was higher than this critical concentration, the $\mathrm{Mg}$ depletion rate was simply the chlorine supply rate (a constant) and no white fume from aluminum chloride emission was observed. When the $\mathrm{Mg}$ concentration in the melt dropped below the critical concentration, however, the $\mathrm{Mg}$ depletion rate dropped and white fume was observed. $\mathrm{Mg}$ concentration dropped exponentially at this stage like that in a first order reaction. The critical $\mathrm{Mg}$ concentration was also found rising linearly with the rising input chlorine concentration in the gas mixture. 


\section{Mathematical Model}

It is well known that reaction of a melt constituent with a bubble could be controlled by mass transport in either the gas phase or the liquid phase, or it could be limited by the reaction kinetics (or formation of a film of reaction product) at the bubble surface. Our experiments on the influence of the meit temperature on reaction suggest no reaction barrier is present when the temperature is above $711^{\circ} \mathrm{C}$. Mass transport, therefore, seems to be the rate controlling step, either on the gas side or on the liquid side. However, if gas phase mass transportation is the rate controlling step, a constant high reaction efficiency at high $\mathrm{Mg}$ concentrations, which has been observed in our experiments, will not be possible This leaves liquid phase mass-transport of magnesium the only possible rate-controlling step.

A simple mass transport controlled model was constructed to explain all of our experimental results. In this model, input $\mathrm{Cl}_{2}$ is assumed to change to $\mathrm{AlCl}_{3}$ instantaneously at the nozzle (on observation of undetectable $\mathrm{AlCl}_{3}$ at temperatures higher than $710^{\circ} \mathrm{C}$ ). The depletion rate of $\mathrm{AlCl}_{3}$ in a bubble is then simply the rate of magnesium transported to the bubble surface. Equation (1) describes this situation

$$
\frac{d\left(C_{g}\right)}{d t}=-\frac{2}{3} \times K_{m} \times\left(\frac{a}{v}\right) \times\left(\frac{\rho_{m}}{\rho_{g}}\right) \times C_{m}
$$

where $\mathrm{K}_{\mathrm{m}}$ is the mass-transfer coefficient for $\mathrm{Mg}, \mathrm{C}_{\mathrm{m}}$ is the magnesium conc. in the melt (assume uniformly distributed), $\mathrm{C}_{\mathrm{g}}$ is the $\mathrm{AlCl}_{3}$ conc. in each rising bubble, $\mathrm{r}_{\mathrm{m}}$ and $\mathrm{rg}_{\mathrm{g}}$ are the molar densities, and $r$ is the radius of the bubble (assumed spherical). The solution for eq. (1) is

$$
C_{8 \mathrm{~T}}=C_{80}-K \times C_{m} \times T
$$

where $K=\frac{2}{3} \times K_{m} \times\left(\frac{a}{v}\right) \times\left(\frac{\rho_{m}}{\rho_{g}}\right), \mathrm{T}$ is the bubble residence time, $\mathrm{C}_{\mathrm{g} 0}$ is the initial $\mathrm{AlCl}_{3}$ concentration in the bubble and $\mathrm{C}_{\mathrm{gT}}$ that in the bubble at the top of the melt. From (2), if the magnesium concentration $\mathrm{C}_{\mathrm{m}}$ is higher than $\mathrm{C}_{\mathrm{g} \sigma} \mathrm{K} / \mathrm{T}$, the $\mathrm{AlCl}_{3}$ input should be converted to $\mathrm{MgCl}_{2}$ stoichiometrically

$$
\frac{d\left(C_{m}\right)}{d t}=-C_{g} \times V g \times\left(\frac{\rho_{g}}{\rho_{m}}\right) / V_{m}=\text { const } .
$$

where $V_{g}$ is the total gas flow rate and $V_{m}$ is the total melt volume. Equation (3) predicted a linear decrease in magnesium concentration at high $\mathrm{Mg}$ concentration stage.

Theoretically, if $C_{m}$ is higher than $C_{m \text { criticas }}=C_{g 0} / K / T$, the 'critical concentration', no gas should be emitted out from the reactor. The actually observed emission (not visible though) in this stage could then came from several sources, 
1. oxidation on the top surface (e.g. $2 \mathrm{MgCl}_{2}+\mathrm{O}_{2} \rightarrow 2 \mathrm{MgO}+2 \mathrm{Cl}_{2}$ )

2. residual moisture (e.g. $\mathrm{MgCl}_{2}+\mathrm{H}_{2} \mathrm{O} \rightarrow \mathrm{MgO}+2 \mathrm{HCl}$ )

3. residual equilibrium gas concentration

When magnesium conc. drops below the 'critical concentration' $C_{\text {meritical, new }}$ phenomena will happen. Magnesium transported to tne bubble will not be able to consume all the $\mathrm{Cl}_{2}$ inside the bubble. Unreacted $\mathrm{AlCl}_{3}$ will then show up as white fume. At this stage, the magnesium depletion rate is the rate of magnesium mass-transfer

$$
\frac{d\left(C_{m}\right)}{d t}=-K_{m} \times C_{m} \times A / V_{m}
$$

where the total reaction area $A=a \times f \times T=\left(\frac{a}{v}\right) \times V_{g} \times T$, a is the reaction area of single bubble, $\mathrm{f}$ is the bubble frequency and $\mathrm{T}$ is the residence time, while $\left(\frac{a}{v}\right)$ is the surface-to-volume ratio of the bubble and $V g$ is the total gas flow rate. Eq.(4) gives rise to an exponential decay of $\mathrm{Cm}$

$$
C_{m}=C_{m 0} \exp \left(-K_{m} \cdot A \cdot t / V_{m}\right)=C_{m 0} \exp (-\beta \cdot t)
$$

where

$$
\beta=K_{m} A / V_{m}
$$

is the exponential factor. If the mass-transfer coefficient $K_{m}$ and the melt volume $V_{m}$ are kept constants, $\beta$ will become proportional to the total reaction area $A$. This explains why small bubbles are preferred to big bubbles, they provide more reaction area under the same flow rate.

From (6), $\beta$ can also be used to calculate the mass-transfer coefficient $K_{m}$. In a typical experiment, a $6 \mathrm{~mm}$ O.D. J-type nozzle, a flow rate of $116 \mathrm{~cm}^{3} / \mathrm{min}$ (room temperature) generated bubbles at $5 \mathrm{~Hz}$ frequency. The residence time was about $0.6 \mathrm{sec}$ for a $22 \mathrm{~cm}$ submergence length. A $\beta$ of $1.725 \times 10^{-3} / \mathrm{sec}$ was typical for a $2.1 \mathrm{~kg}$ melt. This gives a mass-transfer coefficient $K_{m}$ of $0.0893 \mathrm{~cm} / \mathrm{s}$ if the bubbles are assumed spherical. This $K_{m}$ value, if used in surface-renewal theory to calculate the diffusivity of magnesium in molten aluminum, will result in

$$
D=\pi \cdot t_{\cdot} \cdot K_{m}^{2} / 4
$$

where $D$ is the diffusivity and $t_{c}-d_{d} / u_{b}$ is the estimated contact time. When using bubble diameter $d_{b}=1.4 \mathrm{~cm}$, bubble velocity $u_{b}=40 \mathrm{~cm} / \mathrm{s}, D$ was calculated to be about $2.2 \times 10^{-4} \mathrm{~cm}^{2} / \mathrm{s}$. This value is twice the diffusivity value we can find in the literature. The reason is explained as following, since the bubbles are not spherical in the real cases, the mass-transfer-coefficient $\mathrm{K}_{\mathrm{m}}$ we have measured above is actually $\mathrm{K}_{\mathrm{m}} \times \phi$, where $\phi$ is the ratio of the real bubble surface area divided by the nominal spherical value. As we have 
pointed out in the previous report, bubbles generally take ellipsoidal or bell shapes which all have higher surface area than sphere (i.e. $\phi>1$ ). In real applications, if we assume all the bubbles have similar $\phi s$ (not a bad assumption if the bubbles have similar shape), we can greatly simplify the problem by assuming the bubbles as spherical and use the $\mathrm{K}_{\mathrm{m}}$ directly. In this way, the surface ratio $\phi$ is automatically incorporated.

Knowing $\mathrm{K}_{\mathrm{m}}$, we can go backwards to derive the critical magnesium concentrations at different input chlorine concentrations.

$$
C_{m, \text { criical }}=C_{80} / K / T=\frac{2}{3} \times C_{g 0} \times K_{m} \times\left(\frac{a}{v}\right) \times\left(\frac{\rho_{m}}{\rho_{g}}\right) / T
$$

Equation (8) gives a linear relationship between $\mathrm{C}_{\mathrm{g} 0}$, the input $\mathrm{AlCl}_{3}$ concentration, and $\mathrm{C}_{\text {m.cricical }}$, the critical magnesium concentration. The result is plotted in fig. 1.a together with the experimental data and the result from our computer program.

\section{Computer program}

The mathematical model we have constructed above may be good enough for predicting reaction of bubbles of low chlorine concentration. But it would generate big errors when trying to apply this model to high $\mathrm{Cl}_{2}$ concentration bubbles as the bubble volume changes greatly in the rising period due to reaction. Another factor we haven't incorporated into our theoretical model is the equilibrium concentrations of $\mathrm{AlCl}_{3}$ and $\mathrm{Mg}$, which could actually make a big difference in the low-Mg and low- $\mathrm{AlCl}_{3}$ cases.

In order to solve the volume-change and equilibrium concentration problems, and make possible to apply the reaction kinetics to much broader applications, a computer program was constructed to simulate the demagging process. This computer program uses standard numerical techniques (e.g. Runge-Kutta) to emulate a single bubble rising process and then incorporated the results into a bigger loop where magnesium content in the melt was calculated. Several modified versions of the basic program were also constructed to calculate the gas emissions and the critical transition points.

Fig. 2 shows the $\mathrm{AlCl}_{3}$ concentration change inside a single bubble as it rises through the melt. The right edge on the graph represents the residence time, any unreacted $\mathrm{AlCl}_{3}$ at this edge will leave the reactor and become gas emission. As we can see, for a $10 \%$ (molar) $\mathrm{AlCl}_{3}$ input, if the magnesium concentration is higher than $100 \mathrm{ppm}$, very little $\mathrm{AlCl} 3$ is emitted. But if the $\mathrm{Mg}$ concentration drops below 80ppm, the $\mathrm{AlCl} 3$ emission will become enormous. If we take $1 \% \mathrm{AlCl} 3$ emission as the criterion to distinguish the critical points, a relationship between the critical magnesium concentration and input chlorine gas concentration can be drawn. The result is plotted on fig.1.b. On the graph, $\mathrm{C}_{\mathrm{m}, \text { critical }}$ has a linear relationship with $\mathrm{C}_{80}$ at low $\mathrm{C}_{80}$. The curve shoots up as $\mathrm{C}_{80}$ approaches $100 \%$. This 
is because in high chlorine cases, surface area drops dramatically as chlorine content inside a bubble is reacted out. On a magnified view of the very low end of the curve (fig. 1.b), we can see that the curve also start to bend up because of the equilibrium concentrations slow the reactions. Also on the graph, we can see that experimental data follow the same trend as the predicted and only seem to shift a little towards the right, this could be caused by the time delay between fume first start to be emitted and it actually becoming visible.

Fig. 3 shows calculated magnesium content :an during the demagging process. Experimental data with the same conditions were aisu snown. A fairly good match of both the curve shape and the details (e.g. the transition point) shows the program works well.

Fig.4 shows the calculated gas emission during the demagging process. The magnesium concentrations are also shown as a reference. On the graph, the emission jumps to very high level after the magnesium content drops below the critical concentration. This emission pattern matches well with our emission results.

From the above, we can see that our mathematical model simulates the single bubble experimental data very well. It is then possible to incorporate it into future mathematical model where fluid flow, and bubble distribution are considered.

\section{Capacitance bubble probe}

The capacitance probe utilizes the concept that the capacitance between two metal plates is proportional to the plate area when the distance between the plates is kept constant. A schematic drawing of the proposed capacitance probe is shown in fig.5. The probe consists of a thin alumina tubing which is blocked at one end. A metal wire is inserted into the tubing to be one electrode, and the molten aluminum is selected as the other electrode (the ground). The capacitance between these two electrodes is decided by the contact area between the alumina tubing and the melt. The alumina tubing is the active measuring element. When the probe (the tubing) is submerged into the melt, a capacitance measurement will reveal the contact area change between the tubing and the melt. In case of bubbles, when the probe penetrates a bubble, its contact area with the melt will drop and so does the capacitance. If a circuit with linear response to the capacitance change is used, the output (usually a voltage) will reflects this event. For a bubble with diameter less than the probe length, output like fig. 5 is expected. The slope of the front edge will provide information on the velocity of the bubble, and the depth of the "dent" will yield the bubble size.

Capacitance probes like the one described above have been made in our laboratory. An electrical circuit has been developed to measure the capacitance change and store the 
result directly to the computer. Tests were carried out on wood's metal and molten aluminum. Fig. 6 shows some bubble signals collected in molten aluminum. As we can see, the signals are close to the predictions. The deviation possibly was caused by the nonlinearity of the circuit. Another major source of error came from the aluminum coating, which was that molten aluminum stuck on the probe and not repelled by the bubble.

Since the capacitance probe used only alumina for contacting the melt, it survived easily in molten aluminum and was reusable. The simp! tesign of this probe also reduced the level of difficulty for construction.

\section{Conclusions}

In this phase of research, a mathematical model was constructed to explain the experimental results derived. A capacitance probe was tested for bubble measurement in molten metals.

Future work includes completing the results from the single bubble experiments and refining the capacitance probe design and apply it to a bigger furnace which will operate next year. 
Fig.1.a Critical points for different $\mathrm{Cl} 2$ concentrations

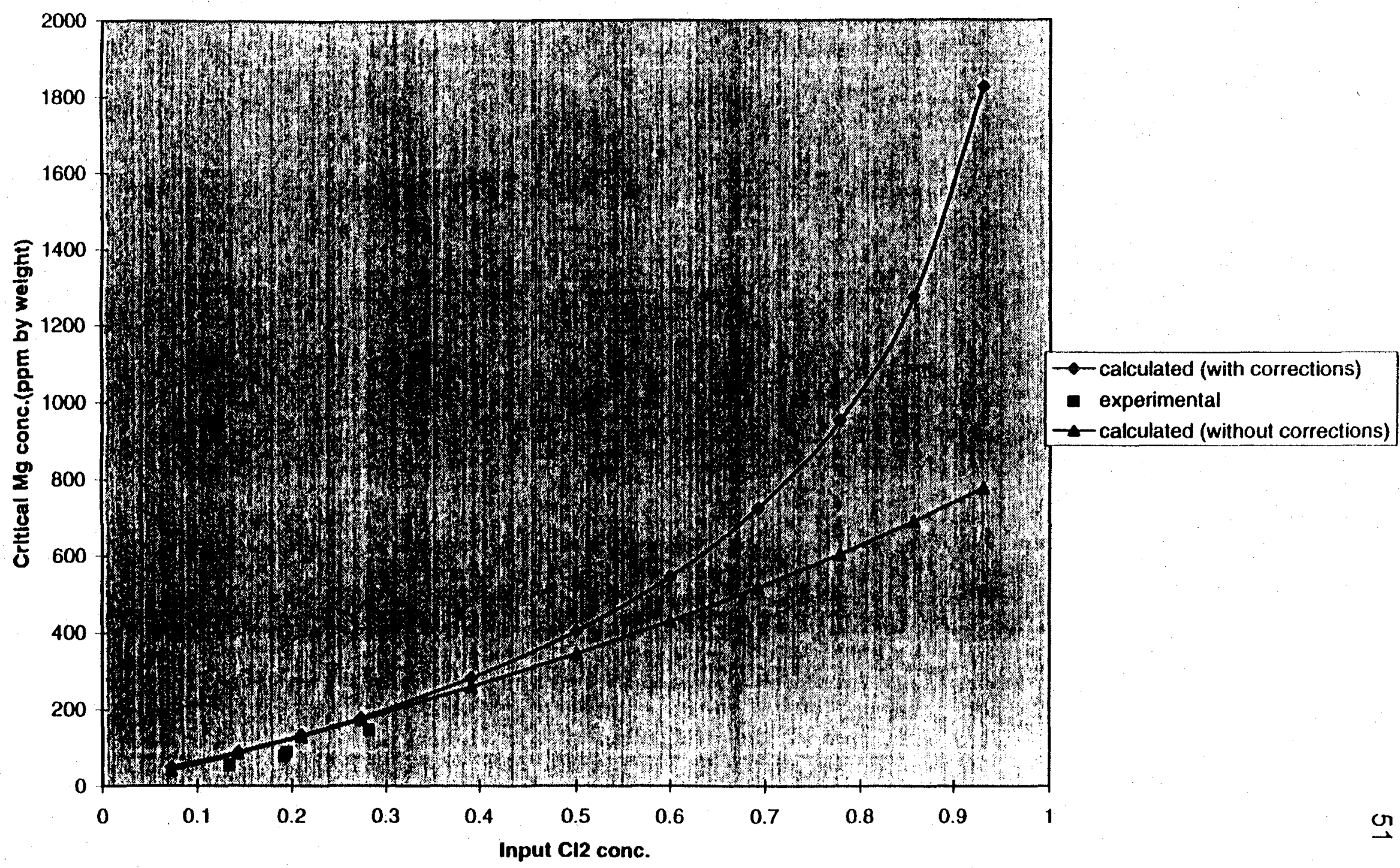




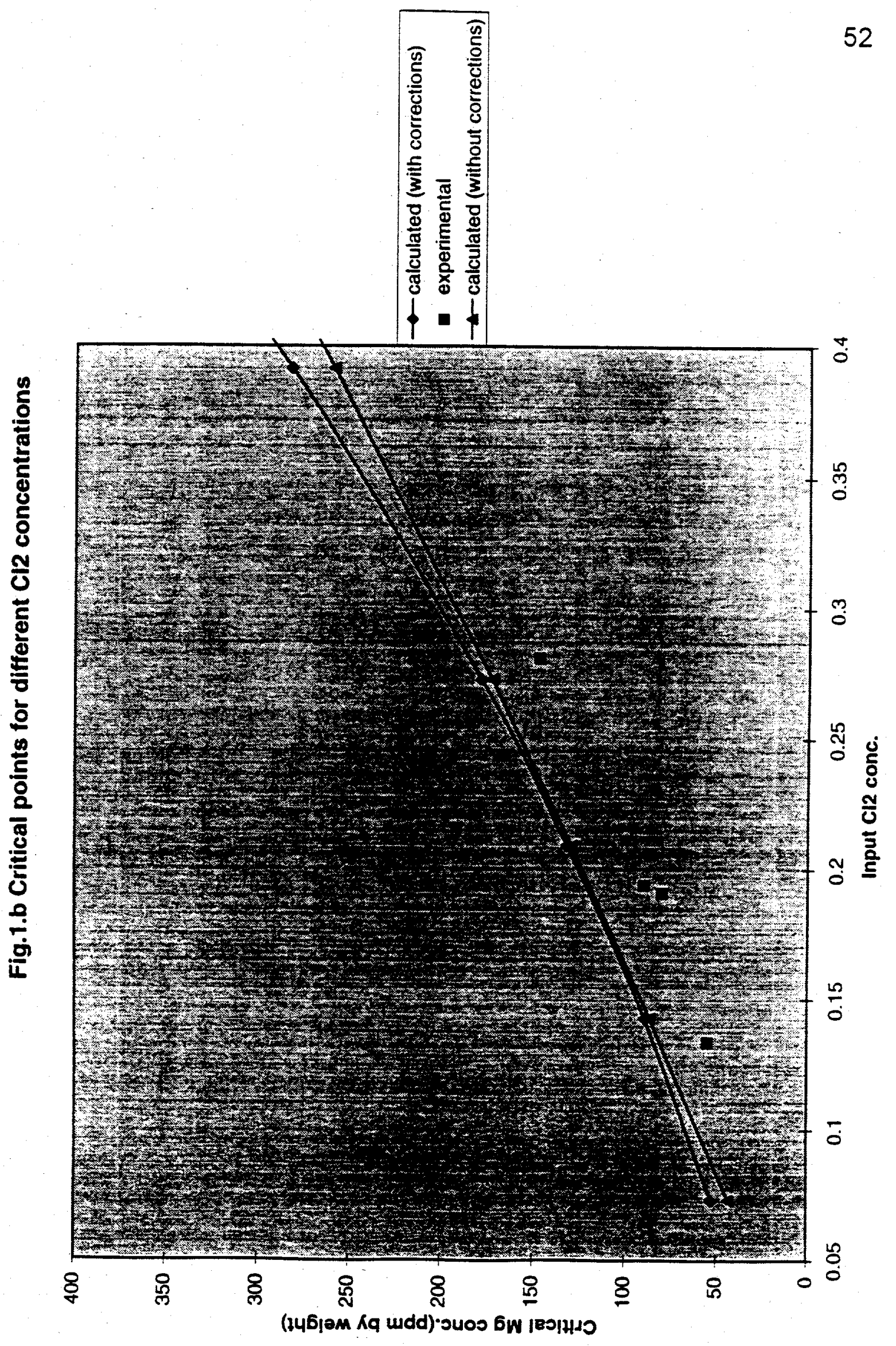



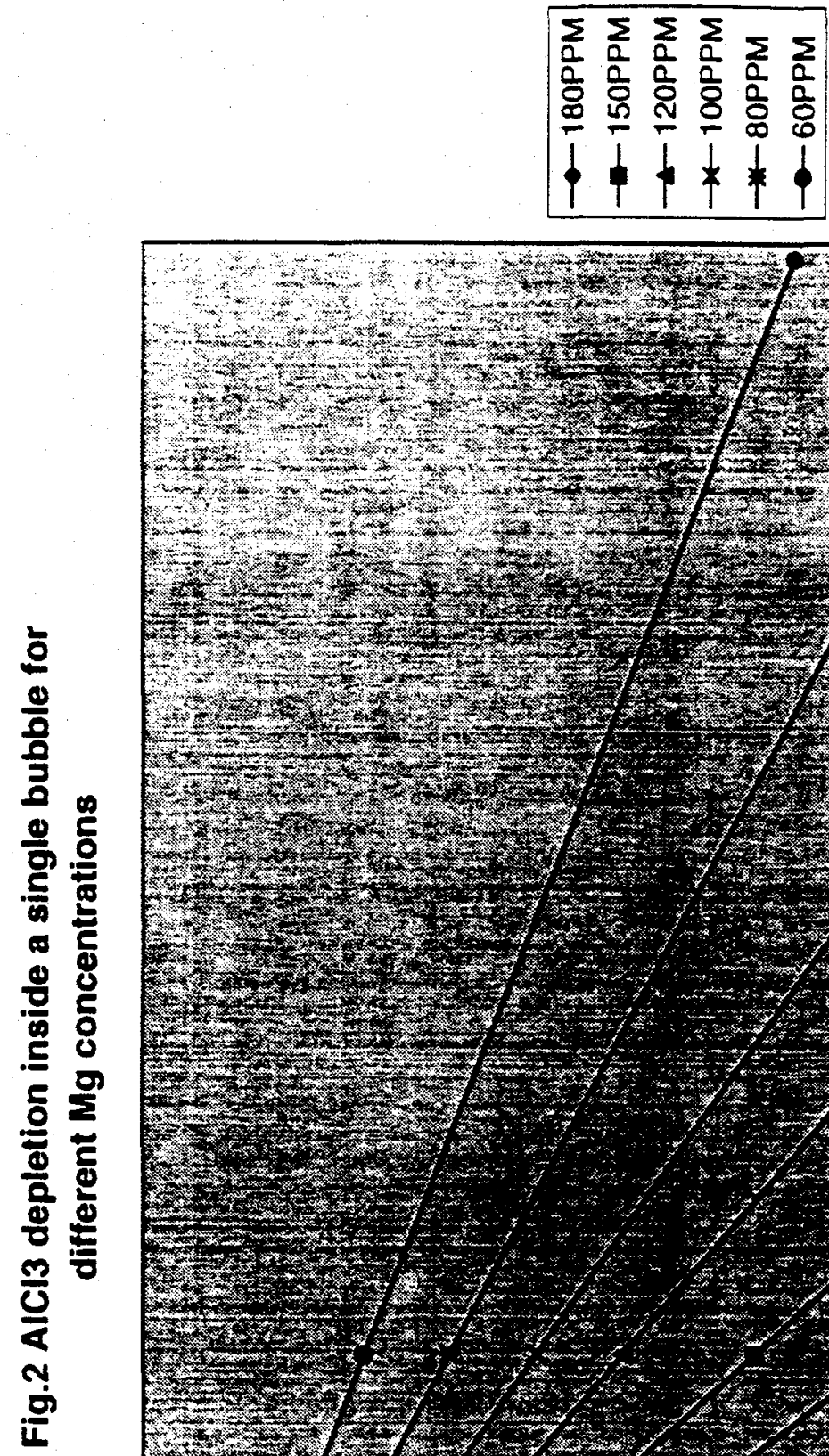

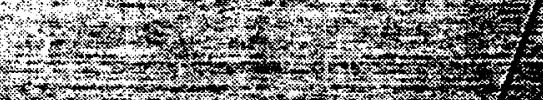

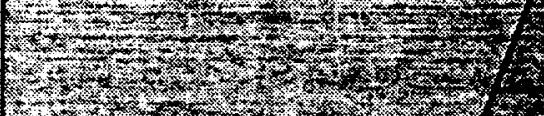

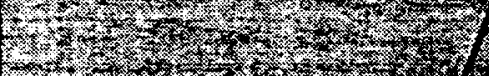

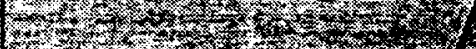

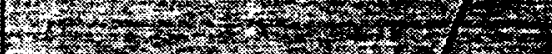

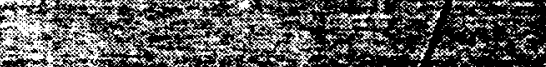

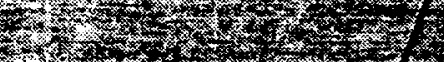

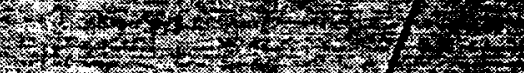

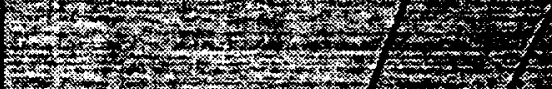

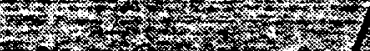

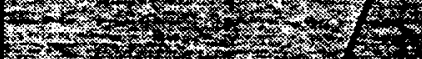

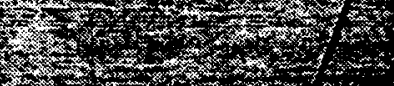

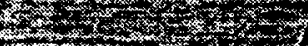

tats.

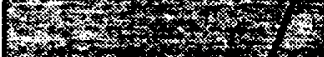

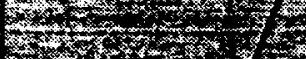

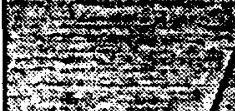

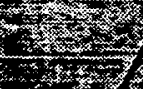

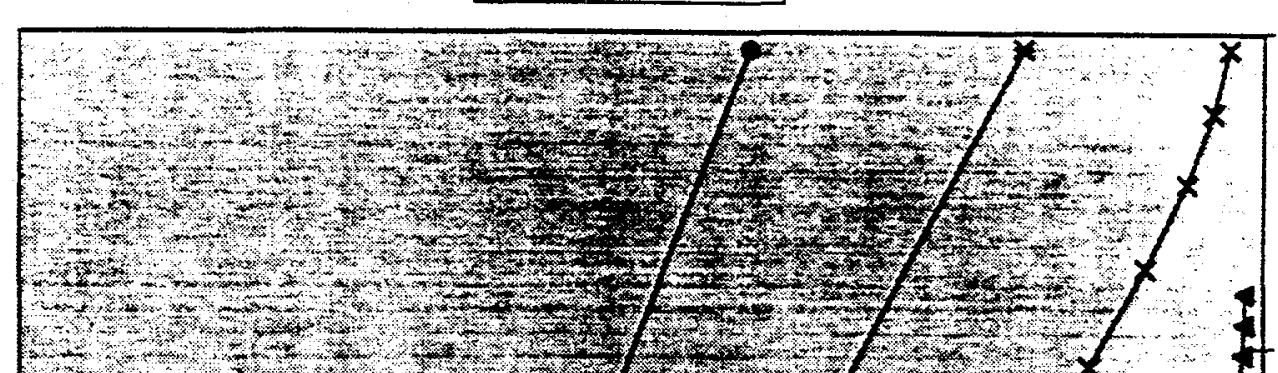

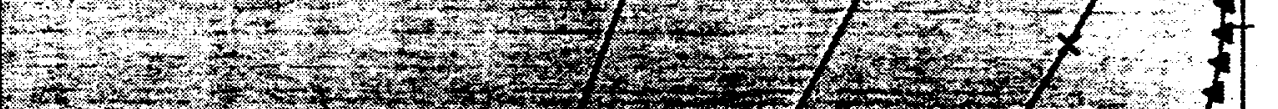
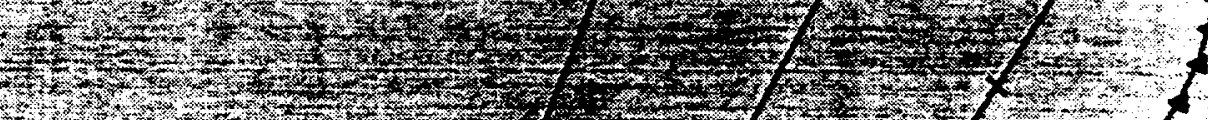

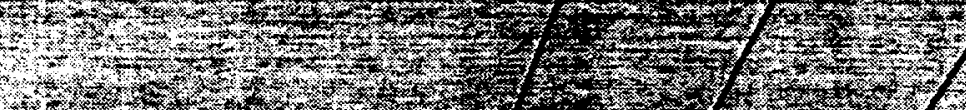

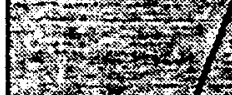

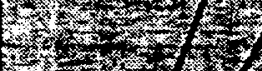

2.

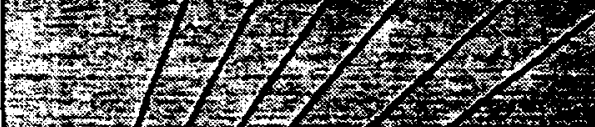

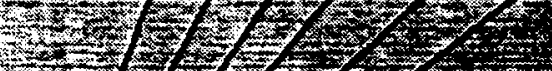

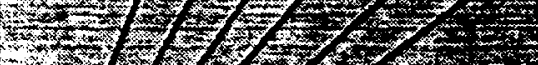

2.

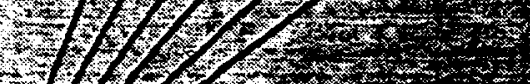

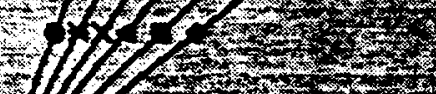

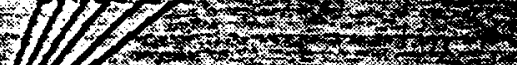

rect

$+2$

$\stackrel{\circ}{\circ}$

$\stackrel{0}{0}$

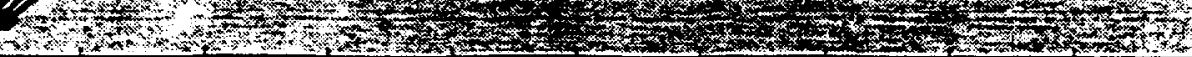

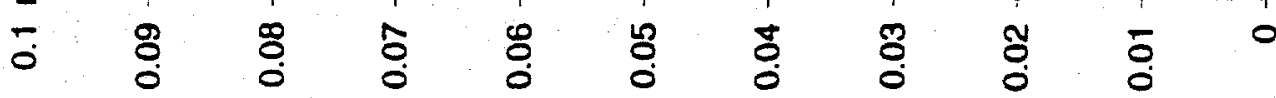


Fig. $3 \mathrm{Mg}$ depletion in the melt

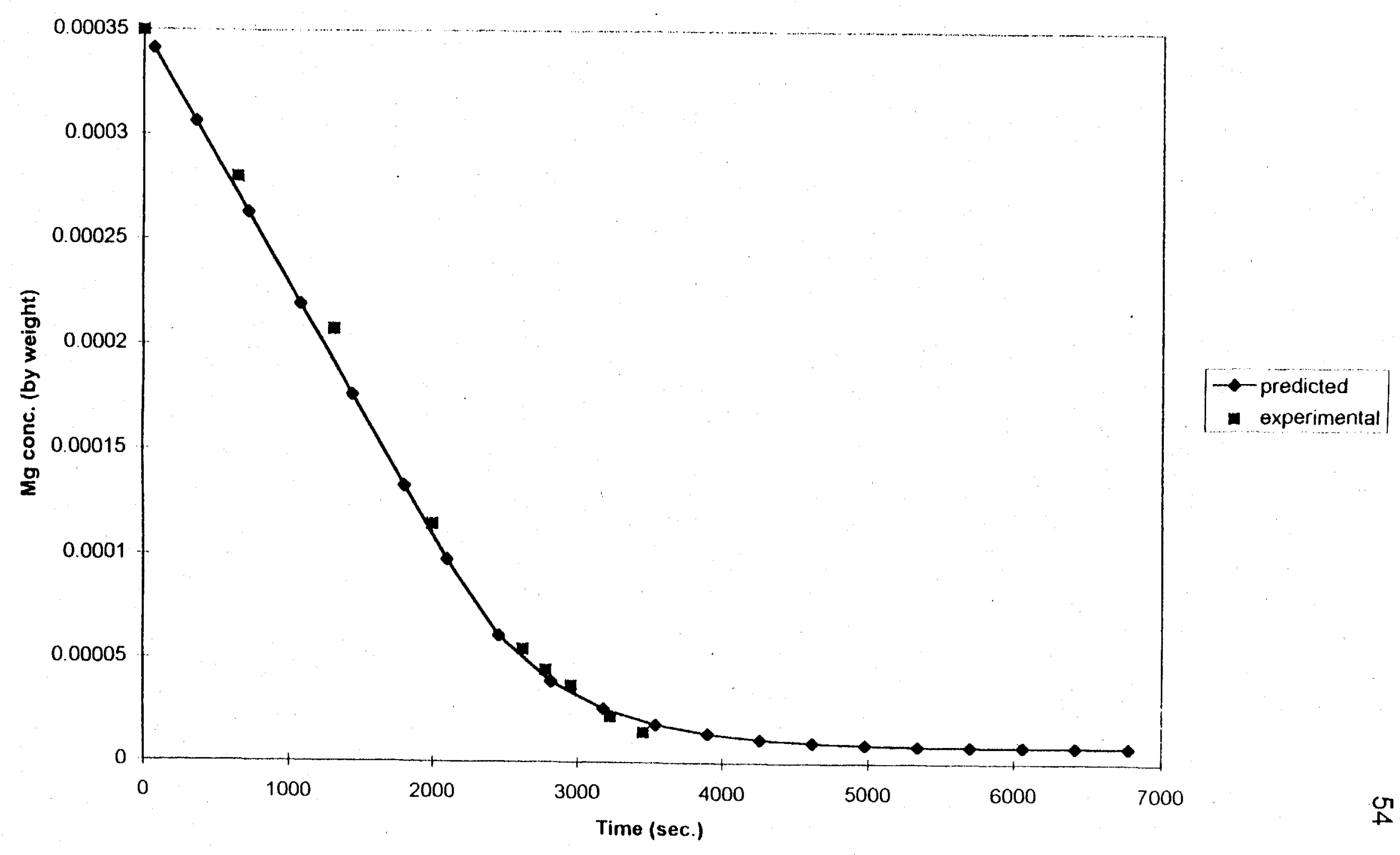

Page 1 


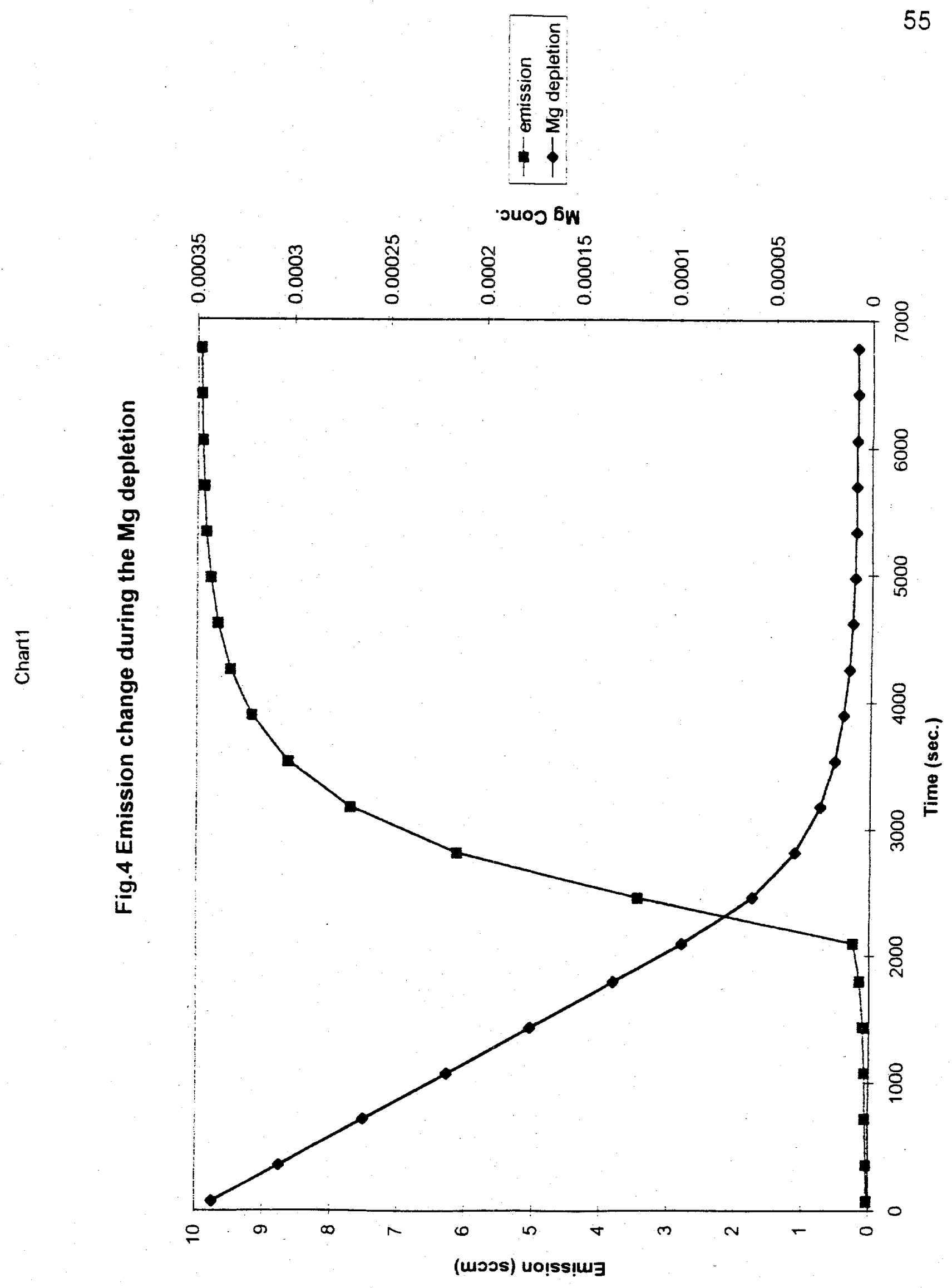




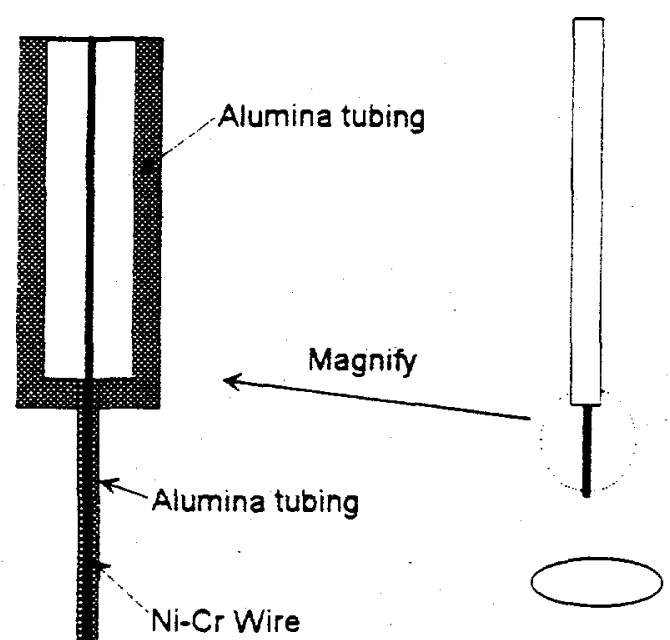

Stage 1

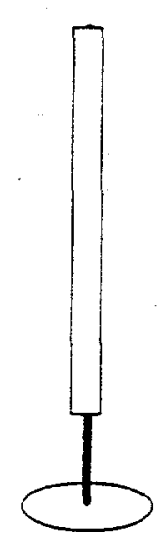

Stage 2

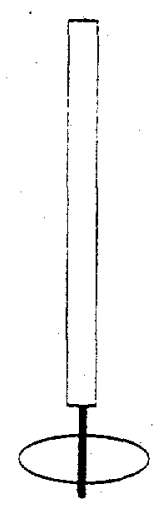

Stage 3

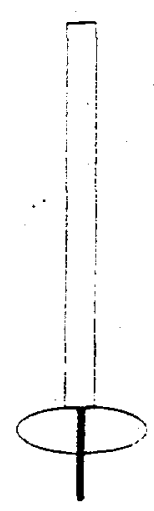

Stage 4

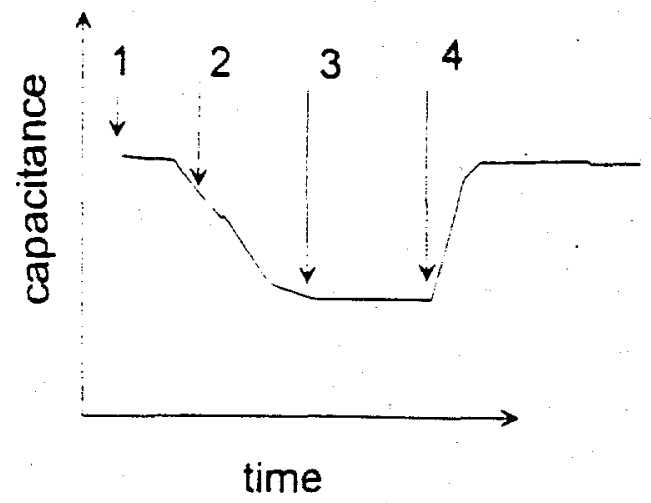

Fig.5 Principles of Capacitance Bubble Probe 


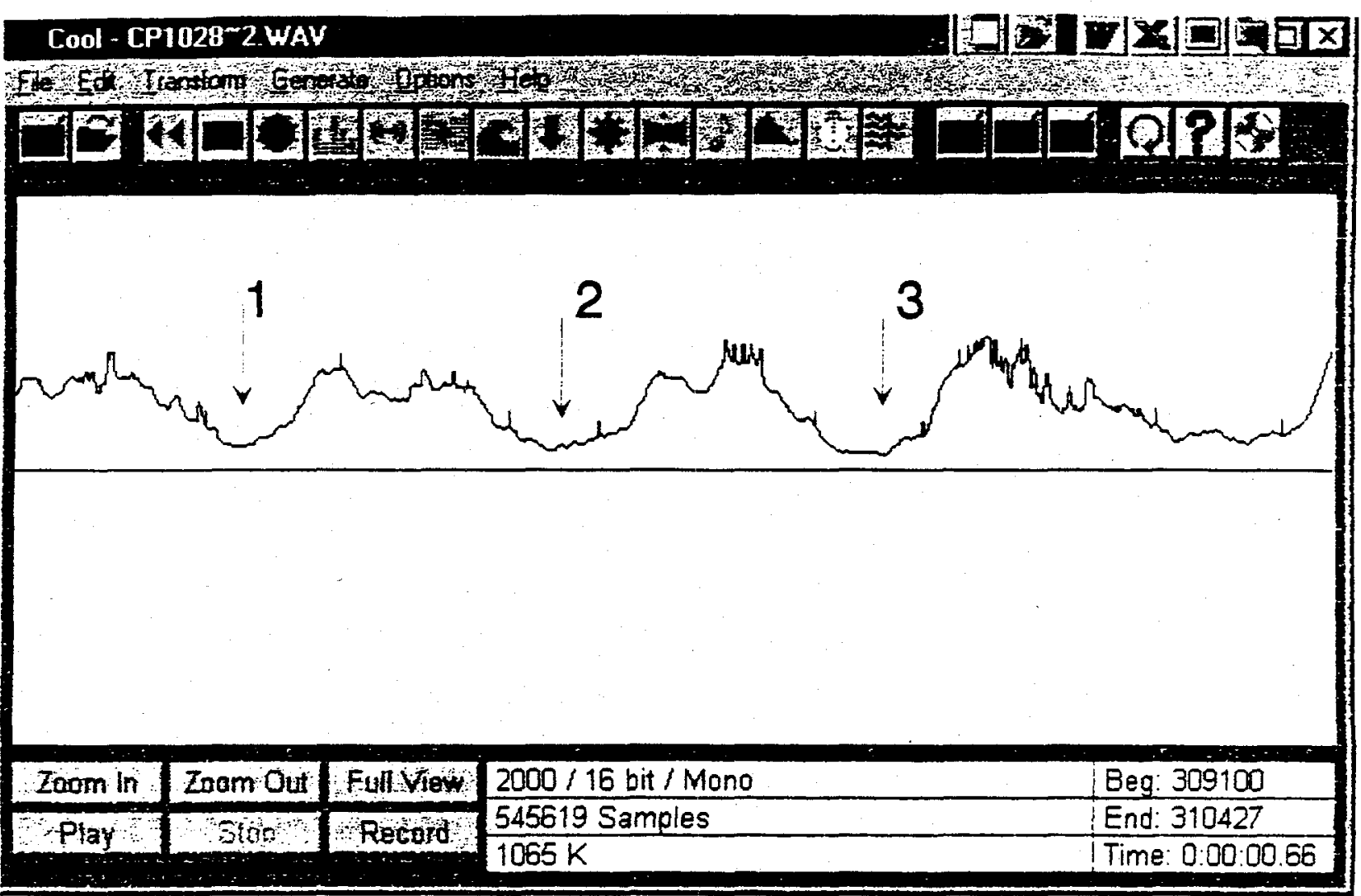

Fig. 6 Bubble signals from the capacitance probe 


\section{Contract/Grant G1155229}

0873 Development of a New Pyrometallurgical Process for the Removal of Heavy Metal Contaminants from Flue Dusts, Contaminated Smelter Soils, and Other Mineral Industry Wastes. (Hager - CSM)

Project Scope and Goals:

See attached progress reports.

Funding: FY95, $96 \quad \$ 58,900$

Graduate Student: Mr. Eric C. Eccleston

Report Period: April 1996 - September 1996 (End)

Progress/Final Report:

Progress reports for the periods April 1 to September 30,1996, and October 1, 1996 to March 31, 1997 are attached as a part of this Final Progress Report. A thesis serves as the Final Project Report. The thesis, "An Experimental Study of a Two-Stage Thermal Processing Technique for the Extraction of Heavy Metals From Waste Materials," by Eric Eccleston (74p.), was approved November 11, 1996 by the Colorado School of Mines in partial fulfillment of the requirements for a Master of Science degree in Metallurgical and Materials Engineering. A copy of the pertinent introductory identifying pages is also attached. (A copy of the complete thesis, along with a copy of Figs. 4-6, revised after the thesis was completed, is being sent to the contract officer under separate cover). 
Report Period - April 11996 to September 301996

0873-Development of a New Pyrometallurgical Process for the Removal of Heavy Metal Contaminants from Flue Dusts, Contaminated Smelter Soils, and Other Mineral Industry Wastes

(Hager-Colorado School of Mines)

\section{Project Scope and Goals}

Many different waste types pose problems to the mineral extraction industry. As an example, the soil immediately adjacent to non-ferrous smelter sites is often contaminated with heavy metals like arsenic, cadmium, and lead. The environmental ramifications of contaminated soil point to the need for a process for the extraction of the heavy metals. Another problem is flue dusts generated in the flash smelting of copper concentrates where bismuth, being highly volatile in smelting atmospheres, invariably reports to the flue dust. When the dust is recycled to the smelter for recovery copper values, an undesirable circulating load of bismuth can develop in the process.

In answer to the above problems, this project was aimed at the development of a new process capable of treating a wide variety of mineral industry wastes. The first goal of the project is to identify conditions in a two-stage thermal processing scheme consisting of selective sulfidization followed by selective chlorination whereby heavy metal contaminants may be selectively removed from contaminated soil. The second goal of the project is to investigate the aspects of achieving a copper/bismuth separation in the treatment of flue dusts. The investigation consisted of a rigorous theoretical study to determine feasibility of the processes and to identify possible operating conditions followed by an experimental study of the identified processing parameters.

\section{Funding}

FY $95 \$ 58,900$

\section{Student}

Mr. Eric C. Eccleston 
Report

This report summarizes the work performed on this project in the period since the last report. In this report, the latest results from the work dealing with the treatment of heavy metal contaminated smelter soil are discussed. The theoretical development of the two-stage thermal processing technique investigated (selective sulfidization followed by selective chlorination) was outlined in the last report.

\section{Experimental Results to Date}

The experimental results presented here represent the completed work aimed at extracting arsenic, cadmium, and lead from contaminated soils. Most of the experiments were conducted using a synthetically prepared material to represent a typical contaminated soil. Various operating conditions were investigated using the synthetic material. Operating conditions that yielded the best results for the synthetic material were then applied to site-specific soil samples provided by ASARCO. Figures 1 through 7 show the results for the synthetic material experiments:

Figure 1 shows the extraction of arsenic from the synthetic material during the first (sulfidization) stage of the process. It is apparent that extractions of better than $90 \%$ were achieved across the temperature range investigated and that the addition of $\mathrm{CS}_{2}$ to the process gas increases arsenic removal during sulfidization.

Figure 2 shows the extraction of cadmium from the synthetic material during the first (sulfidization) stage. Cadmium losses to the vapor phase are minimized in the 600 to $700^{\circ} \mathrm{C}$ range without the addition of $\mathrm{CS}_{2}$ to the process gas.

Figure 3 shows that similar behaviour is observed for lead as with cadmium during sulfidization.

Figure 4 shows the response, in terms of cadmium and lead extractions, to the second (chlorination) stage of the process when varying sulfidization products were chlorinated at $550^{\circ} \mathrm{C}$.

Figure 6 shows the effect of increasing chlorination temperature on the extraction of cadmium from material previously sulfidized at $600^{\circ} \mathrm{C}$ using both $\mathrm{H}_{2} \mathrm{~S}$ and $\mathrm{H}_{2} \mathrm{~S} / \mathrm{CS}_{2}$ mixtures.

Figure 7 shows response for lead extraction during chlorination.

Four experiments were conducted using two different site-specific contaminated soils. The experiments showed that the processed soil passed 
the TCLP test for arsenic, but that the process was less effective with regard to cadmium and lead.

Path Forward

During the coming semi-annual period, investigation of certain aspects of achieving a copper/bismuth separation in flue dust will be completed. 


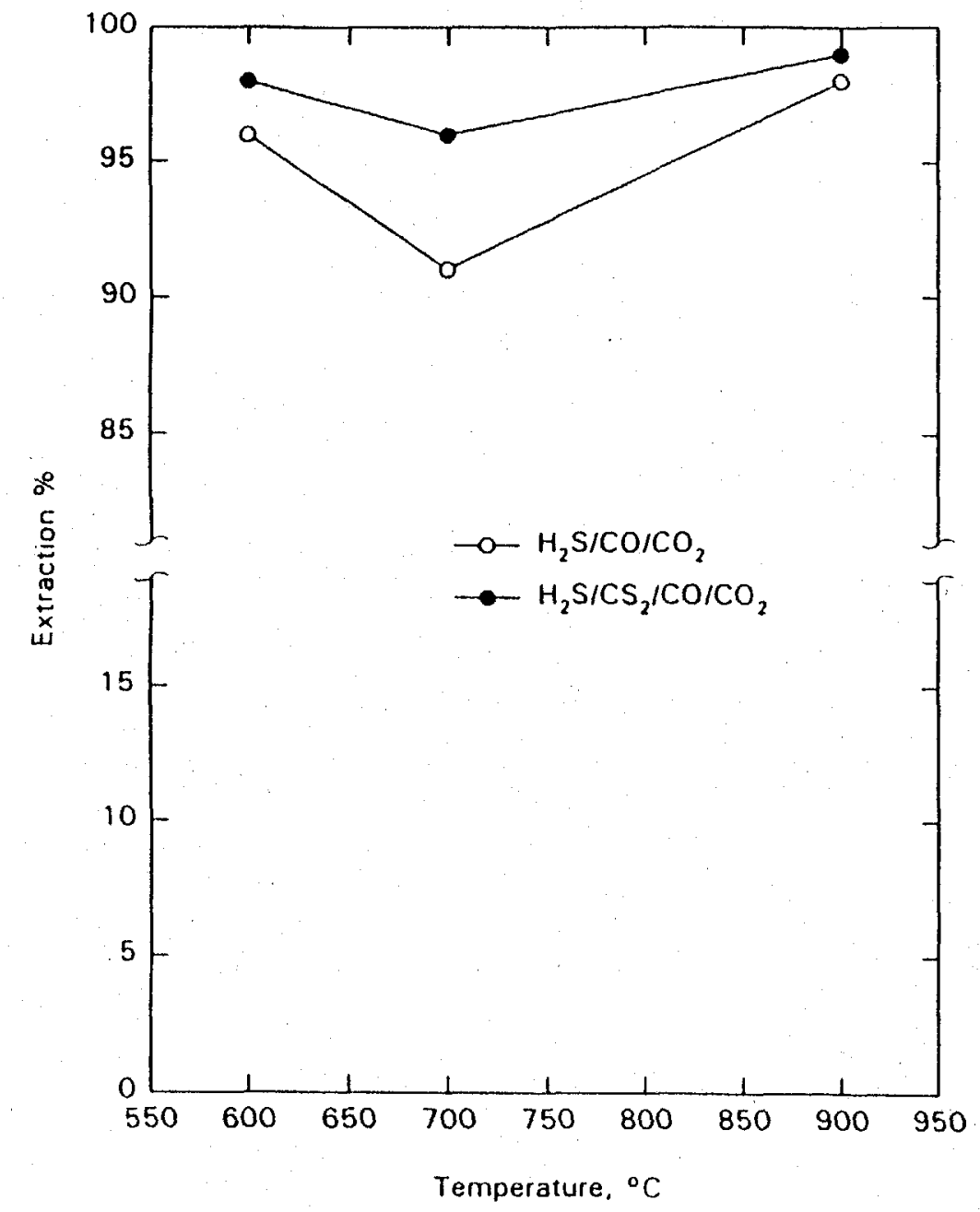

Figure 1. Synthetic Soil Sulfidization Arsenic Extraction as a Function of Temperature

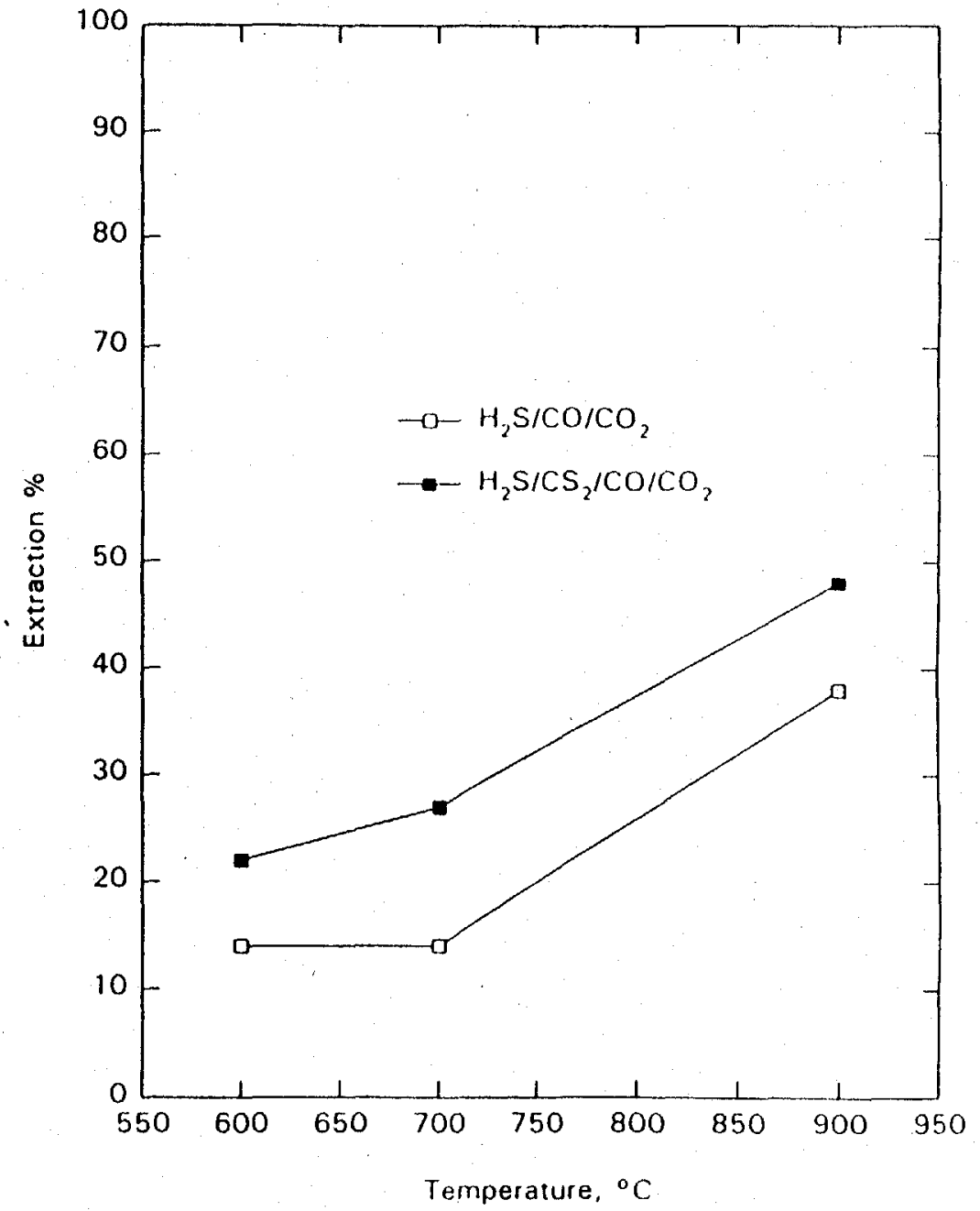

Figure 2. Synthetic Soil Sulfidization Cadmium Extraction as a Function of Temperature 

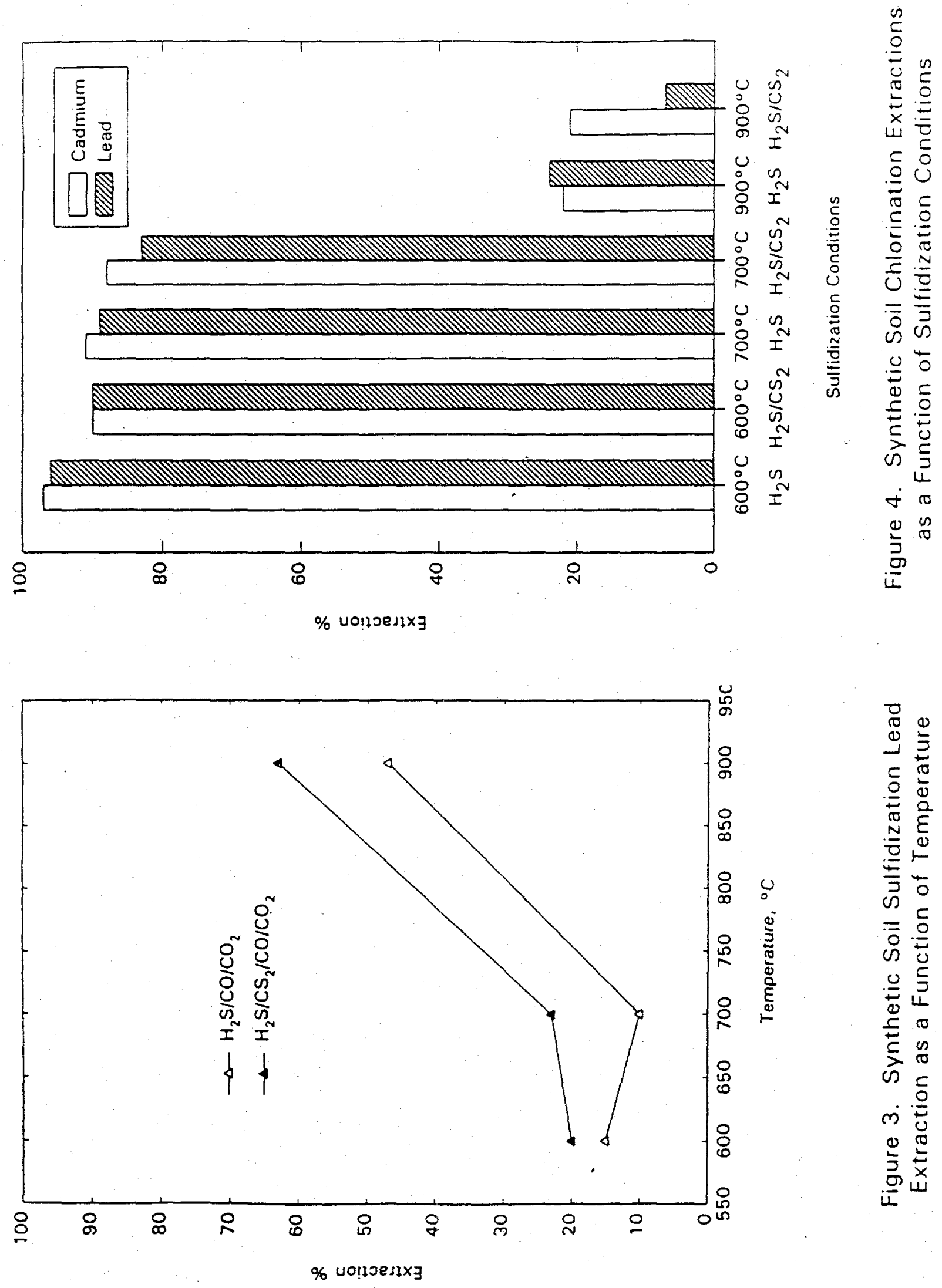

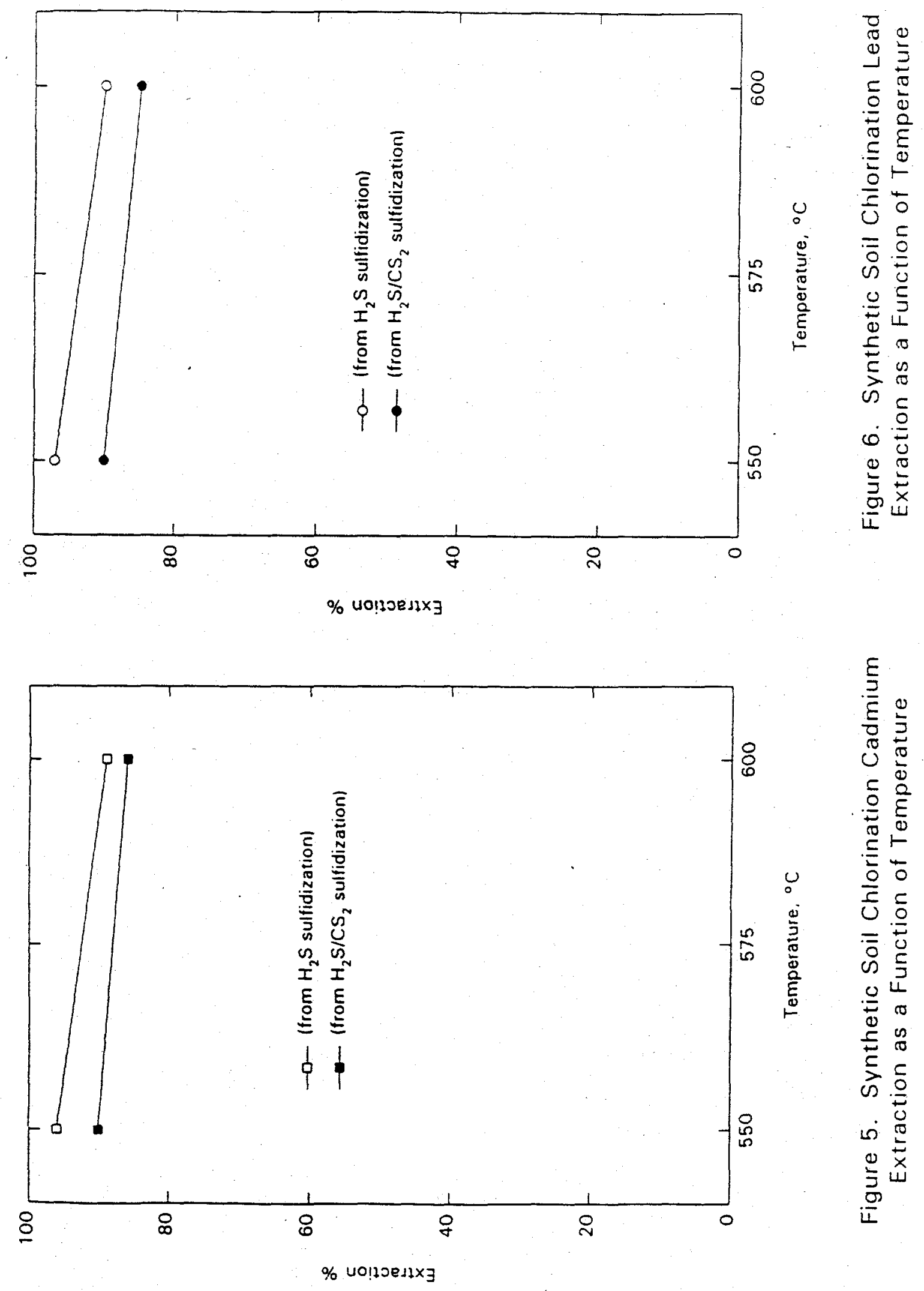


\section{Report Period - October 11996 to March 311997}

0873-Development of a New Pyrometallurgical Process for the Removal of Heavy Metal Contaminants from Flue Dusts, Contaminated Smelter Soils, and Other Mineral Industry Wastes (Hager-Colorado School of Mines)

\section{Project Scope and Goals}

Many different waste types pose problems to the mineral extraction industry. As an example, the soil immediately adjacent to non-ferrous smelter sites is often contaminated with heavy metals like arsenic, cadmium, and lead. The environmental ramifications of contaminated soil point to the need for a process for the extraction of the heavy metals. Another problem is flue dusts generated in the flash smelting of copper concentrates where bismuth, being highly volatile in smelting atmospheres, invariably reports to the flue dust. When the dust is recycled to the smelter for recovery copper values, an undesirable circulating load of bismuth can develop in the process.

In answer to the above problems, this project was aimed at the development of a new process capable of treating a wide variety of mineral industry wastes. The first goal of the project is to identify conditions in a two-stage thermal processing scheme consisting of selective sulfidization followed by selective chlorination whereby heavy metal contaminants may be selectively removed from contaminated soil. The second goal of the project is to investigate the aspects of achieving a copper/bismuth separation in the treatment of flue dusts. The investigation consisted of a rigorous theoretical study to determine feasibility of the processes and to identify possible operating conditions followed by an experimental study of the identified processing parameters.

Funding

FY $95 \$ 58,900$

Student

Mr. Eric C. Eccleston 
Report

This report summarizes the work performed on this project in the period since the last report. In this report, the latest results from the work applied toward bismuth removal from copper flue dust are discussed. Previous reports have dealt with: i) theoretical analysis of both soil treatment and flue dust processing, and ii) results of the soil treatment experiments.

\section{Experimental Results to Date}

The experimental results presented here represent work conducted since the last report which are applicable to bismuth removal from copper flue dust via thermal processing. In a previous report, it was stated that a serious lack of high temperature thermodynamic data exists for the bismuth-sulfur-oxygen system. Reliable high temperature thermodynamic data are unavailable for bismuth sulfate and bismuth oxy-sulfates. Since the stability of bismuth sulfate or oxy-sulfates is an important factor in the thermal processing of copper flue dusts for the extraction of bismuth, experiments were conducted in an attempt to identify high temperature stability regions for Bi-S-O compounds.

A gas/solid equilibration technique was employed to investigate the stability of the aforementioned Bi-S-O compounds. The apparatus employed (shown in Figure 1) allowed for the equilibration of a bismuth-bearing compound with an equilibrium gas mixture of $\mathrm{O}_{2}, \mathrm{SO}_{2}, \mathrm{SO}_{3}$, and $\mathrm{Ar}$. In the experimental apparatus, with both furnaces at the same temperature, $\mathrm{O}_{2}, \mathrm{SO}_{2}$, and $\mathrm{Ar}$ are brought into the furnace at the inlet end. The gases are allowed to equilibrate to a mixture of $\mathrm{O}_{2}, \mathrm{SO}_{2}, \mathrm{SO}_{3}$, and $\mathrm{Ar}$ before they come in contact with the bismuth-containing compound (normally yellow $\mathrm{Bi}_{2} \mathrm{O}_{3}$ ). The solid is allowed to come into equilibrium with the gas mixture for a period of about 8 hours. After equilibration, the sample is removed from the furnace zones of the apparatus and rapidly cooled. The possible equilibrium phases were anticipated to be $\mathrm{Bi}_{2}\left(\mathrm{SO}_{4}\right)_{3}, \mathrm{Bi}_{2} \mathrm{O}\left(\mathrm{SO}_{4}\right)_{2}$, or $(\mathrm{BiO})_{2} \mathrm{SO}_{4}$. Since sulfatization of the bismuth-containing compound to form bismuth sulfate or one of the oxysulfates results in a weight gain of the solid sample, the equilibrium solid phase for each experiment is determined by comparing the actual weight gain of the sample to a theoretical, stoichiometric weight gain. Confirmation of the identified equilibrium phase by $X$-ray diffraction is not possible because standard powder diffraction data is not available.

Figures 2 through 4 show the preliminary results of the Bi-S-O equilibrium experiments. The results of each experiment are shown as 
equilibrium points on stability diagrams at different temperatures (phase stability regions were constructed from available thermodynamic data).

Figures 2 and 3 each show two equilibrium points for $(\mathrm{BiO})_{2} \mathrm{SO}_{4}$ at $578^{\circ} \mathrm{C}$ and $616^{\circ} \mathrm{C}$, respectively. Figure 4 shows a single equilibrium point for the same compound at $666^{\circ} \mathrm{C}$. From the data at 578 and $616^{\circ} \mathrm{C}$ preliminary stability diagrams were constructed that show areas of minimum stability for the bismuth oxy-sulfate, $(\mathrm{BiO})_{2} \mathrm{SO}_{4}$. (See Figures 5 and 6 .)

The data presented here show that the current estimated high temperature thermodynamic data for $\mathrm{Bi}_{2}\left(\mathrm{SO}_{4}\right)_{3}$ appearing in the literature (Barin, 1993) are questionable and that further experimentation in the Bi-S-O system is needed.

Path Forward

In the coming months, equilibrium experiments will continue in an attempt to further define the phase relationships in the bismuth-sulfur-oxygen system.

Reference Cited

Barin, 1. Thermochemical Data of Pure Substances. Weinheim, Germany: VCH Verlagsgessellschaft, 1993. 


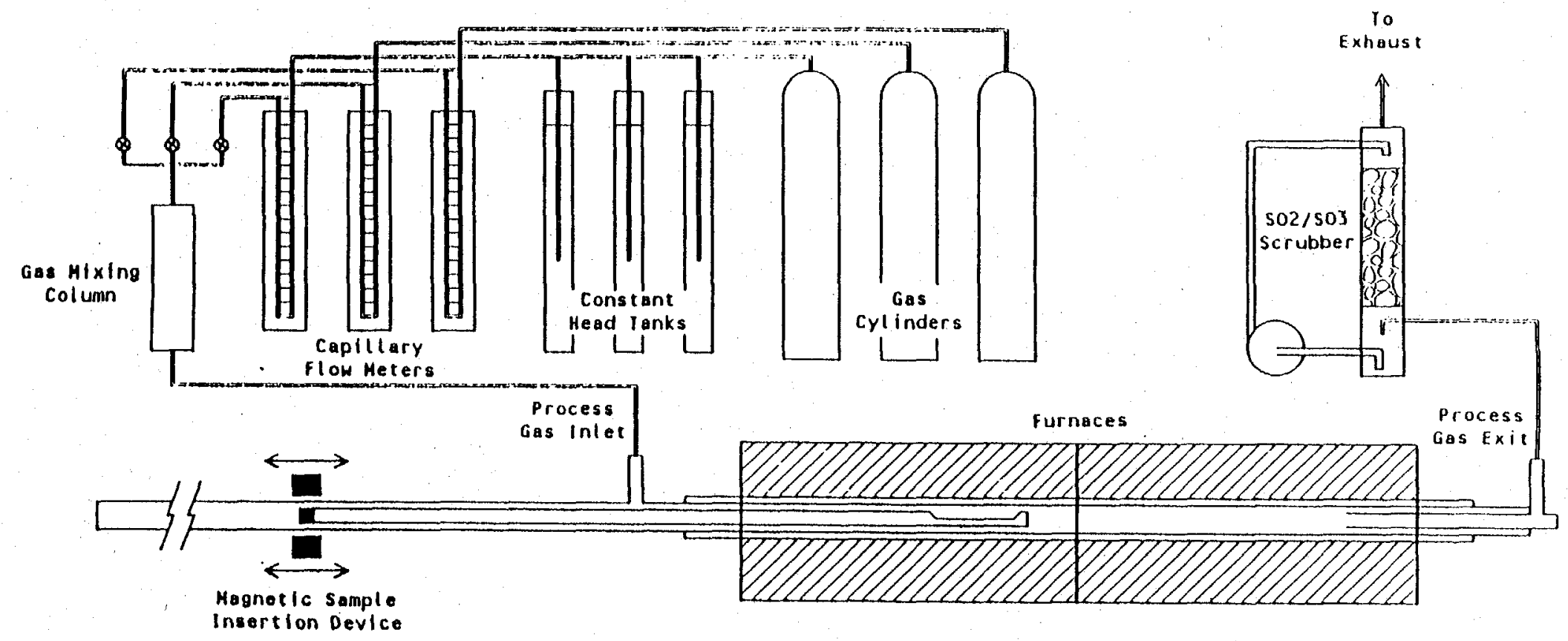

Figure 1. Experimental Apparatus for Bi-S-O Equilibrium Experiments 


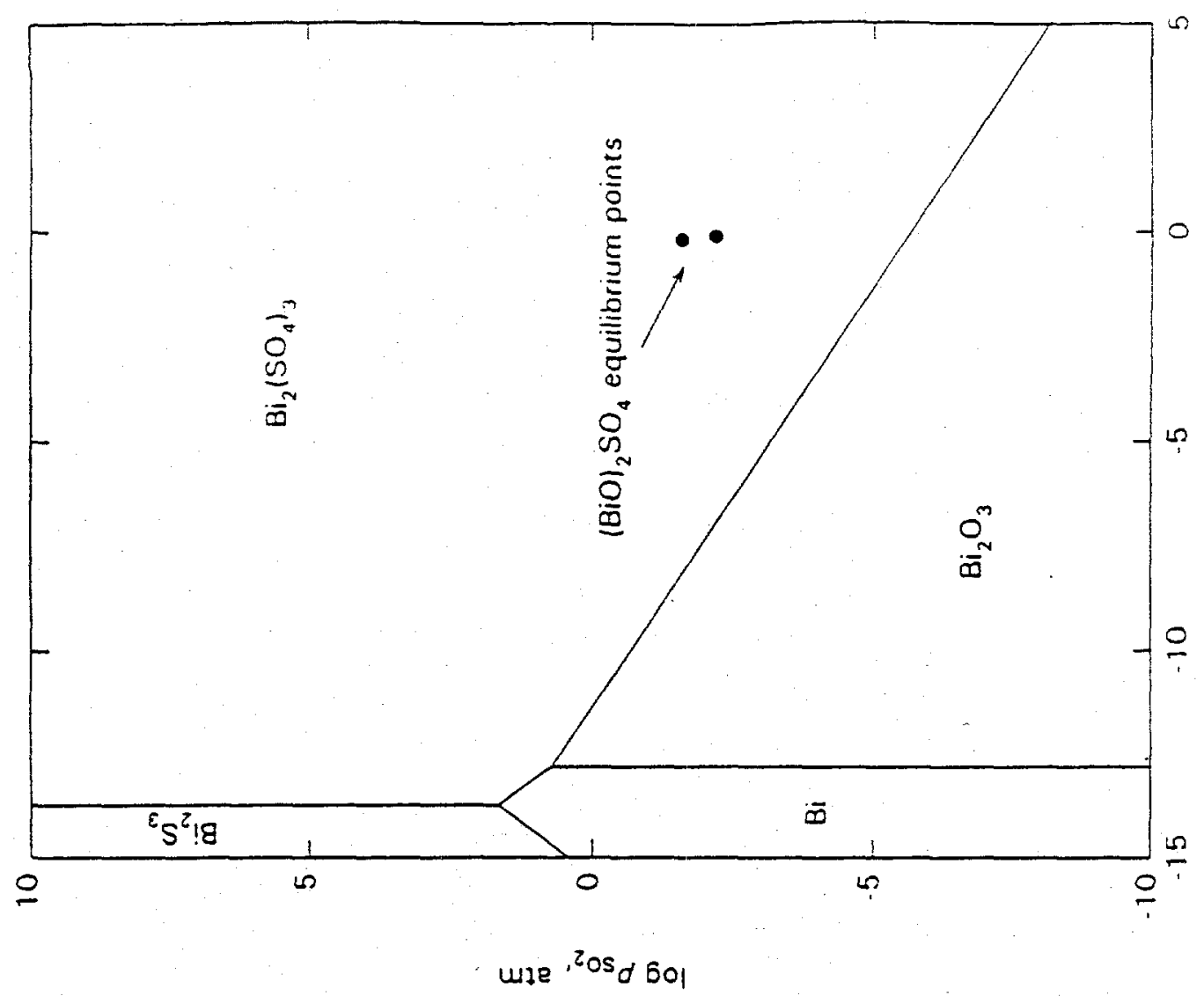

69

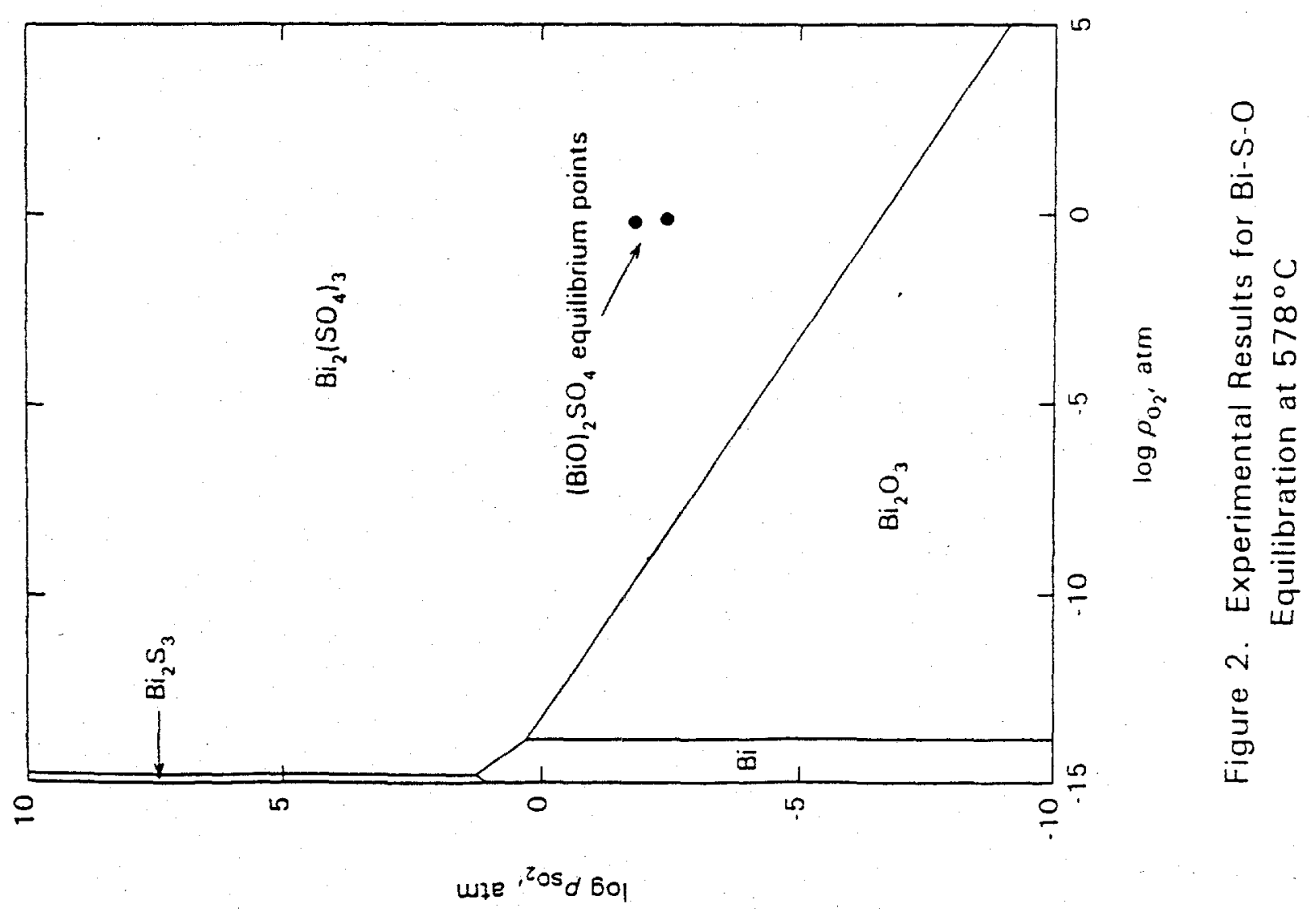



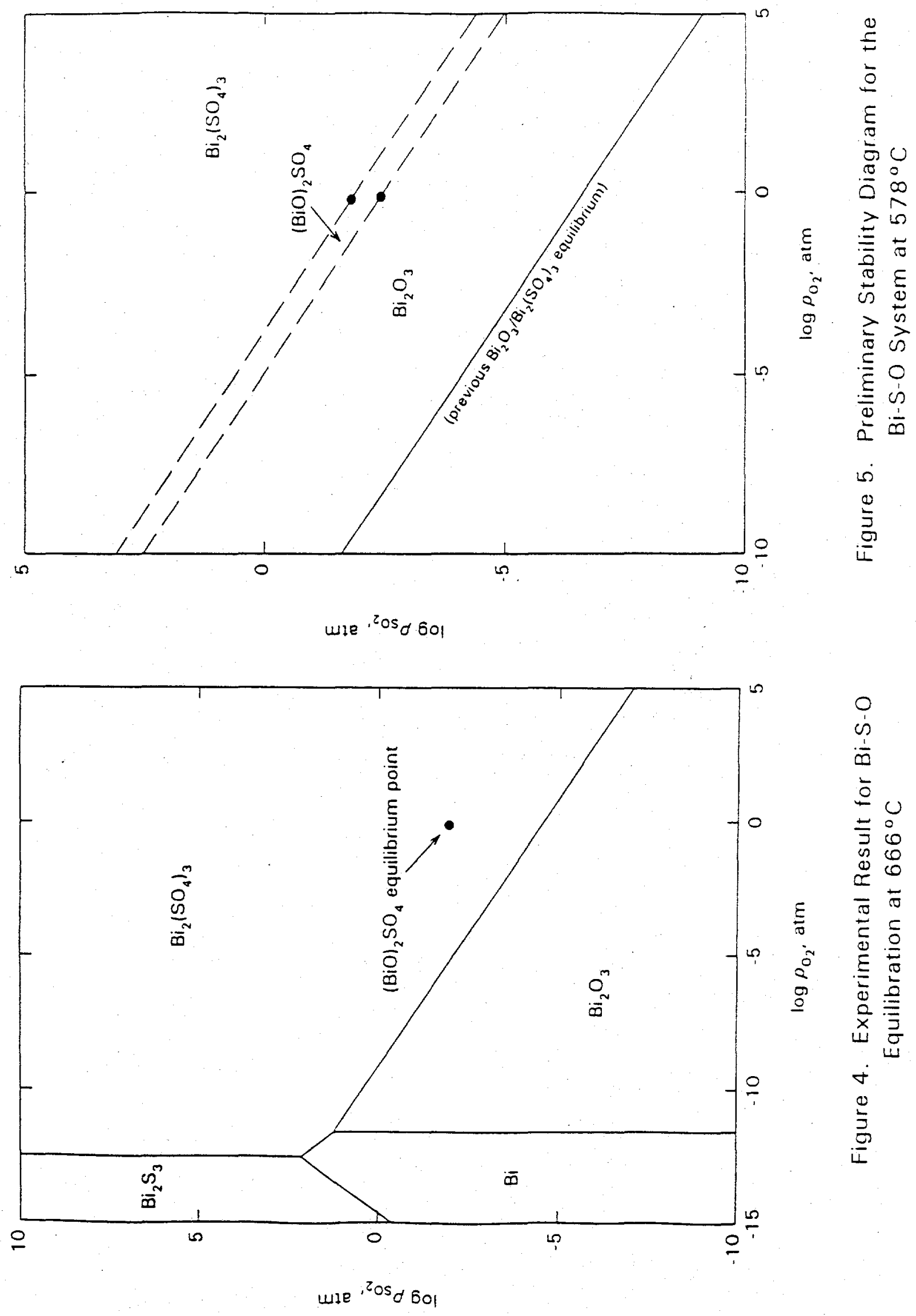


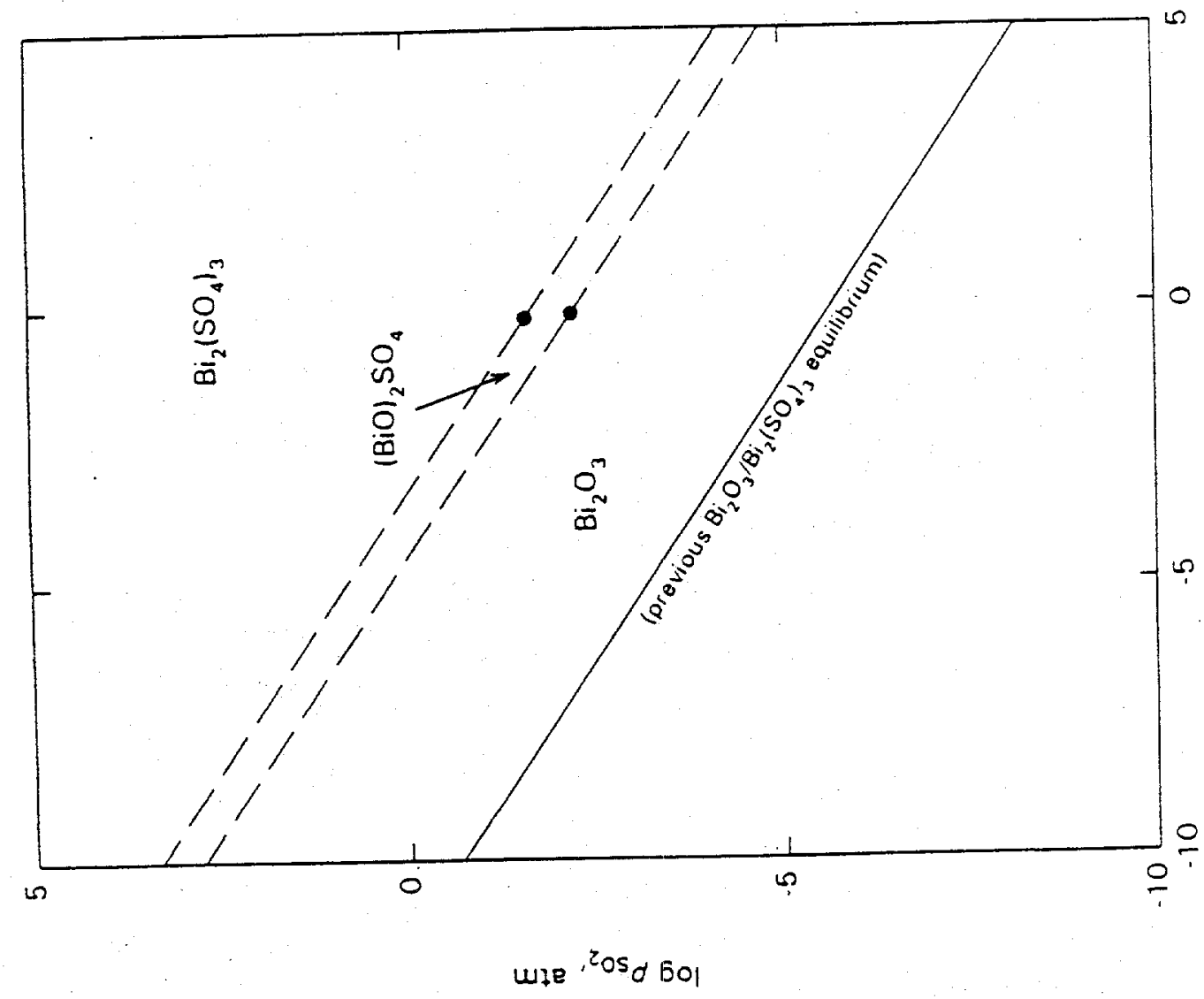

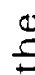

¿

$\varepsilon$

$\div 0$

.

$>\overline{0}$

元

i

$\begin{array}{lll}0 & 0 & 0 \\ 0 & 2 & 0\end{array}$

$\stackrel{\Xi}{E} 0$

है

0

亭 
AN EXPERIVENTAL STUDY OF A TWO-STAGE THERMAI PROCESSNG TECHNTQLE FOR THE EXTRACTION OF HEAVY METAIS FROM WASTE MAATERIIS 
A thesis submitted to the Faculty and Board of Trustees of the Colorado School of Mines in parial fulfilment of the requirements for the degree of Master of Science, Metallurgical and Materials Engineering.

Golden, Colorado

Date $11 / 11 / 96$

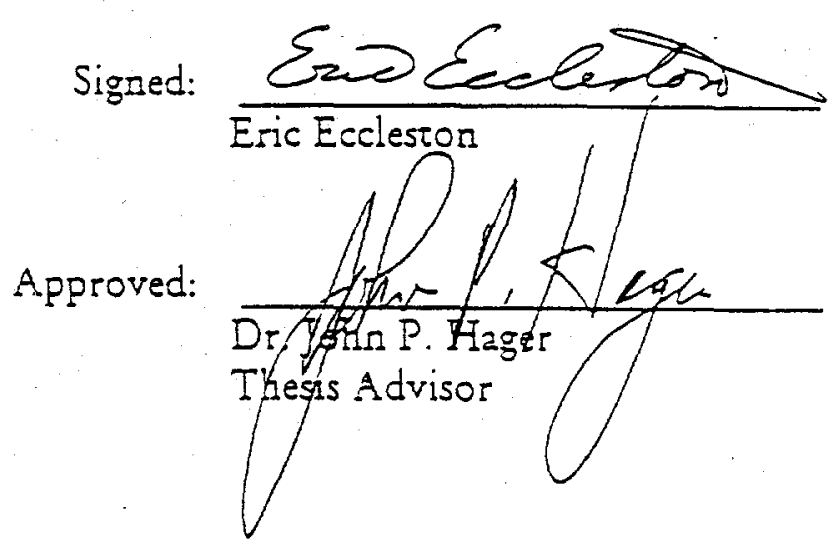

Golden, Coloracio

Dare $\frac{\text { LI Hi } / \mathrm{L}}{1}$

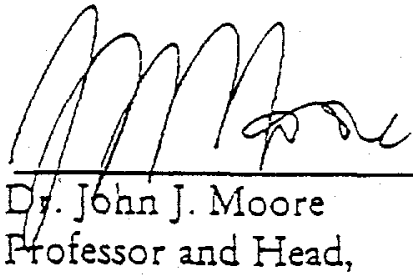

Department of Metallurgica! and Materials Engineering 


\section{Abstract}

A wide variery of waste materials are generated by the mineral industry that, for environmental or economic reasons, have become the focus of processing research in the last few decades. A versatile process capable of selectively removing heavy metals from wastes such as flue dusts, contaminated soils, waste slags, leach residues, and refining siudges is needed. In addition, pyromerallurgical techniques have been shown to make effective separations while avoiding the various problems associated with "wet" chemical processes.

A thermodynamic analysis revealed that a two-stage roasting process involving selective sulfidization or sulfatization (depending on the waste type) followed by selective chlorination was a conceptually feasible method of exracting heavy metal contaminants from the aforementioned waste materials.

The strategy for the application of thermal processing was not only to define the theoretical aspects of a two-stage process, but also to experimentally verify the viability of such a process for two specific waste materials: soil contaminated with arsenic, cadmium, and lead; and copper smelter flue dust. The objective for processing of the contaminated soil was removal of arsenic, cadmium, and lead while the objective for processing of copper flue dust was to achieve a copper/bismuth separation. Roasting experiments were conducted using syntherically prepared as well as sitespecific samples of contaminated soil. Gas/solid equilibration experiments were conducted to explore uncertaincies regarding the phase stability regions in the bismuthsulfur-oxygen system as applied to the processing of copper flue dusts. Fundamental thermodynamic principles were employed to predict the process ourcomes while 
experiments were conducted to derermine the accual response of the processes to various operating parameters.

The experimental results of this study show that the concept of a two-stage roasting process for the removal of heavy metals from contaminated soil is conceprually sound. The resules show that, while arsenic is removed to acceprable levels, soil matrix constituents may interfere with the chlorination of cadmium and lead-an effect that must be furcher investigated.

Results from the gas/solid equilibracion experiments showed that the thermodynamic relarionships for the bisnuth-oxygen-sulfur system are ruch more complex than can be ascertained from the published literarure. Experimentally, regions of stability for bismurh oxy-sulfare $\left((\mathrm{BiO})_{2} \mathrm{SO}_{4}\right)$ were derermined for which no data previously existed. Preliminary stability diagrams for the bismuth-sulfur-oxygen system at high temperatures are presented based on this new equilibrium data. This work is considered to be a valuable contribution in resolving the uncertainties associated with the stability of bismuth sulfate and oxy-sulfares. The data generated may be employed in developing new strategies for copper/bismuth separations. 


\section{Table of Contents}

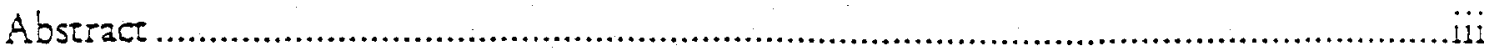

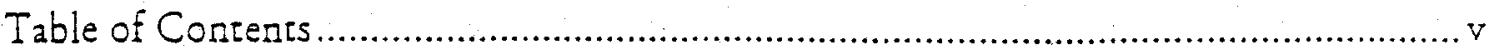

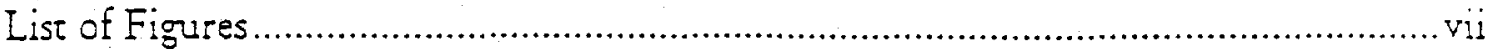

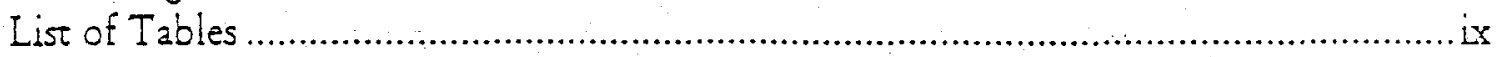

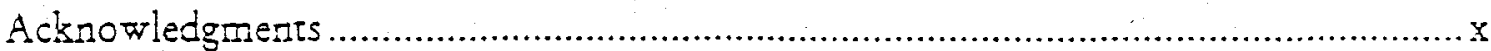

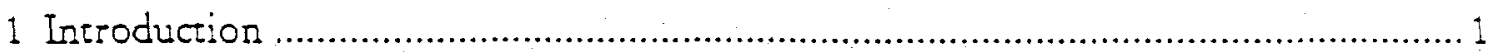

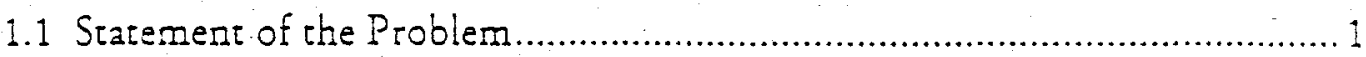

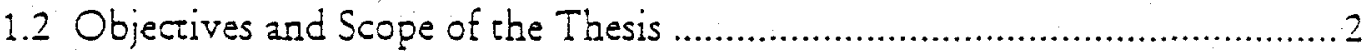

1.2.1 Smelter Soil Processing ..............................................................

1.2.2 Copper Flue Dust Processing........................................................

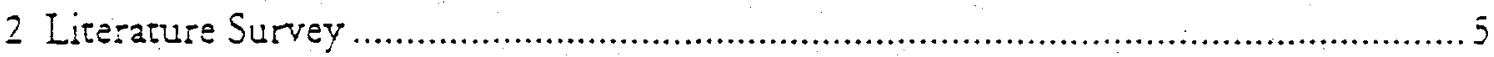

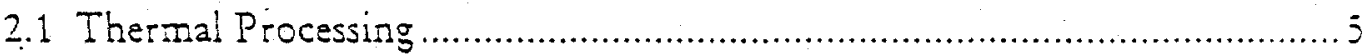

2.2 Thermodynamic Data and Studies ...........................................................

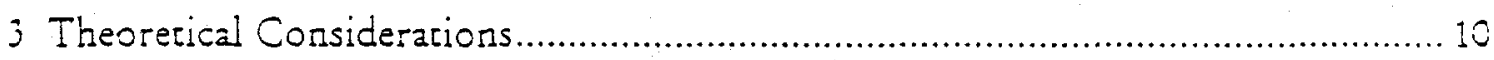

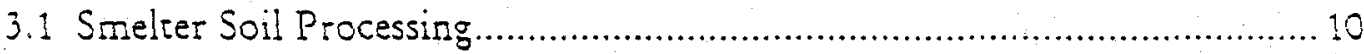

3.1.1 Selective Sulfidization ..........................................................

3.1.2 Selective Chlorination.......................................................... 19

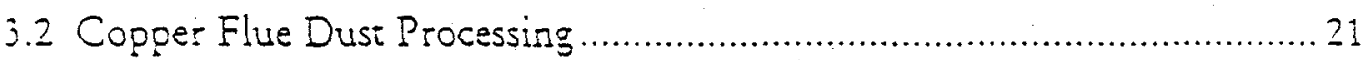

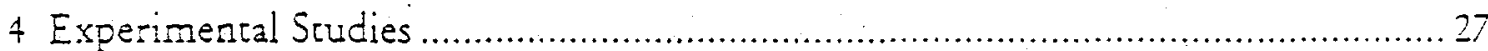

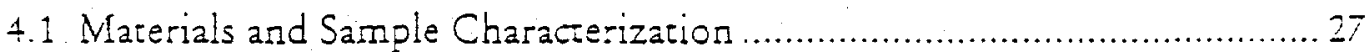

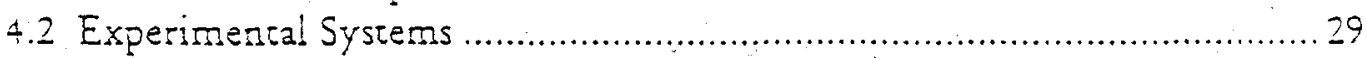

4.2.1 Batch-charged Rotary Kiln System ........................................... 29

4.2.2 Equilibration System ........................................................... 32

4.3 Experimental Procedures ...................................................................... 35

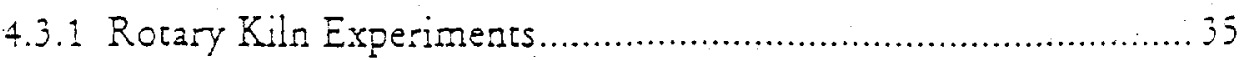

4.3.2 Gas/Solid Equilibration Experiments ........................................ 36 


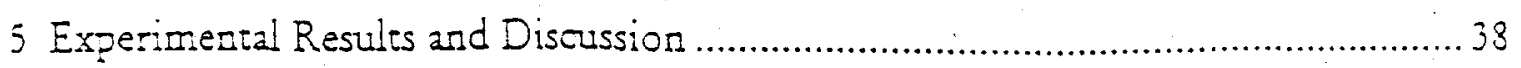

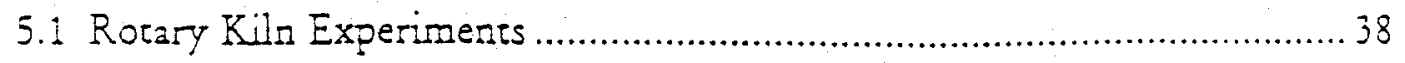

5.1.1 Results for Syntherically Prepared "Soil" .................................... 39

5.1.2 Results for Sire-specific Soil Samples...........................................49

5.2 Gas/Solid Equilibration Experiments ...................................................... 51

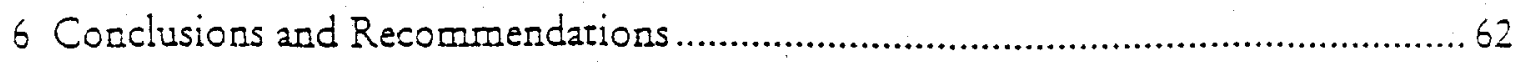

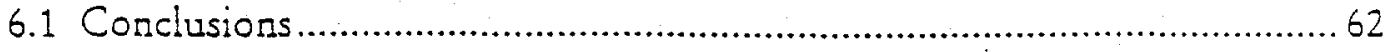

6.2 Recommendations for Further Research ..................................................64

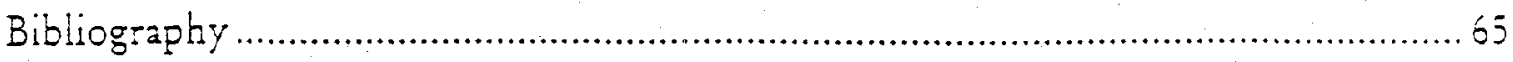

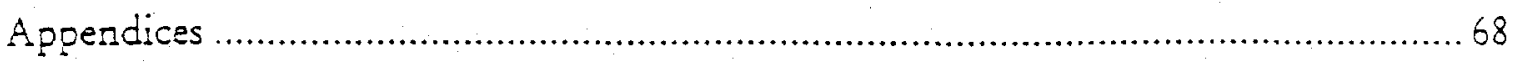

A Contaminated Soil Experimental Conditions ...........................................68

B Contaminated Soil Experimental Exractions ..............................................69

C Contaminated Soil Experimental Mass Closures .........................................70

D X-ray Diffraction Data for Equilibration Experiments............................... 71

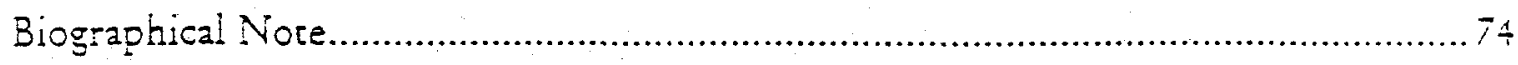




\section{Acknowledgments}

The author wishes to thank those persons who contribured to this research project. Sincere appreciarion is due, first, to Dr. John P. Hager whose guidance and knowledge were invaluable both to this research and to the author's education. Many thanks are also extended to the thesis comminee members, Dr. Gerard P. Martins and Dr. Baki Yarar for their participation in this thesis as well as their excellent classroom instruction.

The American Smelting and Refining Company (ASARCO), Inc. deserves recognition for their analytical work in support of this project and also for providing the soil and flue dust samples. Special thanks are due to Dr. V. Ramachandran of ASARCO for his interest in the project.

The author also wishes to thank his research colleagues whose many discussions (both technical and non-technical) contribured both to this thesis and to the author's growth as an extractive metallurgist: Dr. Guy L. Fredrickson, Mr. Jesse White, Ms. Christina Viklund White, Ms. Jessica Houpt, and Mr. Bryan Templeton.

Finally, the author is graceful to his parents, Carl and Karherine Eccleston, for their encouragement. Most of all, the author is thankful for the love and support of his wife, Elizabeth Tokach Eccleston.

This research project was jointly sponsored by the former United States Bureau of Mines Generic Mineral Technology Center for Pyromerallurgy and by ASARCO, Inc. under grant number G1155229, sub-account 0873 . 


\section{Biographical Note}

The author was born to Katherine and Carl Eccleston in Anaconda, Montana on May 13, 1972. He attended school in Anaconda, and graduated from Anaconda Senior High School in 1990.

The author went on to earn a Bachelor of Science degree in Metallurgical Engineering from the Montana College of Mineral Science and Technology Montana Tech) in May of 1994. After recieving his bachelor's degree, the author began gracuate studies at the Colorado School of Mines.

The author is a member of the Sociery for Mining, Metallurgy, and Exploration (SME) of AME, the Metallurgical Sociery (IMS) of AIME, and the American Scciery for Merals (ASM). 


\section{Contract/Grant G1155229}

1871 Surface Tension of Slags. (Gaskell-Purdue)

Project Scope and Goals:

To measure the influence of oxygen pressure and composition on the surface tensions of iron-based slags with the view to understanding the factors which control the phenomenon of slag framing.

Funding: $\quad F Y 95,96 \quad \$ 63,091$

Graduate Student: Mr. David Skupien

Project Period: $\quad$ April 1996 -September 1996 (End)

Progress/Final Report:

A thesis serves as the Final Project Report. The thesis, "The Surface Tensions of Melts in the System CaO-SiO2-FeO," by David Skupien ( 68 p.), was approved in December 1996 by Purdue University as partial requirement for a Master of Science degree in Metallurgical Engineering. A copy of the introductory identifying pages of the thesis are attached as a part of this Final Progress Report. 


\title{
THE SURFACE IENSIONS OF MELTS IN THE SYSTEM $\mathrm{CaO}-\mathrm{SiO}_{2}-\mathrm{FeO}$.
}

\author{
A Thesis \\ Submitted to the Faculty \\ of Purdue University \\ School of Materials Engineering
}

\begin{abstract}
by
David Skupien

In Partial Fulfillment of the Requirements

for the Degree

of

Master of Science in Metallurgical Engineering.
\end{abstract}

December, 1996 
This is to certify that the thesis prepared

Ey David Skupien

Entrited

The Suriace Tensions of Melts in the System CaO-SiO ${ }_{2}^{-F e O}$

Complies with University regulations and meets the stancares of the Graduate Schcol tor criginality and quality

For the degree of Master of Science in Metallurgical Enginesring

Signed by thefinal exefininecommitge:
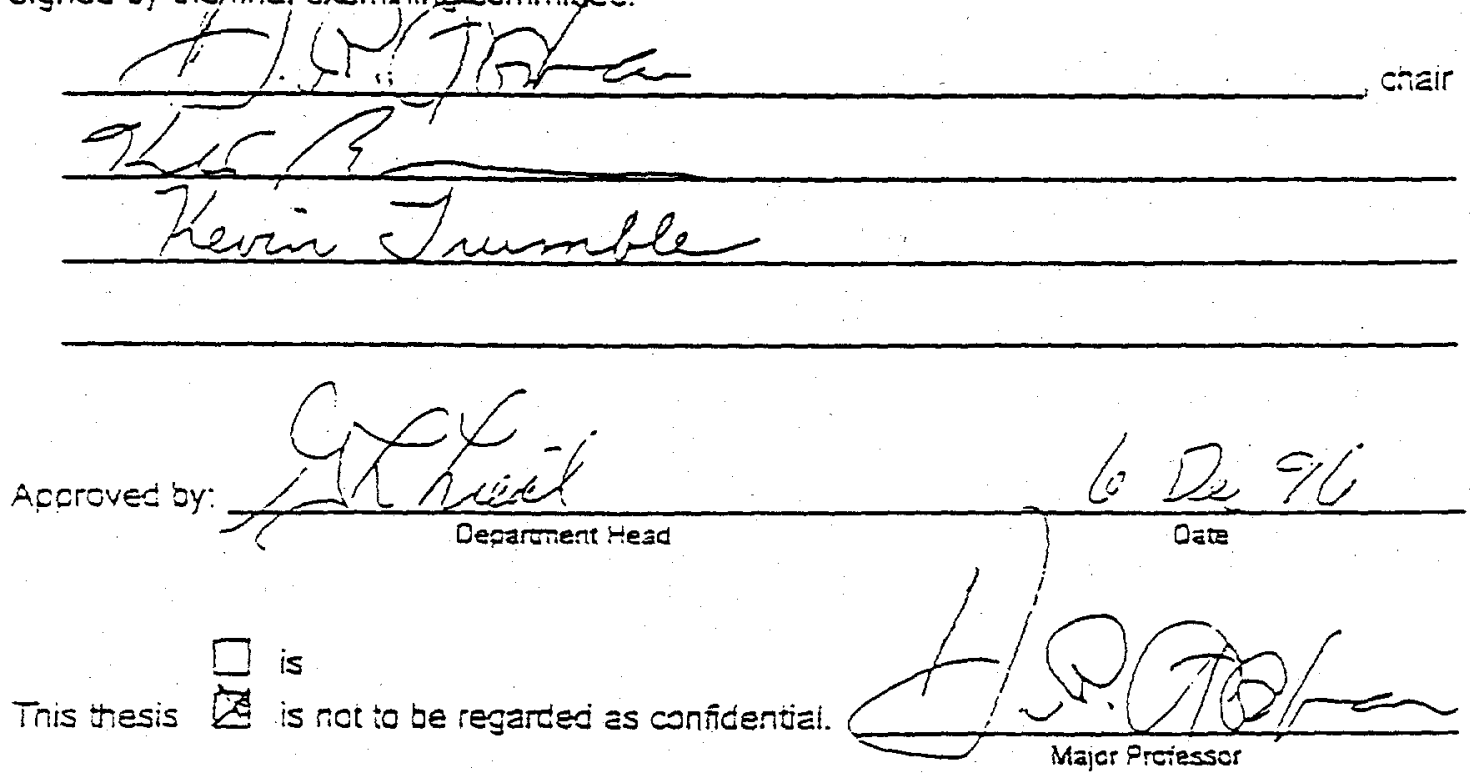

Fomiai Aporoved by:

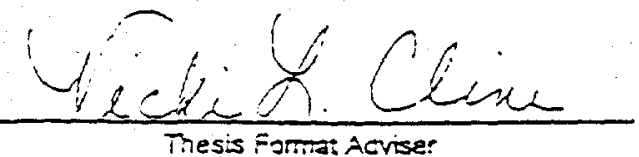


TABLE OF CONTENTS

LIST OF TABLES

LIST OF FIGURES .............................................................................

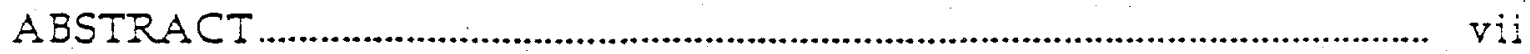

CHAPTER 1- RTRODUCTION .............................................................

1.1. Experimental Goals ........................................................................ 1

1.2. The Phenomenon of Slag Foaming................................................... 1

CHAPTER 2- LIIERATURE REVIEW ……................................................

2.1. Techniques for the Measurement of Surface Tension at High

Temperatures

2.1.1. Maximum Bubble Pressure Techrique..............................

2.1.2 Padday Cone Techrique ...................................................... 6

2.1.3. Wilhelmy Plate Technique................................................. 8

21.4. Dipping Ring/Cylinder Method ....................................... 9

2.2. Surface Tensions of Melts in the System $\mathrm{CaO}-\mathrm{SiO}_{2}-\mathrm{FeO} \ldots . . . . . . . . . . . . \quad 12$

2.3. The Ito and Fruehan Foaming Study .............................................. 14

2.1. The Swisher and MCCabe Study ..................................................... 21

2.5. The Cooper and Kitchener Study ..................................................... 23

CFAPTER 3- APPARATUS AND PREPARATION ................................... 26

3.1. Starting Materials..................................................................... 26

3.2. Preparation of the Melts.................................................................. 26

3.3. Fabrication and Cleaning of the Crucible ....................................... 27

3.4. Preparation of the Platinum Cylinder Assembly........................... 27

3.5. Control of the Position of the Melt in the Furnace....................... 30

3.6. Control of the Fumace Atmosphere .............................................. 30

3.7. Measurement of the Force ............................................................ 32

3.8. Experimental Technique ............................................................ 34

CHAPTER 4RESULTS ......................................................................... 36 


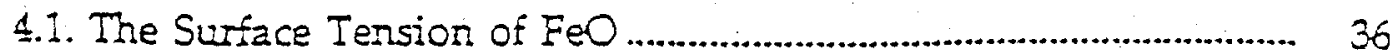

4.2. The Dependence of Suface Tension on Basidty ............................ 36

4.3. The Infiuence of Additions on Surface Tension .......................... 39

CHAIFIER 5- DISCUSSION AND ERROR ANAIYSIS............................... 42

5.1. The Surface Tersion of FeO ...................................................42

5.2. The Influence of Basicity on Surface Tension............................... 42

5.3. The Influence of Temperature on Surface Tension.......................

5.4. The Influence of Additions on Surface Tension ............................ 45

5.5. Foaming Sunmary ....................................................................... 45

5.5.1. Increased Foaming with Decreasing Surface Tension.... 45

5.5.2. Increased Foaming with Increasing Viscosity .................. 46

5.6. Evaluation of the Numerical Analysis of Ito and Fruehan \& Jiang and Fruehan...................................................................... 49

5.7. Error Analysis ............................................................................... 54

5.8. Experimental Assumptions......................................................... 55

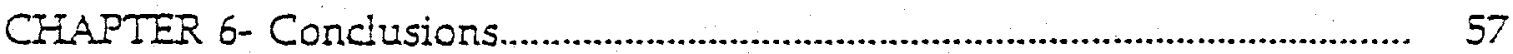

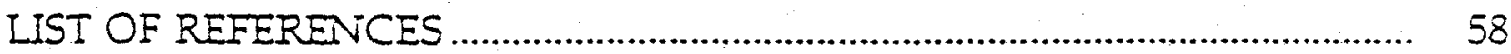

APPENDICES

APPENDIX A. Surface Tension Calculation Using the Cylincer

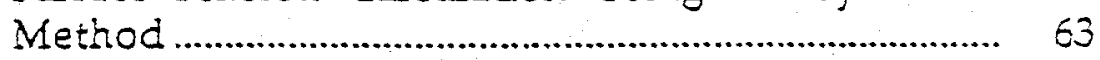

APPENDDX B. Excess Force Measuments and Correction Factors.... 64 APPENDIX C. Sample of Strip Chart Data.............................................. 68 


\section{Contract/Grant G1155229}

3972 Modeling and Simulation of Strip Casting Processes. (Sahai - OSU)

Project Scope and Goals:

To investigate the strip casting process by devising modeling to simulate the technique; evaluate properties and characteristics such as melt flow, heat transfer, and progressive melt solidification.

Funding: FY95,96,97 \$116,240

Graduate Student: Shailesh Gupta

Report Period: $\quad$ April 1996 - September 1997 (End)

Progress/Final Report:

A project report for the period October 1996 to March 1997 is included as a part of this Final Progress Report. The Final Project Report is also included (a four page report by Dr. Y. Sahai). A thesis also comprises part of the Final Project Report. The thesis, entitled "Modeling and Simulation of Strip Casting Processes," by Shailesh Gupta (108 p.), was approved by the Ohio State University in 1997, as partial requirement for a Master of Science degree. A copy of the pertinent identifying introductory pages of the thesis are included as a part of this Final Progress Report. 
Revised: March 13, 1997

\author{
Progress Report on \\ "Modeling and Simulation of Strip Casting Processes" \\ Sanjiv Gupta, Jian Ye, and Yogeshwar Sahai \\ Department of Materials Science and Engineering \\ The Ohio State University \\ Columbus, $\mathrm{OH} 43210$
}

The project is progressing very satisfactorily. Sanjiv Gupta, a graduate student and Jian $\mathrm{Ye}$ (50\% time), a post-doctoral researcher are working on this project at the present time. So one FTE of graduate student and $50 \%$ of post-doctoral person are currently supported. Results of the melt flow, heat transfer, and solidification in the melt drag process were reported in the previous progress report. In the past six months or so, efforts are devoted to model the twin roller casting processes. The following report describes the current status of the work.

\title{
Introduction
}

Processes, which cast molten metal directly into thin strip of desired thickness and width, are very important and are currently being developed around the world. When developed reliably, these processes will decrease energy consumption, production time, segregation, and grain size while enhance mechanical properties and corrosion resistance. Approximately $800 \mathrm{~kJ} /$ ton energy savings are possible with a strip casting process over the conventional casting and rolling processes [1].

Twin Roller casting is one of the thin strip casting process. This process was first proposed by $\mathrm{H}$. Bessemer over 100 years ago [2]. A simple schematic is shown in Fig. 1, in which molten metal is fed between the two counter rotating water cooled rollers. Solidification start at the point of first molten metal-roller contact, and binding of shell formed on two rollers should take place at the 'kissing point' where rollers are closest to each other. In practice, it is difficult to achieve, which makes the control of this process difficult. Last decade has seen tremendous activity in the twin roller casting process development [3-18]. Fujita et. al. [3] performed casting experiments using paraffin wax to study solidification and roll binding characteristics in twin roll casting process. He found that the roll gap has a large influence on the casting behavior. In case of narrow roll gap, 
mushy layer of the shell squeezed remaining molten metal out of it into the molten pool. This resulted in negative segregation and lowering of pool temperature. On the other hand, large roll gap may not solidify molten metal and may result in break out of strip. So stable casting operation can only be obtained if solidification is completed in the very vicinity of the kissing point. To obtain this, the roll gap should be set using a lot of experimental data or a sophisticated mathematical model capable of predicting strip thickness as a function of different process variables. Miyazawa and Szekely [4] developed a model to predict heat flow and solidification in twin-roll system. They concluded that there existed only a narrow range of process variables that provides a stable mode of operation. They used a simple model and did not consider turbulence and mushy zone. Hwang et. al. [16] considered mushy zone in their transient fluid flow and heat transfer analysis. However, turbulent flow was not considered in their study. On the other hand, Murakami et. al. [9] included turbulent flow in their model to predict fluid flow and heat transfer characteristic but strip thickness was not obtained as a function of different process variables. Turbulent melt flow considerations are closer to the real system, but there is no comprehensive study dealing with the turbulent melt flow and its role on cast strip thickness.

In the present work, a two dimensional mathematical model is developed to simulate turbulent fluid flow, heat transfer, and solidification of twin roller casting process. Calculated strip thickness is compared with a pilot plant data which are found to be in good agreement. The effect of turbulence on fluid flow and strip thickness has been studied, and strip thickness has been obtained as a function of different process variables.

\section{Formulation of Mathematical Model Solution Methodology}

A finite element model is developed to simulate turbulent fluid flow, heat transfer, and solidification. The main assumptions are as follows:

1) The process is steady state, i.e. after the initial small transient period, process variables do not change with time.

2) Process is assumed to be symmetrical about the vertical axis.

3) The liquid steel is incompressible and behaves like a Newtonian fluid. 
4) Material properties (except viscosity and specific heat) are temperature independent.

5) There is no segregation.

6) Temperature may be used as a criteria for the determination of strip thickness.

7) There is no slip condition between the wheel and solidified strip.

8) The geometry is assumed to be two-dimensional. This is because of width/thickness ratio is very high, and end effects have been neglected.

Based on the above assumptions, the model involves solution of the twodimensional turbulent Navier-Stokes and energy equations. Two aspects associated with the solidification phenomena are the drastic change in liquid viscosity near solidifying interface and the release of latent heat due to phase change have also been considered. The former affects the fluid flow behavior while the later affects the heat transfer. The solidified steel strip is assumed to have an extremely large value $10^{8} \mathrm{~Pa}$.s of effective viscosity (solidified strip). In this model, viscosity is modeled as a function of temperature with liquid viscosity at liquidus and very high viscosity at solidus. The presence of the mushy zone is characterized by a suitable gradient of the viscosity over the range of temperature between liquidus and solidus. In the turbulent regime, effective viscosity was the sum of laminar and turbulent viscosity. In the solid phase, turbulent viscosity decayed to zero in some transition zone.

$$
\begin{aligned}
& \mu=\mu_{\mathrm{t}}{ }^{*} \mathrm{f}_{\text {decay }} \\
& \mathrm{f}_{\text {decay }}=\lambda^{1.5} \exp \left[\left(-3.4 /\left(1+\mathrm{R}_{\mathrm{t}} / 50\right)^{2}\right]\right. \\
& \mathrm{R}_{\mathrm{t}}=\rho \mathrm{K}^{2} /\left(\mu_{\mathrm{o}} \varepsilon\right) \\
& \lambda=\left[\left(\mathrm{T}-\mathrm{T}_{\text {liq }}\right) /\left(\mathrm{T}_{\text {sol }}-\mathrm{T}_{\mathrm{liq}}\right)\right]
\end{aligned}
$$

Value of 'power' in Eq. 4 can be set to the desired slope of viscosity in the transition zone.

Specific heat was used to calculate the release of latent heat of fusion at the solid/liquid interface. In the mushy zone, latent heat of fusion was released between the solidus and liquidus temperatures. The transport equations were converted into simultaneous algebraic equations by using finite element method, and solved by a general purpose finite element FDI commercial code for fluid flow, FIDAP [19]. 


\section{Results and Discussions}

To validate the present mathematical model, a set of published pilot plant data was used [5]. There exists a heat transfer coefficient which represents the thermal contact between strip and roll whose value is not precisely known. This is created when liquid steel comes in contact with a clean chilled surface. Initially, for few milliseconds, this heat transfer coefficient is known to have very high value (practically infinite) because the bond between roller and solidified material is supposed to be very strong and heat flows without any drop in temperature at the interface. But as time progresses, the solidifying shell and wheel experience different contraction/expansion as they have different thermal expansion coefficient. Once the stress, caused by this differential expansion, crosses a threshold value, the bond is broken, and a gap is created between the two surfaces causing the heat transfer coefficient to drop sharply. Heat transfer coefficient again increases as the strip reaches near the nip point, as increase in pressure results in a good contact. Anti-sticking agents and unpreheated mold surfaces are also known to reduce heat transfer coefficient [20-22]. It has been found to vary in wide range, as reported in literature [15,23-26] on the basis of modeling but very few experimental data are available to support this predicted range of values [27]. As already discussed, it is difficult to get a proper value of heat transfer coefficient for this type of analysis since factors affecting this value are diverse, such as roll speed, roughness of wheel, and thickness of air gap, as discussed in [20-22]. In the present investigation, gap heat transfer coefficient was calculated using one pilot plant data, and this value was used in all subsequent predictions of strip thickness values. Fig. 2 shows a comparison of predicted (for $h_{\text {gap }}=11.5 \mathrm{~kJ} / \mathrm{kg} . \mathrm{K}$ ) as well as pilot plant values. As it can be seen from Fig 2., predicted values match very well with the pilot plant range. This heat transfer coefficient value is found to be in the range as reported in literature [15,23-26].

To predict the effect of turbulence, the predicted strip thickness results were compared under the same process conditions except the turbulence model was excluded in one case. It was found that the strip thickness was higher assuming the flow to be laminar. This is due to the fundamental characteristic of turbulence i.e. good mixing and heat transfer by the eddy packets. Strip thickness was $0.83 \mathrm{~mm}$ as compared to $0.63 \mathrm{~mm}$ considering turbulence under the same operating conditions for roller velocity of 1.55 
$\mathrm{m} / \mathrm{sec}$. Fig. 3 shows a typical contour plot for kinetic energy of turbulence in the melt. Mean turbulent kinetic energy of $0.0457 \mathrm{~m}^{2} / \mathrm{sec}^{2}$ has been calculated in the melt pool, which corresponds to a fluctuating component of velocity of $0.365 \mathrm{~m} / \mathrm{sec}$. Fig. 4 shows a typical velocity strean line plot in the melt pool.

Effect of different process variables on the solidified strip thickness has also been investigated. Fig. 5 shows the effect of roller velocity on the solidifying strip thickness. The speed of rotating roller or casting speed is the most important parameter that affects the productivity of a strip caster. At higher casting speed, contact time of melt with the roller will be less which results in lower thickness of strip.

Fig. 6 shows the effect of contact angle of melt contact with the wheel (angle $\theta$ in Fig. 1) on the solidifying strip. Decrease in the contact angle decreases residence time of the strip in the pool bath and results in a thinner strip. Fig 6 shows the straight line behavior, which has also been reported elsewhere [15].

Increase in superheat in liquid steel acts to slow down solidification of the melt because this heat must be removed before solidification. But it seems to have less effect on the overall thickness as major part of the heat is due to the release of latent heat of fusion. Comparison of the latent heat of fusion and sensible heat shows that the sensible due to $40^{\circ} \mathrm{C}$ superheat is about $1 / 10$ of the latent heat of fusion.

\section{Conclusion}

In summary, the proposed model is capable of predicting fluid flow and heat transfer behavior and the strip thickness. Predictions are in reasonable agreement with the limited design and experimental conditions available. Predictions are possible for a wide range of operating conditions and physical properties with a modest effort. Contact angle and casting speed are found to be main parameter effecting strip thickness while cooling fluid temperature, superheat, roller diameter, roller thickness, roller material have little effect.

\section{Nomenclature}

$\mathrm{Cp}=$ Specific heat $(\mathrm{J} / \mathrm{kg} \mathrm{K})$

$\mathrm{h}_{\mathrm{gap}}=$ Convective heat transfer coefficient between strip and roller $\left(\mathrm{w} / \mathrm{m}^{2} \mathrm{~K}\right)$

$\mathrm{k}_{\mathrm{o}}=$ Molecular thermal conductivity $(\mathrm{w} / \mathrm{mK})$ 
$\mathrm{k}_{\mathrm{t}}=$ Turbulent thermal conductivity $(\mathrm{w} / \mathrm{mK})$

$\mathrm{k}_{\mathrm{eff}}=$ Effective thermal conductivity (w/mK)

$k=$ Kinetic energy of turbulence

Pr $=$ Prandtl Number $(\mu \mathrm{Cp} / \mathrm{k})$

Tin=Inlet temperature of molten steel $(\mathrm{K})$

Tliq=Liquidus temperature of molten steel $(\mathrm{K})$

Tsol=Solidus temperature of molten steel $(\mathrm{K})$

Tsup=Superheat in the molten steel

$\mu_{\mathrm{o}}=$ Molecular Viscosity (Pa.s)

$\mu_{\mathrm{t}}=$ Turbulent Viscosity (Pa.s)

$\mu_{\text {eff }}=$ Effective Viscosity (Pa.s)

$\varepsilon=$ Dissipation rate of kinetic energy

\section{References}

1) H. Yasunaka, K. Taniguchi, M Kokita and T. Inoue: ISIJ International, $35(1995) 784$.

2) H. Bessemer: Stahl und Eisen, 11(1881)921.

3) Y.Fujita, H.Sato, T.Kitagawa, S.-I.Nishioka, Y.Tsuchinda and A.Ozeki: Trans. ISIJ, (1989) 485

4). K. Miyazawa and J. Szekely: Metallurgical Transaction A, 12A(1981)1047.

5) K. Miyazawa, T. Mizoguchi, M.Nakamura and T.Ohashi: Casting of Near Net Shape Product edited by Y. Sahai, J. E. Battles, R. S. Carbonara and C. E. Mobley, (1988)629.

6) T. Saitoh, H.Hojo, H.Yaguchi and C.G.Kang: Metallurgical Transaction B, 20B(1989)381.

7) J.W.Hlinka, J.A.Burgo, T.J.Conarty and I.G.Saucedo: Steelmaking Conference Proceedings, (1989)133.

8) M.Yun, D.J.Monaghan, X.Yang, J.Jang, D.V.Edmonds, J.D.Hunt, R.Cook and P.M.Thomas: Cast Metals, 4(1991)108.

9) H.Murakami, M.Hasan and R.I.L. Guthrie: $10^{\text {th }}$ PTD Conference Proceedings, (1992)347.

10) H. Yamane, M. Yukomoto, S. Miyake and M. Ozawa: ibid, (1992)343.

11) D-Y. Ju and T. Inoue: International Conference on Computer-assisted Materials Design and Process Simulation, (1993) 84.

12) M.Y.Ha, K.Kim, K.C.Kim and S.W.Lee: Int. J. of Heat and Mass Transfer, $37(1994) 2059$.

13) T.Arai, M.Yamada, H.Nakashima, H.Takehchi, S.Tanaka, Y.Yamakami, K.Sasaki and K. Yamamoto: Steelmaking Conference Proceedings, (1994)357. 
14) Y.K.Shin, T.Kang, T.Reynolds and L.Wright: Ironmaking and Steelmaking, 22(1995)35.

15) B. Q. Li: Journal of Metals, 8(1995)13.

16) S.M.Hwang and Y.H.Kang: Joumal of Engineering for Industry, $117(1995) 304$.

17) X.Liang, F.Pan, S.Zhou, P.Ding and C.Xu: Journal of Materials Processing Technology, 63(1997)788.

18) F.Pan, S.Zhou, X.Liang, P.Ding and C.Xu: ibid, 63(1997)792.

19) FIDAP Theory Manual: Fluid Dynamics International Inc., (1993).

20) R. E. Maringer: Casting of Near Net Shape Product edited by Y. Sahai, J. E. Battles, R. S. Carbonara and C. E. Mobley, (1988), 351.

21) J. T. Berry: ibid, (1988), 41.

22) Y. Nishida, W. Droste and S. Engler: Metallurgical Transaction B, 17B(1986), 833.

23) A. Kasma, S. Mizoguchi, K. Miyazawa, M. Ito and T. Sugai: Proceedings of Near Net Shape Casting Processes, (1987), 849.

24) K.Miyazawa, T. Choh and M. Inoye: Transaction of Japan institute of metals, 24(1983), 696.

25) T. Yamauchi, T. Nakanori, M. Hasegawa, T. Yabuki and N. Ohnishi: Transaction ISIJ,(1988), 23.

26) K. Murata, H. Morise, M. Mitsutsuka, H. Maito and S. Shida: Transaction ISIJ, (1988), B309. 


\section{Two Roller Casting Apparatus}

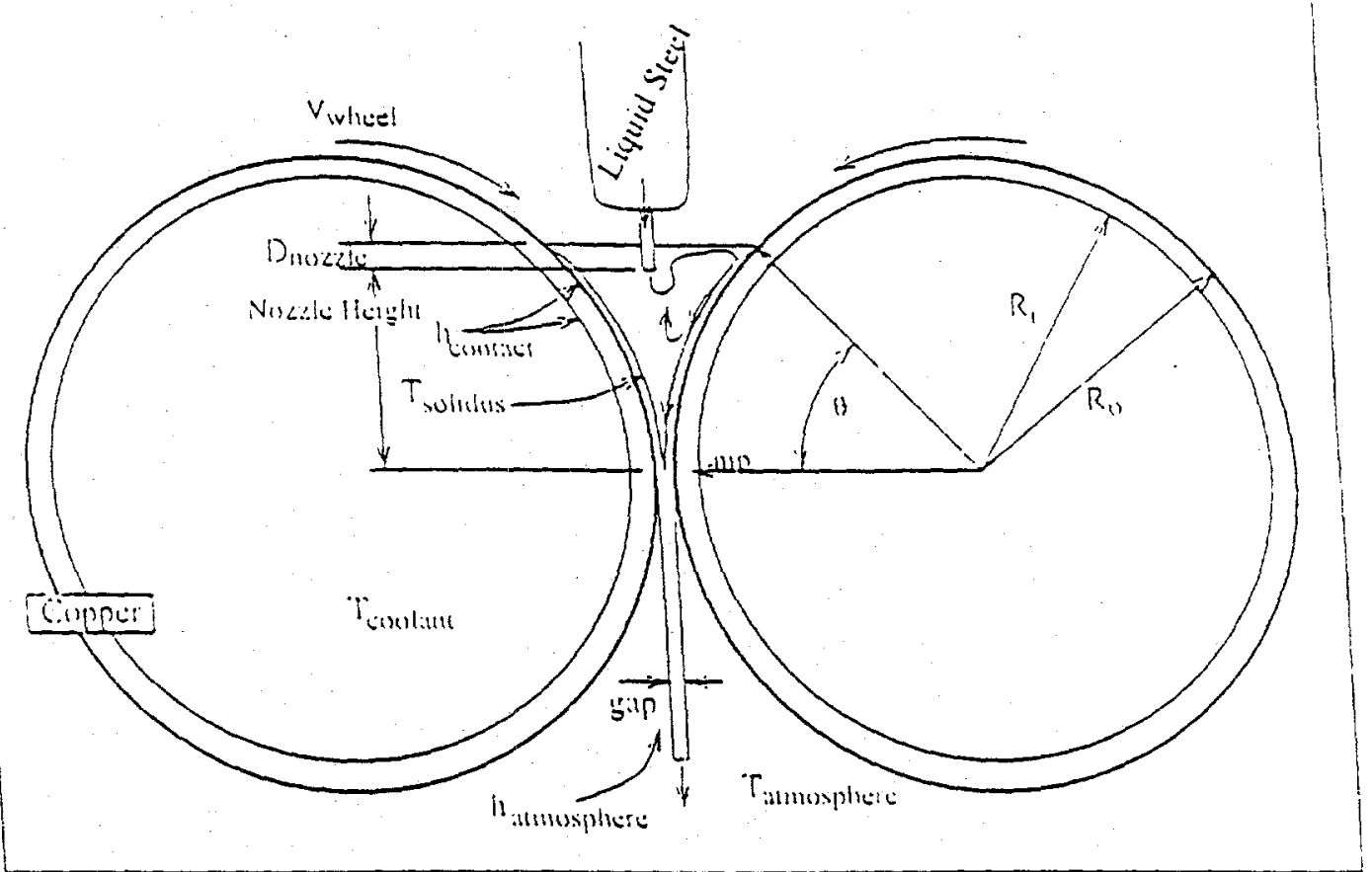

Fig. 1: Schematic of twin roller casting apparatus. 


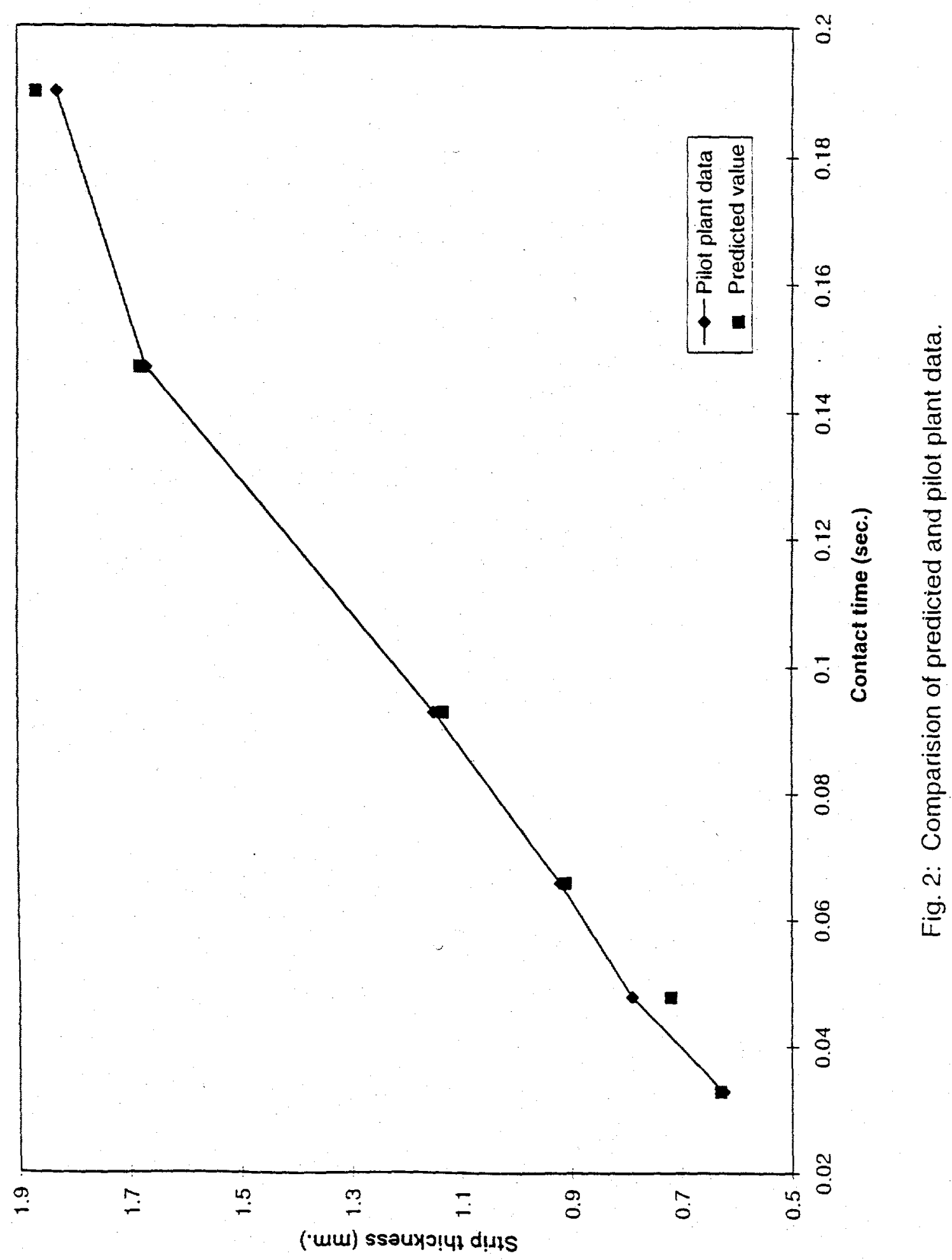




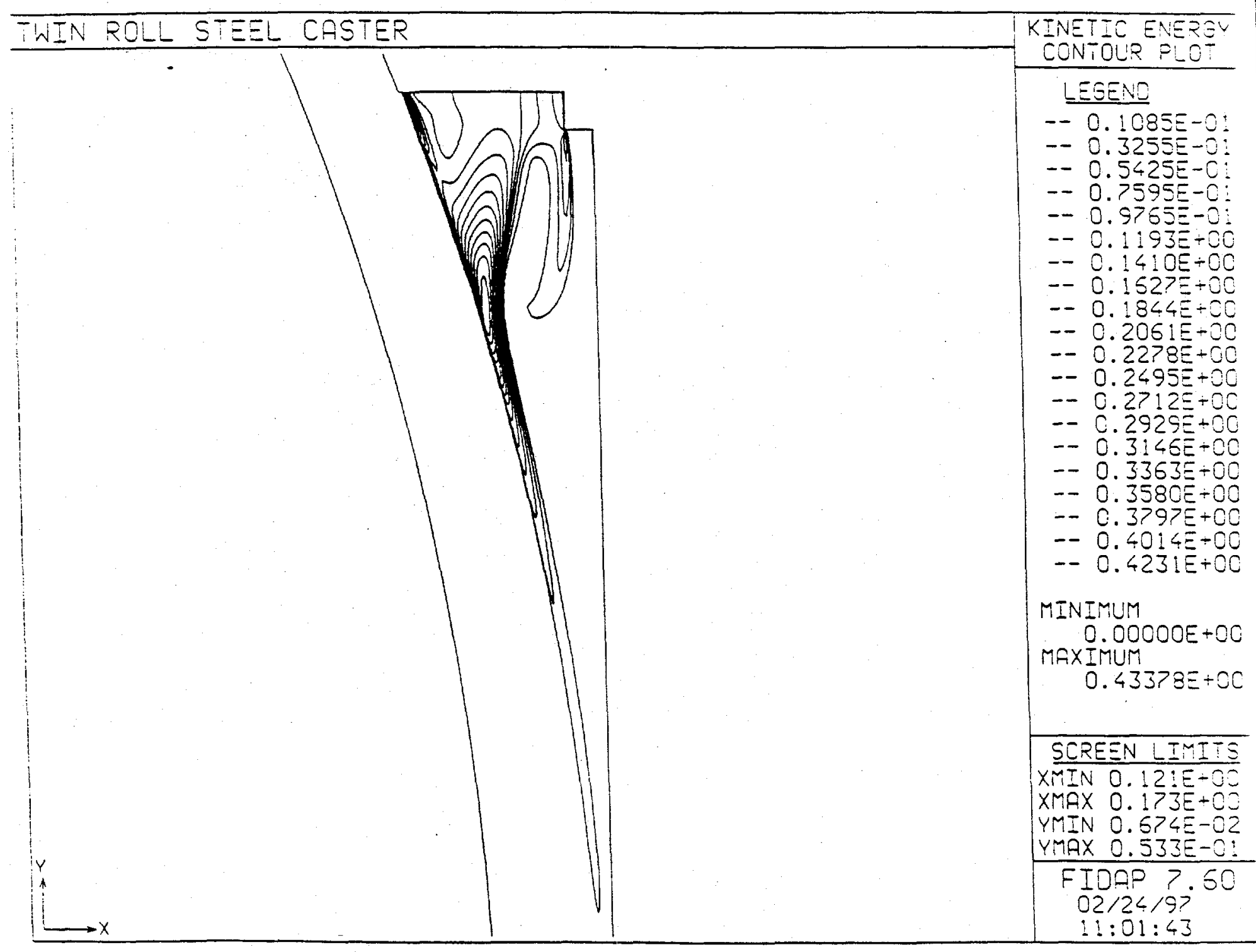

Fig. 3: Kinetic energy contours in the melt. 


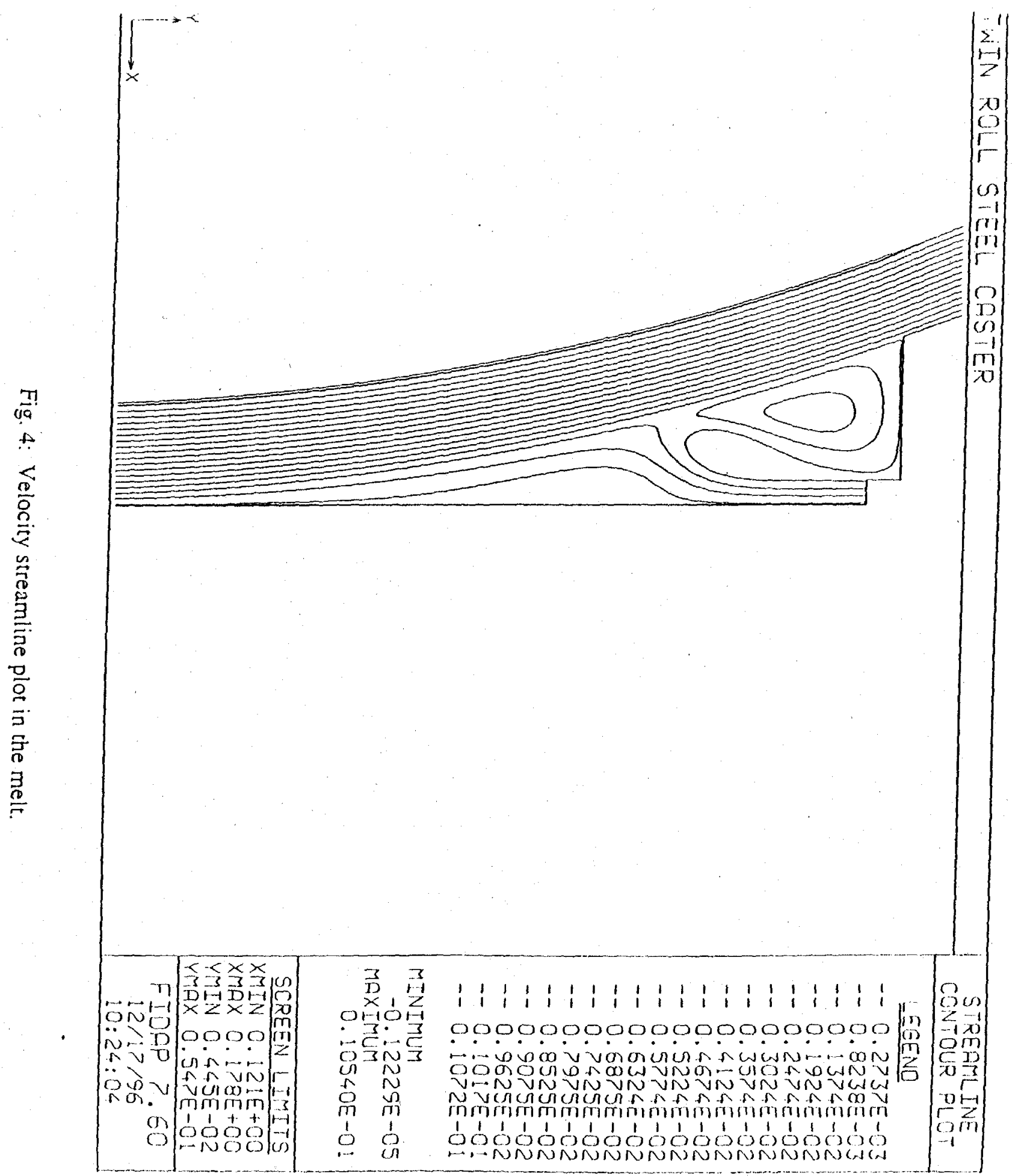




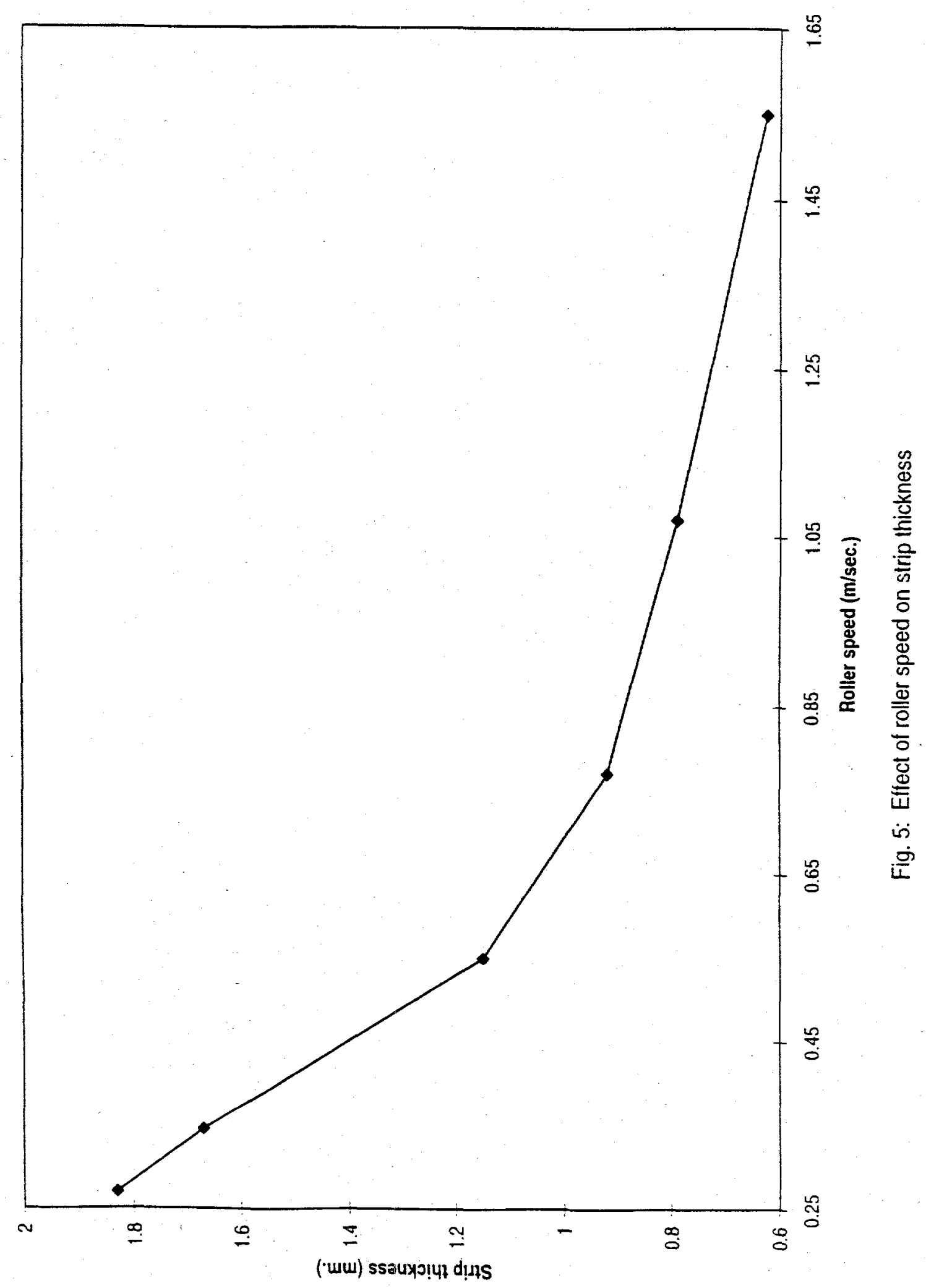


107

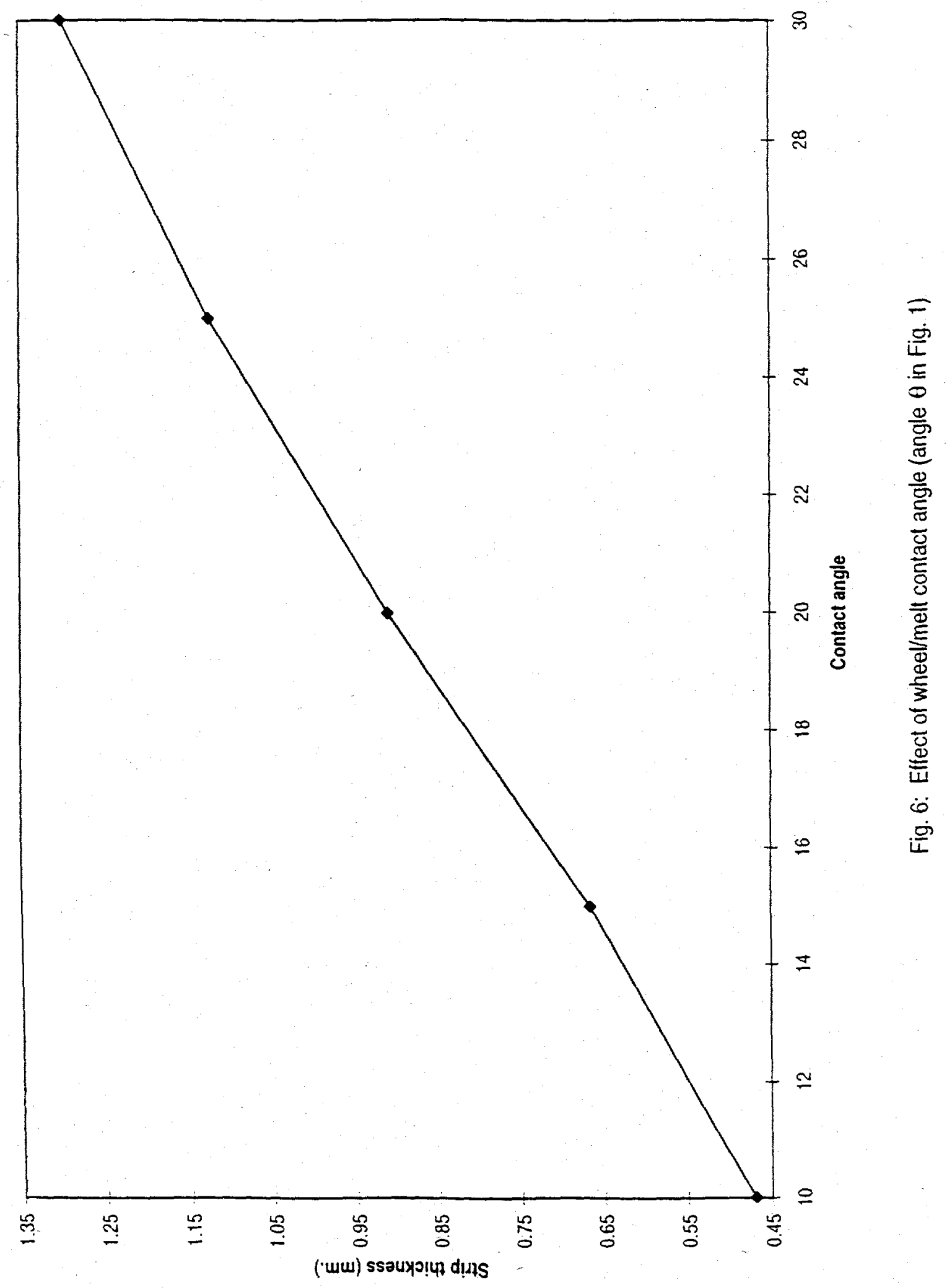


Final Report on

\title{
"Modeling and Simulation of Strip Casting Processes"
}

by

Yogeshwar Sahai

Professor

Department of Materials Science and Engineering

The Ohio State University

Columbus, OH 43210

\author{
Submitted to \\ Dr. David G.C. Robertson \\ Director, Center for Pyrometallurgy \\ University of Missouri, Rolla
}

September 30, 1997 


\section{Modeling and Simulation of Strip Casting Processes}

In this project, which started in September 1995, one graduate student, Shailesh Gupta, worked for his MS thesis, which will complete by the end of this month. Dr. Jian Ye is also partially supported on this project. In the present investigation, a twodimensional mathematical model was developed to simulate turbulent fluid flow, heat transfer, and solidification in the melt drag process. Same methodology was used to develop models for the twin-roller and the two roller melt drag process.

Thin strip casting processes for casting molten metal directly into thin strips of desired thickness and width are relatively new, and are currently being developed around the world. When developed reliably, they will decrease energy consumption, production time, segregation, and grain size while enhance mechanical properties and corrosion resistance. Strip casting processes are quite different from the conventional ingot making and continuous casting processes. However, they are facing many processing problems such as high roll wear, low productivity and yield, cracking and surface defects, homogenous flow problem. Mathematical modeling of turbulent fluid flow, heat transfer, and solidification provides some insight into the process, which may help in overcoming these processing and technical problems and may increase productivity:

The equations of continuity, momentum, and energy were coupled with twoequation $k-\varepsilon$ turbulence model. To consider the solidification, viscosity was changed from its liquid phase viscosity value $(0.0050 \mathrm{~Pa} . \mathrm{s})$ at liquidus to an extremely large value $10^{8} \mathrm{~Pa} . \mathrm{s}$ (solidified strip) at solidus temperature. The release of latent heat of fusion at the solid/liquid interface was not considered explicitly, but the specific heat was 
increased appropriately to account for the released latent heat. Transport equations were converted into algebraic equations by using a finite element method, assembled, and solved simultaneously by a general purpose finite element method, commercial code for solving transport equations, FDAP. Successive Substitution method using an under relaxation factor of 0.5 was found to be very useful and it took around 25 to 35 iterations for the solution to converge with relative error in residual force vector stably reduced to less than $0.3 \%$.

Two-dimensional finite element models were developed to simulate turbulent fluid flow, heat transfer, and solidification in the three thin strip casting processes: melt drag, twin-roller, and two roller melt drag process. The finite element software, FIDAP generated the grids. The independency of grid size on the results was checked for all the processes. Two-equation $k-\varepsilon$ model was used for the turbulence considerations. Model results were validated using the pilot plant data set available in opén literature for the melt drag and the twin-roller processes. Predictions were in good agreement with the experimental results. Analysis can be conducted for various metals and alloy systems with a modest effort by changing physical and thermal properties. Effect of turbulence on fluid flow and strip thickness was also investigated. Laminar flow was found to overpredict the strip thickness by about $20 \%$. The model predicted velocity and temperature profile, and thickness of the solidified strip for different operating conditions in stainless steel casting. The effects of different operational variables on the cast strip thickness were predicted. Relationships between the solidified strip thickness and the various operating parameters were obtained. Melt Depth near wheel contact (or contact angle) and casting speed were found to be the main parameters which affected the strip 
thickness. Cooling fluid temperature, superheat, roller diameter, roller thickness, and roller material were found to have less effect. Since the entire roller was part of the calculation domain, temperature profile in the roller was alșo predicted which may provide information on roller softening and distortion. An effective viscosity analysis was conducted to save computational time and cost for the melt drag process. Using this method, similar results were obtained with less CPU time. A similar analysis can be performed for the twin-roller and the two roller melt drag processes. The effect of different molten metal injection angles $\left(0,45\right.$, and $\left.90^{\circ}\right)$ of submerged entry from the nozzle were also studied for the twin-roller casting process. The $45^{\circ}$ injection angle was found to be the best.

More details of the models and results are provided in Shailesh Gupta's MS thesis which is enclosed here as part of this report. Three technical papers from this work are at different stages of submission for publication. 


\title{
MATHEMATICAL MODELING OF THIN STRIP CASTING PROCESSES
}

\author{
A Thesis \\ Presented in Partial Fulfillment of the Requirements for \\ the Degree Master of Science in the \\ Graduate School of The Ohio State University
}

By

Shailesh Gupta, M. Tech.

*****

The Ohio State University 1997

Master's Examination Committee:

Approved by

Dr. Y. Sahai, Adviser

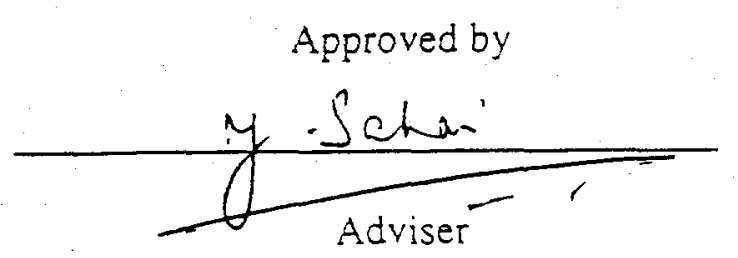

Dr. C. E. Mobley

Department of Materials Science and Engineering 


\section{ABSTRACT}

Two-dimensional finite element models were developed to simulate turbulent fluid flow, heat transfer, and solidification in the three thin strip casting processes: melt drag, twin-roller, and two roller melt drag process. Two-equation $k-\varepsilon$ model was used for the turbulence considerations. The finite element software, FIDAP generated the grids and solved the transport equations for all the processes. The independency of grid size on the results was checked for all the processes. Model results were validated using the pilot plant data set available in the open literature for the melt drag and the twin-roller processes. Predictions were in good agreement with the experimental results. Effect of turbulence on fluid flow and strip thickness was also investigated. Laminar flow was found to overpredict the strip thickness by about $20 \%$. The model predicted velocity and temperature profile, and thickness of the solidified strip for different operating conditions in stainless steel casting. Thus, The effects of different operational variables on the cast strip thickness were predicted. Since the entire roller was part of the calculation domain, temperature profile in the roller was also predicted. Results were also predicted by increasing the melt viscosity to a high value for the melt drag process. The use of this effective viscosity model gave satisfactory results with much less computational time. Different molten metal injection angles from the nozzle were studied for the twin-roller casting process. A $45^{\circ}$ injection angle was found to be the best. 


\section{ACKNOWLEDGMENTS}

I wish to express my sincere gratitude to my adviser, Dr. Y. Sahai for his inspiring supervision, encouragement, and continued help throughout the project. I am very grateful to him for his valuable suggestions and advice during the research. I am also thankful to him for giving me his time for simulating discussion concerning my work.

I am grateful to Dr. J. C. Moore and Dr. J. Ye for discussing with me various aspects of this thesis and FIDAP software.

Help from Prof. B. Li is appreciated.

I also wish to thank those who helped me to handle various computer problems, especially Steve Koehl and Judith Horwitz.

I am grateful for the award of computer time on the Cray YMP8 at The Ohio Supercomputer Center, without which the calculations would not have been possible.

This research was partially supported by the bureau of mines through the Center for Pyrometallurgy, University of Missouri at Rolla. Help from our industrial partners Armco Steel, Inc. and Reynolds Metals Co is greatly appreciated. 


\section{TABLE OF CONTENTS}

\section{Page}

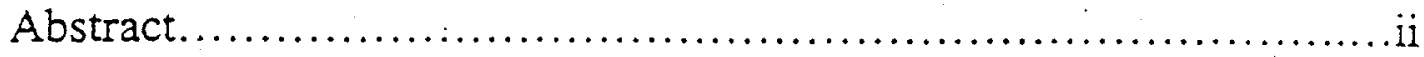

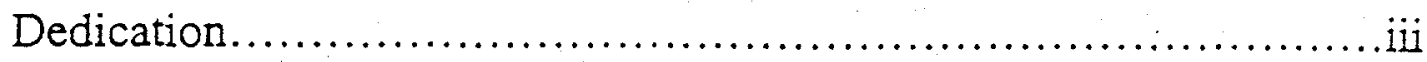

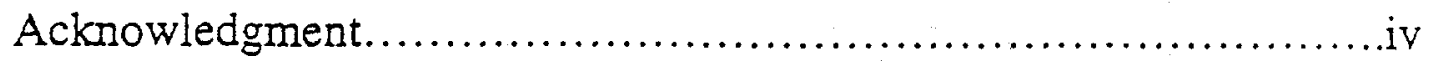

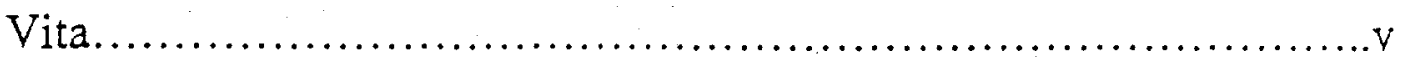

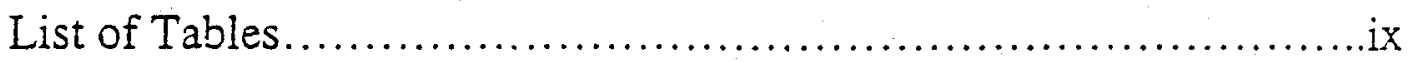

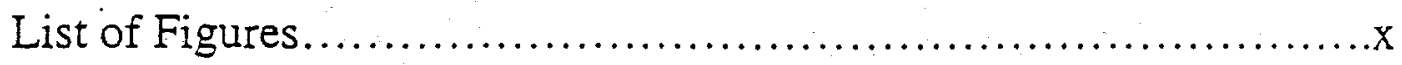

Nomenclature.............................................

\section{Chapter:}

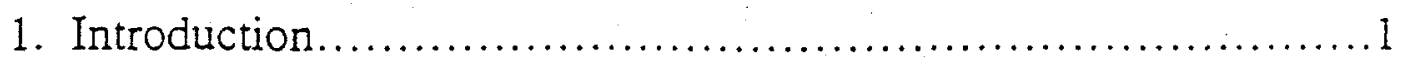

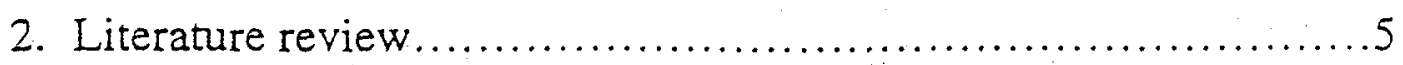

2.1 Different thin strip casting processes..............................6

2.1.1 Melt drag process.................................................6

2.1.2 Twin-roller strip casting process..................................7

2.1.3 Two roller melt drag process......................................... 8 
2.2 Past studies 9

2.2.1 Effect of process variables...........................................

2.2.1.1 Melt drag process.......................................12

2.2.1.2 Twin-roller strip caster.................................13

2.2.1.2.1 Strip properties..................................14

3. Mathematical model.............................................17

3.1 One-dimensional heat balance analysis...............................17

3.2 Two-dimensional models for strip casting process......................20

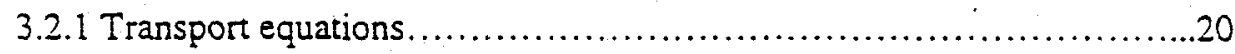

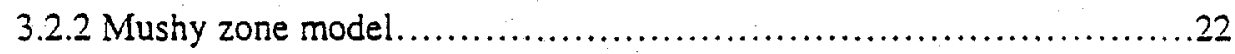

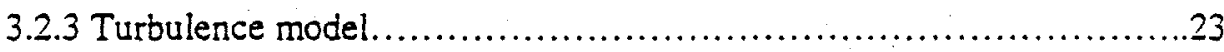

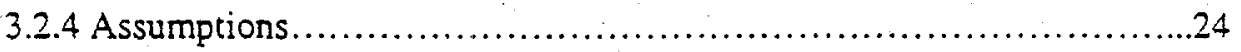

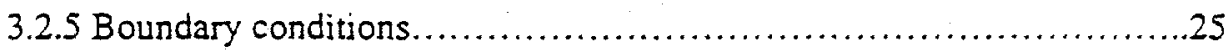

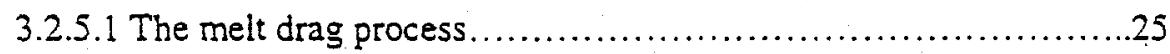

3.2.5.2 The twin-roller casting process ..................................28

3.2.5.3 The two-roller melt drag process...................................30

3.2.6 Solution Methodology .................................................

3.2.6.1 Solution procedure ..............................................

3.2.6.2 Convergence criteria.......................................... 33

4. Results and discussion......................................... 35

4.1 One-dimensional analysis..........................................

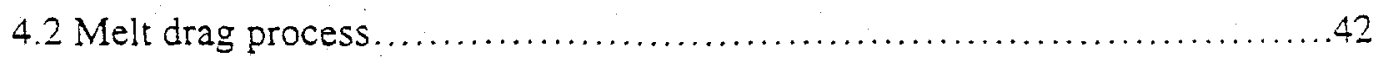

4.2.1 Validation of the mathematical model ...................................45

4.2.2 Effect of turbulence consideration.......................................... 51 
4.2.3 Effect of different process variables 60

4.2.4 Pseudo-turbulent viscosity approach....................................65

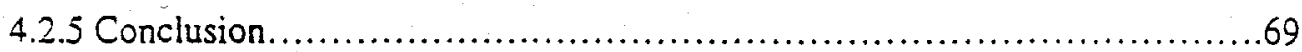

4.3 Twin-roll strip casting process......................................69

4.3.1 Validation of the mathematical model ..................................70

4.3.2 Effect of turbulence consideration.................................73

4.3.3 Effect of various process operational parameters........................83

4.3.4 Effect of melt infection angle....................................... 87

4.3 .5 Conclusion..........................................................

4.4 Two roller melt drag process..................................... 91

4.4.1 Effect of turbulence consideration....................................92

4.4.2 Effect of different process variables..................................97

4.4 .3 Conclusion............................................................ 102

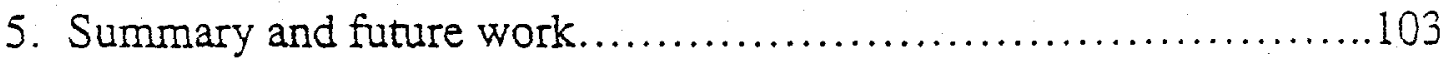

5.1 Conclusions......................................................... 103

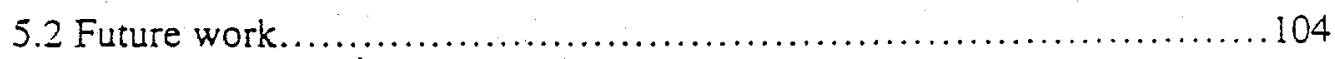

References.............................................................. 105 